UNIVERSIDADE DE SÃO PAULO

ESCOLA DE ENGENHARIA DE SÃO CARLOS

DEPARTAMENTO DE ENGENHARIA DE PRODUÇÃO

Herick Fernando Moralles

DESENVOLVIMENTO SÓCIO-ECONÔMICO, INFRAESTRUTURA DE TRANSPORTES E INOVAÇÃO: UM ESTUDO ECONOMÉTRICO ESPACIAL DOS EFEITOS DE SPILLOVER NOS ESTADOS BRASILEIROS.

São Carlos

2012 
Herick Fernando Moralles

\section{DESENVOLVIMENTO SÓCIO-ECONÔMICO, INFRAESTRUTURA DE TRANSPORTES E INOVAÇÃO: UM ESTUDO ECONOMÉTRICO ESPACIAL DOS EFEITOS DE SPILLOVER NOS ESTADOS BRASILEIROS.}

Tese de Doutorado apresentada a Escola de Engenharia de São Carlos da Universidade de São Paulo como requisito à obtenção do título de doutor em Engenharia de Produção.

Área de Concentração: Economia, Organizações e Gestão do Conhecimento.

Orientadora: Prof. ${ }^{a}$ Assoc ${ }^{a}$. Daisy A. N. Rebelatto.

São Carlos 
AUTORIZO A REPRODUÇÃO TOTAL OU PARCIAL DESTE TRABALHO, POR QUALQUER MEIO CONVENCIONAL OU ELETRÓNICO, PARA FINS DE ESTUDO E PESQUISA, DESDE QUE CITADA A FONTE.

$x 828 d$

yoralles, Heziek Fernando

Desenvolvinanto sbeip-Econonice, Infracstrutura de Transportes a Inovacto: Un Estudo Economberico Espacia dos Efeitos de Spillover nos Estados Brasileiros/ Reriek Fernando Moralles; orientadora baisy Aparecida do Nascimento Rabelatto. Sao Carlos, 2012.

Tese (Doutorado) - Prograna de Pos-Graduaça en Engenharia de Froduço a frea de Concentraço en Econonia, Organizaças a Gasta Conheci-nento -- Escola de Engenharia de Sao Carlos da Universidade de Sao $P=10,2012$

1. Crescimento econanico. 2. Deservolvimento bocio-econamico, 3. In fransirutura de cransportes. 4 Inovaço. 5. Economatria espacial. 6. Spillover. I. Titulo. 


\section{FOLHA DE JULGAMENTO}

Candidato: Bacharel HERICK FERNANDO MORALLES.

Título da tese: "Desenvolvimento sócio-econômico, infraestrutura de transportes e inovação: um estudo econométrico espacial dos efeitos de spillover nos estados brasileiros".

Data da defesa: $13 / 11 / 2012$

\section{Comissão Julgadora:}

Profa. Associada Daisy Aparecida do Nascimento Rebelatto (Orientadora)

(Escola de Engenharia de São Carlos/EESC)

Prof. Dr. Marcelo Seido Nagano

(Escola de Engenharia de São Carlos/EESC)

Profa. Dra. Ana Lúcia Vitale Torkomian

(Universidade Federal de São Carlos/UFSCar)

Prof. Dr. Alexandre Sartoris Neto

(Universidade Estadual Paulista "Júlio de Mesquita Filho"/UNESP-Araraquara)

Prof. Dr. Edemilson Nogueira

(Universidade Federal de São Carlos/UFSCar)

\section{Resultado:}
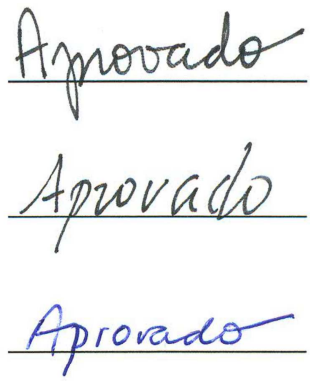

Apraverdo

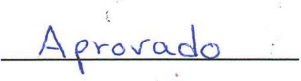

Coordenador do Programa de Pós-Graduação em Engenharia de Produção Prof. Titular Henrique Rozenfeld

Presidente da Comissão de Pós-Graduação:

Prof. Titular Denis Vinicius Coury 


\section{AGRADECIMENTOS}

A Deus, pelo dom da vida e por estar comigo mesmo nos momentos em que não estive com ele.

A professora e amiga Daisy que me ouviu quando ninguém mais o fez, e me deu uma oportunidade e um voto de confiança que jamais esquecerei. E, mais do que ensinar me educou e foi fundamental para que eu desenvolvesse meu potencial.

Ao meu pai pelo amor e pelo exemplo de homem que é para mim e por todas as dificuldades que passou para que eu tivesse a melhor educação disponível.

A minha mãe pelo amor e por estar sempre comigo, acreditar sempre no meu potencial e cuidar sempre de mim.

A minha noiva Patricia, meu grande amor e orgulho, que sempre esteve ao meu lado nos momentos mais difíceis, me aconselhando e auxiliando no desenvolvimento do trabalho.

A minha irmã por estar sempre por perto quando precisei.

Aos meus amigos de laboratório Naja, Enzo, e Flávia, e todos os outros que ajudaram e estiveram por perto em alguma ocasião.

Ao professor Alexandre Sartoris por ser meu amigo e mestre.

A Fundação de Amparo à Pesquisa do Estado de São Paulo (FAPESP) pela bolsa de doutorado concedida referente ao processo 2010/18837-6.

E por fim, aos professores e funcionários do departamento de Engenharia de Produção. 
"Quem nunca errou nunca experimentou algo novo"

Albert Einstein 
RESUMO

MORALLES, H. F. DESENVOLVIMENTO SÓCIO-ECONÔMICO, INFRAESTRUTURA DE TRANPORTES E INOVAÇÃO: UM ESTUDO ECONOMÉTRICO ESPACIAL DOS EFEITOS DE SPILLOVER NOS ESTADOS

BRASILEIROS. Tese (doutorado) - Escola de Engenharia de São Carlos, Universidade de São Paulo, São Carlos, 2012.

Ao longo das últimas décadas, um número cada vez maior de pesquisadores tem argumentado que simples índices como crescimento do PIB ou exportações são insuficientes para descrever o bem estar da população de um país. Contudo, apesar de estudos recentes adicionarem variáveis como desigualdade de renda, infraestrutura e inovação tecnológica às análises, a maioria dos autores falham na consideração de aspectos espaciais, tais quais os efeitos de vizinhança para estratégias governamentais de infraestrutura e desenvolvimento sócio-econômico. Nesse sentido, o presente trabalho tem como principal objetivo analisar a relação entre crescimento econômico, infraestrutura de transportes, gastos em inovação tecnológica e desenvolvimento sócio-econômico nos estados federativos brasileiros e seus efeitos de spillover (difusão), por meio de técnicas de econometria espacial. Os principais resultados demonstram a infraestrutura rodoviária como maior promotor de spillovers positivos para crescimento e desenvolvimento. Quanto à inovação, os resultados indicaram spillovers negativos, tanto para crescimento como para desenvolvimento, sendo significante somente para desenvolvimento.

\section{Palavras-Chave:}

Crescimento Econômico, Desenvolvimento, Infraestrutura de Transportes, Inovação, Econometria espacial, Spillover. 


\begin{abstract}
MORALLES, H.F. SOCIO-ECONOMIC DEVELOPMENT, TRANSPORTATION INFRASTRUCTURE AND INNOVATION: A SPATIAL ECONOMETRIC STUDY OF THE SPILLOVER EFFECTS IN THE BRAZILIAN STATES. Thesis

(PhD) - Engineering School of São Carlos, University of São Paulo, São Carlos, 2012.

Over the past decades, an increasing number of researchers have argued that simple indices such as GDP growth and exports are insufficient to describe the welfare of a country. However, in spite of recent studies add variables such as income inequality, infrastructure and technological innovation to the analysis, most authors fail to consider spatial aspects, as is the neighborhood effects for government strategies on infrastructure and socio-economic development. Accordingly, the present work aims to examine the relationship between economic growth, capital investment in public transport infrastructure, spending on technological innovation, and socio-economic development in the Brazilian federal states and their spillover effects, using spatial econometrics techniques. The main results show the road infrastructure as the biggest promoter of positive spillovers for growth and development. As for innovation, results indicated negative spillovers, both for growth and for development, being significant only for development.
\end{abstract}

\title{
Keywords:
}

Economic Growth, Development, Spatial Econometrics, Transport Infrastructure, Innovation, Spillover 


\section{SUMÁRIO}

RESUMO

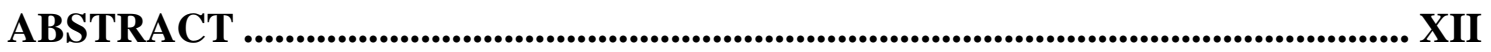

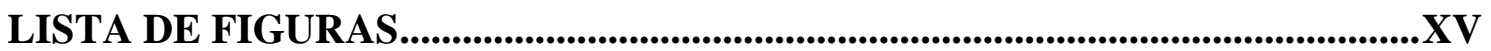

LISTA DE TABELAS ............................................................................................

CAPÍTULO 1 - INTRODUÇÃO ................................................................................... 17

CAPÍTULO 2 - CRESCIMENTO, DESENVOLVIMENTO, INFRAESTRUTURA

DE TRANSPORTES E INOVAÇÃO ......................................................................... 23

2.1 - CRESCIMENTO ECONÔMICO E DESENVOLVIMENTO ............................................... 23

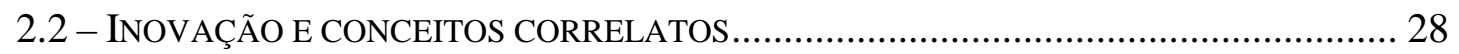

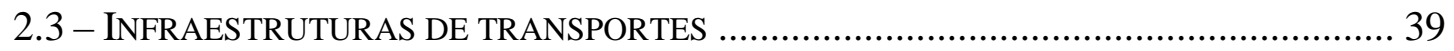

CAPÍTULO 3 - ECONOMETRIA ESPACIAL E O CONCEITO DE SPILLOVER

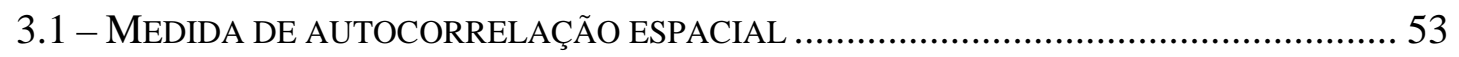

3.2 - PRINCIPAIS MODELOS DE ECONOMETRIA ESPACIAL .......................................... 56

3.3 - DEPENDÊNCIA ESPACIAL E ESTIMAÇÃO DE MODELOS DE DADOS EM PAINEL ........ 58

3.4 - Modelo ESPACIAL DE DURBIN (SDM) PARA DADOS EM PAINEL......................... 75

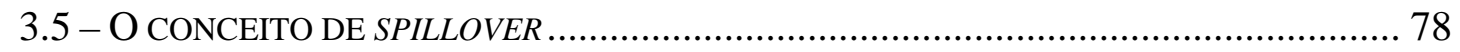

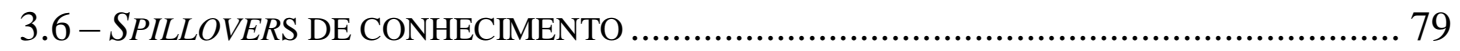

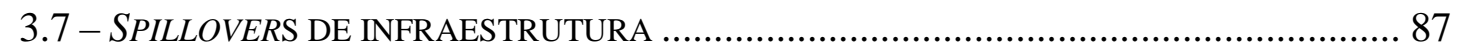

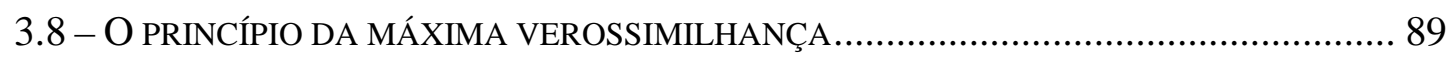

3.8.1. Maximização da verossimilhança .......................................................... 104

3.8.2. Séries de Taylor para extremos relativos ................................................. 107

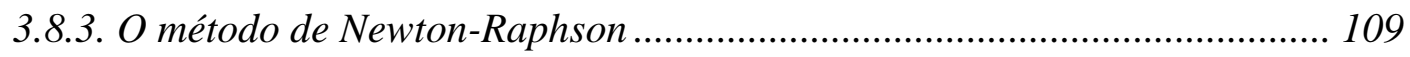

3.8.4. Encontrando o máximo da verossimilhança via método de Newton-Raphson 111

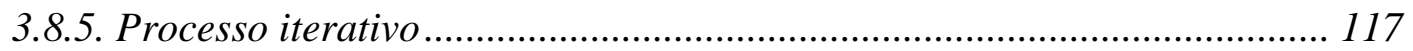

3.8.6. Testes de hipótese baseados na máxima verossimilhança ........................ 119

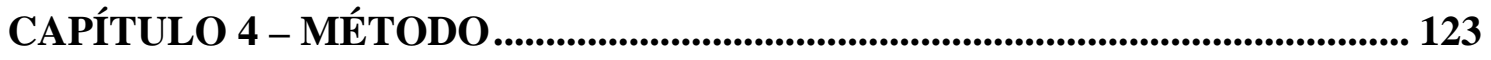

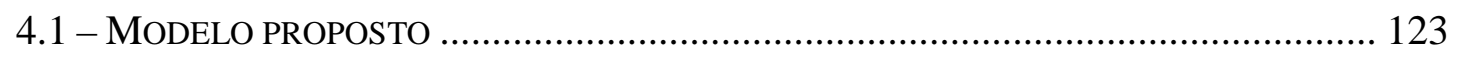

4.2 - MODELO A - SEM DEFASAGEM EM C\&T ................................................... 127 
4.3 - MODELO B - SEM DEFASAGEM E COM INÉRCIA ............................................. 128

4.4 - MODELO C - Modelo De UlVELling \& FLETCHER ....................................... 129

4.5 - MATRIZES DE PONDERAÇÃO ESPACIAL................................................................ 130

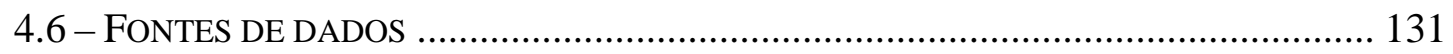

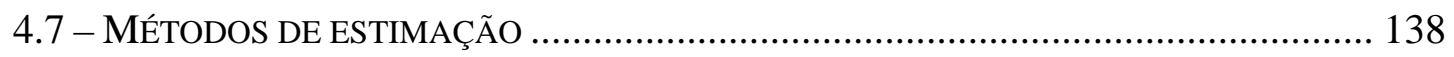

CAPÍTULO 5 - RESULTADOS E DISCUSSÕES ............................................. 145

5.1 - COMENTÁRIOS A RESPEITO dos RESULTADOS OBTIDOS NO MODELO A........... 153

5.2 - COMPARAÇÃO DOS RESULTADOS DE SPILLOVERS ESPACIAIS OBTIDOS COM OUTROS ESTUDOS RELEVANTES PUBLICADOS RECENTEMENTE. ............................................. 159

CAPÍTULO 6 - CONCLUSÃO ......................................................................... 163

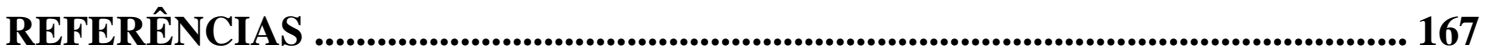

APÊNDICE - CONCEITOS MATEMÁTICOS UTILIZADOS EM

ECONOMETRIA ESPACIAL ................................................................................ 181

A.1. DERIVADAS PARCIAIS E DETERMINANTE JACOBIANO ...................... 181

A.2. OTIMIZAÇÃ

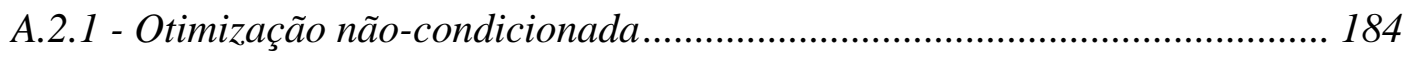

A.2.2 - Otimização condicionada ................................................................. 187 


\section{LISTA DE FIGURAS}

Figura 1 - Modelo de pobreza e performance inovativa. ............................................... 38

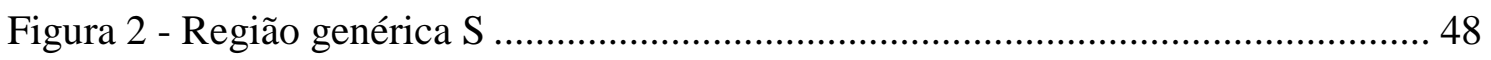

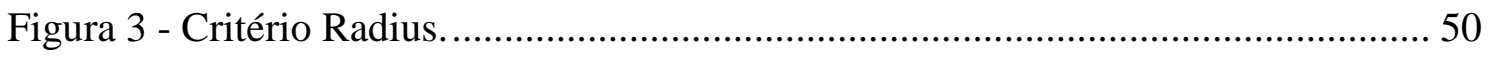

Figura 4 - Contiguidade de segunda ordem........................................................... 51

Figura 5 - Coeficiente de I de Moran para mensuração de autocorrelação espacial. ..... 55

Figura 6 - Matriz de vizinhança binária para dados cross-section. ................................. 73

Figura 7 - Matriz de vizinhança binária para dados em painel....................................... 73

Figura 8 - Estrutura de contiguidade cross-section ................................................... 74

Figura 9 - Estrutura de contiguidade para dados em painel ........................................ 74

Figura 10 - Esquema de inter-relacionamento das variáveis do modelo proposto....... 126

Figura 11 - Representação gráfica da derivada parcial................................................ 182

Figura 12 - Demonstração gráfica da otimização condicionada e não-condicionada.. 189

\section{LISTA DE TABELAS}

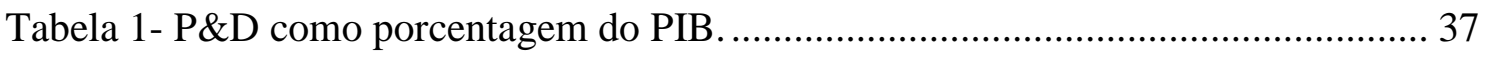

Tabela 2 - Estatísticas descritivas dos dados coletados .............................................. 135

Tabela 3 - Resultados preliminares para a estimação da Equação 1 do modelo. ......... 147

Tabela 4 - Resultados preliminares para a estimação da Equação 1 do modelo sem defasagem na variável de inovação. ....................................................................... 148

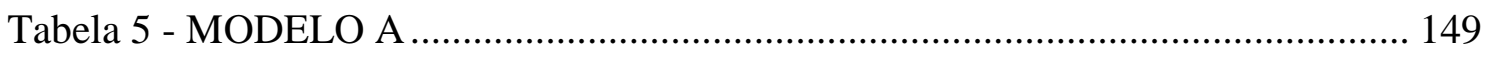

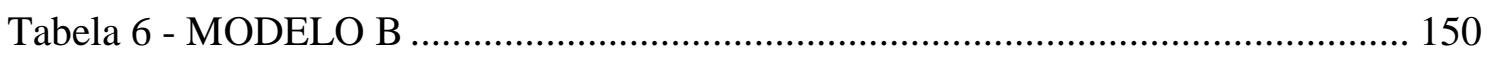

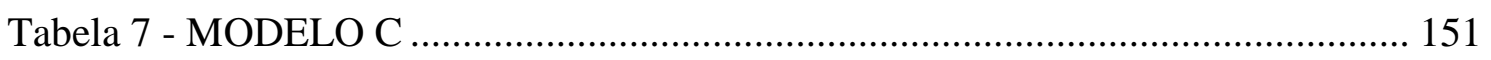

Tabela 8 - Critérios de informação para os MODELOS A e B.................................... 152

Tabela 9 - Resultados encontrados em outros estudos relevantes.............................. 160 


\section{CAPÍTULO 1 - INTRODUÇÃ O}

A literatura econômica, notadamente, tem relacionado variáveis como crescimento econômico, desigualdade de renda, inovação tecnológica, além de outras, a fim de mensurar o desempenho das nações e identificar seus determinantes, de maneira a propor formas de solucionar a questão do desenvolvimento.

Autores como Naudé e Gries (2009) tratam da liberalização comercial dos anos noventa, que, aparentemente, não foi capaz de reduzir desequilíbrios geográficos na economia sul-africana, bem como gerar convergência na renda per capita da população. Contudo, a despeito disso, algumas regiões geográficas obtiveram certos benefícios em função de exportações. Os autores também argumentam que exportações de um país são boas para seu crescimento e desenvolvimento, observando a realidade de alguns países africanos apontados como subdesenvolvidos em função da escassez de exportações de produtos manufaturados.

Variáveis como desigualdade de renda também surgem na literatura como importantes para explicar o crescimento econômico, tal como ocorre em Roine, Vlachos et al. (2009). Os autores também fazem considerações sobre a abertura comercial e exploram o papel do gasto governamental para os escalões sociais de alta renda, concluindo que tal abertura aparentemente não teve efeito positivo ou negativo sobre estes.

Nesses termos, é possível verificar que simples índices como crescimento do Produto Interno Bruto (PIB) ou exportações são insuficientes para descrever ou explicar o bem estar da população de um país. Assim, Cracolici et al. (2009) combinam aspectos 
econômicos e não econômicos para avaliação do desempenho nacional por meio de um modelo de equações múltiplas que contempla variáveis como PIB, expectativa de vida, taxa de alfabetização, inovação tecnológica, acesso à informação, e poluição. A despeito da consideração de tais variáveis, os autores falham na consideração de aspectos espaciais, bem como da interação intra-regional.

Em oposição, Massimo et al. (2010) além de considerarem aspectos de disparidades regionais utilizando-se de técnicas de econometria espacial, também verificam o papel do estoque de infraestruturas dos países da União Européia (UE), e seu papel na definição do processo de crescimento e convergência entre regiões da UE, à medida que a dimensão espacial dos dados afeta os resultados.

Apesar de alguns estudos considerarem a infraestrutura como um determinante para o sucesso econômico, são raros os estudos que avaliam o papel das infraestruturas de transporte. Dentre estes, estão Cohen e Monaco (2009) que, utilizando dados de condados, avaliaram o impacto da infraestrutura portuária para o comércio varejista da Califórnia por meio de um modelo econométrico espacial. Tal trabalho, além de levar em conta questões espaciais e de infraestrutura de transportes, também mensurou o efeito de spillover (difusão ou externalidade) entre os condados, observando que o aumento de $1 \%$ nos investimentos em infraestrutura de transportes de um condado causa uma adição da ordem de $0,22 \%$ nas exportações varejistas dos condados vizinhos. Eis, portanto, a essência do efeito spillover, que equivale ao efeito das políticas de uma localidade para com suas vizinhas.

Resultados como os apresentados reforçam a importância das questões espaciais em estudos que relacionem variáveis sócio-econômicas, bem como a importância da consideração dos efeitos de vizinhança para estratégias governamentais de infraestrutura e desenvolvimento sócio-econômico. 
Com respeito a questões de vizinhança, a primeira lei geográfica de Tobler (1970) faz uma afirmação quase que intuitiva sobre essas influências, no sentido de que tudo está relacionado, porém regiões próximas a uma determinada localidade estão mais relacionadas a esta do que regiões mais distantes. A noção de influência de vizinhos próximos é considerada em modelos de econometria espacial, pois a dependência espacial entre duas localidades (autocorrelação entre unidades regionais no espaço), entre outras causas, é resultado do efeito de spillover (ANSELIN, 1988a).

Mais especificamente, as relações espaciais entre unidades provêm da essência da geografia e ciências regionais que postulam tanto localização quanto distância, como fatores causadores de interdependência espacial. Nesses termos, o que ocorre em uma unidade espacial pode ser explicado, em parte, pelo que ocorre no restante do sistema em questão.

Assim, a identificação e quantificação dos efeitos de spillover se mostram interessantes do ponto de vista dos estudos sócio-econômicos, também pela ótica da qualidade dos parâmetros estimados nos modelos econométricos. Autores como (ANSELIN, 1988a) demonstram que características de ordem espacial, como a autocorrelação espacial, podem levar a problemas de estimação.

Dado este contexto, o conhecimento dos efeitos de spillover entre estados federativos de um país, bem como os efeitos diretos dos investimentos de um estado sobre seus aspectos sócio-econômicos e de seus vizinhos próximos, pode ser uma interessante ferramenta de planejamento de investimentos.

Para o caso brasileiro são escassos os trabalhos que tratam sobre spillover nos estados ou regiões. Ainda que existam estudos internacionais do gênero, não são encontrados nas principais bases de dados estudos que contemplem spillovers 
inovativos, spillovers de distribuição de renda e spillovers de exportações, bem como a relação entre eles.

A partir da busca em bases de dados tradicionais como JSTOR e SCOPUS termos (parâmetros de busca) como spillover and gini, spillover and infrastructure, spillover and $P \& D$, ou spillover and exports, são raros os trabalhos encontrados e, quando o são, não abordam questões espaciais, sendo possível citar Drewes (1987), Meyer e Whittier (1994), Levin (1988), e Conley e Topa (2002).

Diante do exposto, o presente trabalho tem como principal objetivo analisar a relação entre crescimento econômico, infraestrutura de transporte, gastos relacionados à inovação tecnológica e desenvolvimento nos estados federativos brasileiros, bem como seus efeitos de spillover, por meio de técnicas de econometria espacial. Tal ferramenta irá possibilitar não somente o cômputo dos efeitos de spillover, como também a adição de características espaciais aos modelos propostos, tornando as estimativas dos parâmetros mais precisas.

A escolha de infraestrutura de transporte e gastos em inovação tecnológica, como variáveis explicativas, é calcada no fato destas figurarem entre os principais entraves para o crescimento econômico e desenvolvimento social das economias emergentes. Especialmente a infraestrutura de transportes, no que tange às facilidades econômicas e bem estar social que propicia; bem como as inovações, cada vez mais preponderantes no cenário econômico atual, têm sido apontadas como determinantes de competitividade e geração de atividade econômica. A composição dos fatores inovação e infraestrutura de transportes adiciona maior confiabilidade ao modelo econométrico a ser estimado, de modo a evitar viés de especificação. Vários autores têm relacionado infraestruturas de transporte e variáveis relativas à inovação ao crescimento econômico, 
de forma separada. As elasticidades, no entanto, sempre se apresentam positivas, o que indica não haver motivo para tratá-las em modelos econométricos distintos.

Considerando o contexto apresentado, o presente trabalho parte da hipótese de que os investimentos públicos em infraestrutura de transporte e inovação tecnológica são capazes de gerar crescimento e desenvolvimento econômico, de forma direta ou indireta, tanto para estados investidores quanto para estados próximos geograficamente.

O problema a ser investigado consiste na verificação das relações entre tais variáveis, que levam a formular as seguintes perguntas de pesquisa:

Pergunta de pesquisa 1: A infraestrutura de transporte de um Estado afeta significativamente seu crescimento econômico, bem como o crescimento de outros Estados próximos? Quanto?

Pergunta de pesquisa 2: O gasto em inovação tecnológica de um Estado afeta significativamente seu crescimento econômico, bem como o crescimento de outros Estados próximos? Quanto?

Pergunta de pesquisa 3: $\mathrm{O}$ crescimento de um Estado contribui significativamente para seu desenvolvimento, bem como para o desenvolvimento de outros Estados próximos? Quanto?

Pergunta de pesquisa 4: O investimento em inovação tecnológica de um Estado contribui significativamente para seu desenvolvimento, bem como para o desenvolvimento dos Estados próximos? Quanto?

Pergunta de pesquisa 5: A infraestrutura de transporte de um Estado contribui significativamente para seu desenvolvimento, bem como para o desenvolvimento dos Estados próximos? Quanto? 
Para fins de esclarecimentos preliminares, entenda-se a expressão "crescimento econômico" como a dimensão material do bem estar de uma população, a qual pode ser refletida pelo PIB; enquanto a expressão "desenvolvimento" é compreendida como a dimensão social do bem estar, aproximada pelo acesso da população a serviços de saúde, educação e emprego, refletido pelo índice Firjan de desenvolvimento (IFDM) no Brasil.

Tendo em vista tal panorama, fica clara a intenção do trabalho proposto em mensurar, não apenas as relações entre as variáveis, mas seu efeito difusor para regiões próximas geograficamente (efeito de spillover).

Desta maneira, o presente trabalho pretende contribuir em duas vertentes. Primeiramente, a partir da exploração das relações sócio-econômicas existentes entre os estados brasileiros (spillover), permitindo que os modelos econométricos sejam estimados de forma a permitir a mensuração de possíveis efeitos espaciais. Por outro lado, contribuir para a recente discussão sobre desenvolvimento sócio-econômico e suas relações espaciais em um contexto brasileiro, possibilitando uma maior qualidade no planejamento de investimentos públicos em infraestruturas e inovação tecnológica. 


\section{CAPÍTULO 2 - CRESCIMENTO, DESENVOLVIMENTO, INFRAESTRUTURA DE TRANSPORTES E INOVAÇÃO}

Neste capítulo serão apresentadas as principais relações entre as variáveis crescimento, desenvolvimento, infraestrutura de transportes e inovação, de modo a caracterizar, a partir do conhecimento disponível na literatura, o estado da arte dos estudos que analisam o impacto de inovação e infraestrutura de transporte para o crescimento e desenvolvimento das nações.

Os artigos explorados neste capítulo resultam de buscas realizadas na base de dados SCOPUS, coletando primeiramente os artigos mais citados, e posteriormente, os mais atuais para a busca realizada com a palavra-chave de cada uma das variáveis estudadas no presente trabalho.

\section{1 - Crescimento econômico e desenvolvimento}

A noção de crescimento econômico é nitidamente um dos aspectos do desenvolvimento e bem estar material de uma nação. Contudo, a forma ou estratégia de promoção do crescimento de uma dada localidade está longe de ser unanimidade entre os pesquisadores existindo, portanto, uma gama de teorias e escolas que contemplam diferentes abordagens para a promoção do crescimento.

Lucas (1988) constrói uma teoria neoclássica de crescimento e comércio internacional, consistente com as principais características do desenvolvimento econômico. O modelo desenvolvido, que considera a taxa de crescimento populacional como dada, e sem influências endógenas, leva em conta dois tipos de capital no sistema. 
O primeiro é o capital físico, o qual é acumulado e utilizado na produção, sob a condição de tecnologia neoclássica. O segundo é o capital humano, que melhora a produtividade tanto do capital físico, quanto do trabalho, acumulado segundo uma lei que prevê que um nível constante de esforço produz uma taxa constante de crescimento, independente do nível já alcançado.

Existem estudos que apontam a influência de um sistema financeiro eficiente para o crescimento econômico de uma nação. Mercados financeiros afetam e são afetados pelo desenvolvimento econômico, existindo vários trabalhos em nível micro e macro, que indicam uma forte e positiva ligação entre o funcionamento do sistema financeiro e o crescimento econômico no longo prazo (LEVINE, 1997). Assim, mesmo as flutuações de curto prazo no crescimento econômico não são passíveis de refutar tal ligação de longo prazo. O estudo aponta, ainda, que o desenvolvimento do sistema financeiro é moldado por fatores não financeiros como o desenvolvimento tecnológico e de telecomunicações, denotando a importância de tais fatores para o desenvolvimento econômico.

Mesmo Schumpeter (1912) afirma que um sistema financeiro bem estruturado estimula a inovação tecnológica ao identificar e financiar projetos com boas chances de sucesso, implementando produtos e processos inovadores (LAUMAS, 1962).

Outros autores como Christopoulos e Tsionas (2004) também evidenciam a relação entre desenvolvimento financeiro e crescimento econômico via teste de raiz unitária, enquanto a teoria do crescimento endógeno também salienta a influência dos mercados financeiros para o crescimento econômico medido pelo crescimento do PIB ou produtividade total de fatores (GREENWOOD e SMITH, 1997; BECK, LEVINE et al., 2000). 
Modelos neoclássicos de crescimento como Solow (1956) e Diamond (1965) sugerem que países com ambientes físicos similares não deveriam apresentar, no longo prazo, diferenciais de taxas de crescimento, mesmo com trajetórias iniciais distintas.

Contudo, existem evidências contrárias a essa concepção, como em Azariadis e Drazen (1990) que intentam, por meio de um modelo que permite estados estacionários múltiplos e localmente estáveis, explicar diferenciais em taxas de crescimento nas nações.

A não convergência das taxas de crescimento pode ser, em parte, explicada por diferenças sistemáticas nas nações como cultura, religião, política econômica, países mais pobres fazendo catching-up para alcançar os ricos, e outros fatores exógenos (AZARIADIS e DRAZEN, 1990).

Países com acesso a tecnologias similares, mas taxas distintas de crescimento sugerem a noção de estratégias de crescimento. Assim, para uma dada tecnologia de transformação disponível para produtores individuais, diferenças no estoque de fatores podem implicar em diferenças nas taxas de crescimento. Desse modo, a dotação inicial de fatores como estoque de capital ou estoque de conhecimento apresentam certos valores críticos que configuram condições para que a produção se expanda rapidamente (AZARIADIS e DRAZEN, 1990).

Surge então uma distinção de fatores de produção privados e sociais, os últimos, não passíveis de serem controlados pela empresa, podendo se configurar, por exemplo, em fatores intangíveis, como o conhecimento. Assim, em termos econométricos, tais fatores sociais seriam captados pelo intercepto da função de produção estimada para o agregado, sendo tais retornos crescentes se tal intercepto for uma função também crescente (AZARIADIS e DRAZEN, 1990). 
Nesse contexto, para o modelo que explique diferenciais de taxas de crescimento econômico, Azariadis e Drazen (1990) analisam uma elaboração baseada na acumulação de capital humano, e na existência de retornos crescentes quando algumas variáveis importantes atingem um limiar ou massa crítica. É essa ideia que explica as múltiplas taxas de crescimento.

A noção de crescimento econômico também está fortemente associada às externalidades (spillovers). Nesse sentido, externalidades tecnológicas ocorrem quando taxas de retorno privados de investimento em capital humano dependem da qualidade média dos recursos humanos existentes. Assim, ceteris paribus, o retorno privado da educação deve ser maior em países desenvolvidos do que nas nações em desenvolvimento (AZARIADIS e DRAZEN, 1990).

A quase totalidade dos estudos citados neste capítulo associa o conceito de crescimento econômico ao PIB. Contudo, quando se deseja apurar o bem estar social de uma nação, é comum que medidas como o PIB ou o PIB per capita não sejam suficientes. De fato, Cracolici et al. (2010), argumentam que o PIB não é capaz de capturar as desigualdades reais entre países em termos de diferentes dimensões do bemestar social.

Em verdade, o PIB é uma medida parcial de um conceito amplo de bem-estar social, o qual incorpora aspectos econômicos e não econômicos (como saúde e educação), ou liberdades (SEN, 1984; DASGUPTA e WEALE, 1992).

O conceito de bem-estar social está fortemente ligado ao desenvolvimento de uma nação, cujo indicador mais frequentemente utilizado é o Índice de Desenvolvimento Humano (IDH), criado pelo Programa das Nações Unidas para o Desenvolvimento (PNUD), a fim de mensurar os diferenciais de desenvolvimento entre países. Tal índice leva em conta as características de longevidade, educação e renda. 
No Brasil, semelhante ao IDH, existe o índice IFDM (Índice FIRJAN de Desenvolvimento Municipal) criado pela Fundação FIRJAN para calcular as diferenças municipais nas esferas de emprego e renda, educação, e saúde. Tal índice também possui uma contrapartida estadual.

Especificamente, o Índice FIRJAN de Desenvolvimento Municipal (IFDM) é um estudo anual do Sistema FIRJAN que acompanha o desenvolvimento de todos os 5.564 municípios brasileiros em três áreas - emprego e renda, educação, e saúde baseado em estatísticas públicas oficiais, disponibilizadas pelos ministérios do Trabalho, Educação e Saúde (FIRJAN, 2012).

Apesar de ser um índice primordialmente municipal, a entidade responsável gera um índice nacional discriminado para unidades da Federação, tendo em vista a divulgação oficial das variáveis componentes do indicador por estados e para o país. O índice varia de 0 a 1, sendo a interpretação de quanto mais próximo da unidade, maior é o desenvolvimento da localidade ou unidade da federação analisada (FIRJAN, 2012).

Nesse sentido, a melhoria do PIB per capita é considerada como pré-requisito para a melhoria dos padrões de vida da população, melhoria dos serviços de saúde, segurança, acesso à educação, trabalho, e ambiente sustentável. De modo análogo, boas condições de vida constituem uma boa base para a melhoria da produtividade e consequentemente, do PIB. Assim, verifica-se uma relação bidirecional entre dimensões econômicas e não econômicas da performance de um país (CRACOLICI et al., 2010).

Para Saviotti e Pyka (2004), o desenvolvimento econômico pode ser considerado como o resultado de dois processos: o primeiro, relativo ao aumento de eficiência, e o segundo referente ao aumento de variedade e mudança qualitativa em termos de novos produtos, substituindo ou coexistindo com os antigos. O autor comenta as implicações 
de um modelo de crescimento econômico pela criação de novos setores na economia para o emprego demonstrando que, mesmo com uma tendência de diminuição de emprego, a oferta de trabalho agregada pode continuar crescendo pela criação de novos setores e atividades econômicas em períodos corretos.

\section{2 - Inovação e conceitos correlatos}

A relação entre inovação, crescimento e desenvolvimento é observada desde Marshall (1890), reconhecendo que o conhecimento é capaz de alterar a atividade econômica, bem como o inverso também pode ocorrer.

Segundo Howells (2005) a inovação é capaz de criar e sustentar riqueza, produzindo amplos benefícios sociais e econômicos, bem como otimizando o desempenho econômico.

De acordo com Schumpeter (1934), a inovação tecnológica é a implementação de novos produtos ou processos, ou, mudanças significativas naqueles já existentes.

Um dos principais fatores a influenciar ativamente o processo de inovação tecnológica são os gastos com pesquisa e desenvolvimento (P\&D) que abrangem:

1) Pesquisa Básica: Trabalho experimental ou teórico com a finalidade de compreender fenômenos e fatores observáveis, mas sem aplicação particular.

2) Pesquisa Aplicada: Investigação de novos conhecimentos com objetivo prático.

3) Desenvolvimento experimental: Aplicação dos conhecimentos já adquiridos com a finalidade de desenvolver novos materiais, produtos, processos, sistemas e serviços, ou melhorar os existentes. 
As inovações tecnológicas em produtos e processos (TPP) compreendem a implantação de produtos e processos tecnologicamente novos e substanciais melhorias tecnológicas nestes (OCDE, 2005).

Uma inovação TPP é considerada implantada se tiver sido introduzida no mercado ou usada no processo produtivo. Tais inovações envolvem uma série de atividades científicas e tecnológicas, organizacionais, financeiras e comerciais (OCDE, 2005).

As inovações em empresas podem ocorrer via substituição de equipamentos ou aquisição de novos conhecimentos e métodos, contudo, para realizarem inovações, ou seja, viabilizarem novos produtos, melhorar a qualidade dos existentes, e diminuir os custos de produção, as atividades de $\mathrm{P} \& \mathrm{D}$ são vistas como fundamentais (CALLIGARIS e TORKOMIAN, 2003).

A atividade de pesquisa envolve a geração de novos conhecimentos, e a de desenvolvimento envolve aplicação de conhecimentos gerados, objetivando a criação de novos produtos, ou aperfeiçoando os existentes, com a intenção de torná-los melhores e mais baratos (FERRO, 1997, apud CALLIGARIS e TORKOMIAN, 2003).

Segundo a Embrapa (1999),

"O conceito de P\&D é o conjunto de ações que envolvem a geração de conhecimentos e a transformação dos conhecimentos e a adaptação de tecnologias já existentes em novas tecnologias, na forma de produtos e processos acabados que atendem às necessidades do mercado".

O conceito de $\mathrm{P} \& \mathrm{D}$ inclui o trabalho criativo levado a cabo de forma sistemática para aumentar o campo dos conhecimentos, incluindo o conhecimento do homem, da cultura, e da sociedade, e a utilização desses conhecimentos para criar novas aplicações. 
A P\&D envolve a investigação básica, investigação aplicada, e desenvolvimento experimental (OCDE, 2002)

Basicamente, em OCDE (2002) se definem como atividades de P\&D "todo o trabalho criativo efetuado sistematicamente para ampliar a base de conhecimentos científicos e tecnológicos e o uso desses conhecimentos para criar novas aplicações".

Sob a denominação "ciência e tecnologia" (C\&T) estão os investimentos em P\&D mais os realizados em "atividades científicas e técnicas correlatas" (ACTC). Estão incluídas em ACTC atividades não criativas: serviços científicos e tecnológicos prestados por bibliotecas, arquivos, museus de ciência, jardins botânicos e zoológicos, levantamentos topográficos, geológicos, hidrológicos, prospecção para identificação de petróleo e outros recursos minerais, metrologia, padronização, controle de qualidade, entre outras (OCDE, 2002).

Existe também o conceito de atividade científica e tecnológica (ACT) criada pela UNESCO, que além de $\mathrm{P} \& \mathrm{D}$, compreendem o ensino e a formação científica e técnica, e os serviços científicos e técnicos, como atividades de C\&T de bibliotecas e museus, tradução e edição de literatura em C\&T, a vigilância e prospecção, a compilação de dados sobre fenômenos sócio-econômicos atividades em matérias de patentes, entre outros (OCDE, 2002).

Mas P\&D não é apenas a soma dos processos “pesquisa” e "desenvolvimento". A P\&D é um dos elos fundamentais da cadeia de ações e atividades que compõem o processo maior de desenvolvimento sócio-econômico, que, embora sendo essencial, tal contribuição das instituições de ciência e tecnologia (C\&T) não é suficiente para que o desenvolvimento ocorra, sendo necessários, portanto, outros fatores como legislação adequada, investimentos em infraestrutura de produção, comercialização e recursos humanos especializados (EMBRAPA, 1999) 
Historicamente, as instituições de C\&T que promovem P\&D têm determinado cada vez mais o desenvolvimento social e econômico regional, tendo em vista que a P\&D é capaz de resolver problemas de base tecnológica instalada, bem como reestruturam tais bases, possibilitando novas formas de desenvolvimento e negócios (EMBRAPA, 1999).

As atividades de inovação tecnológica são o conjunto de etapas científicas tecnológica, organizacionais, financeiras, e comerciais, incluindo os conhecimentos que levam à implementação de novos produtos e processos, ou melhoramentos destes (OCDE, 2002).

A P\&D é apenas uma dessas atividades e pode ser definida em diferentes fases do processo de inovação, não sendo usada apenas enquanto fonte de ideias criativas, mas também, para resolver qualquer problema durante o decorrer de seu processo de implantação.

Quanto à medição dos inputs da $\mathrm{P} \& \mathrm{D}$, basicamente são utilizadas as despesas dedicadas à P\&D e o pessoal designado a essas atividades, o que compreende apenas a esfera de recursos humanos da P\&D (OCDE, 2002).

Existe também a possibilidade de expressar os inputs da P\&D em termos monetários. Contudo, existem problemas com essa abordagem, o principal deles reside nos diferentes níveis de preço entre os países e as constantes variações nas taxas de câmbio. Ademais, em períodos de alta inflação, os índices gerais de preços não refletem fielmente a evolução dos custos de execução da P\&D. Outra possibilidade é a mensuração das instalações para $\mathrm{P} \& \mathrm{D}$, contudo, são escassos dados dessa natureza (OCDE, 2002).

O interesse em P\&D está mais relacionado com os conhecimentos e inovações gerados, bem como os efeitos sociais e econômicos resultantes. 
Existem várias formas de se medir os outputs de P\&D, ou em geral, C\&T, como, por exemplo, o balanço de pagamentos da tecnologia, dados de patentes como indicadores de C\&T, bibliometria, e análise de dados comerciais, do ponto de vista de intensidade tecnológica (OCDE, 2002).

Assim, independentemente de convenções e denominações, observa-se que a capacidade inovativa de um país é uma das forças primordiais da performance econômica de uma nação.

O conceito de capacidade inovativa nacional $\left(\mathrm{NIC}^{1}\right)$ se refere, segundo Furman et al. (2002), a capacidade de produzir e comercializar um fluxo de tecnologias inovativas no longo prazo. Tal conceito depende da infraestrutura inovativa comum da nação (fatores transversais que contribuem amplamente para a efetividade da inovação em toda a economia), o ambiente de clusters industriais, e a interação entre estes.

Assim, uma infraestrutura inovativa comum resulta em um fluxo de output inovativo mais produtivo quando há mecanismos ou instituições (como universidades vibrantes e fundos financeiros) estabelecidos para novos empreendimentos. Portanto, a qualidade da ligação entre o ambiente específico de clusters de inovação e a infraestrutura inovativa comum definem muito da disparidade das taxa de inovação dos países (FURMAN et al., 2002).

De fato, Furman et al. (2002) encontram que grande parte desse diferencial inovativo entre países se deve a diferenças nos níveis de inputs devotados a inovação, como pessoal e gastos com P\&D. Contudo, outra parte desse diferencial está relacionada a fatores associados com diferenças na produtividade da $\mathrm{P} \& \mathrm{D}$, como:

- Proteção à produção intelectual;

- Abertura ao comércio internacional;

\footnotetext{
${ }^{1}$ National Innovative Capacity
} 
- Proporção entre setor público e privado no financiamento à pesquisa;

- Nível de especialização tecnológica;

- Estoque de conhecimento individual do País (patentes).

Especialmente para países em desenvolvimento, o estoque de patentes e o gasto com P\&D determinam respectivamente 91,4 e $63,8 \%$ da capacidade inovativa. A partir dessa constatação, Hu e Mathews (2005) apontam o papel indispensável da P\&D público para os estágios iniciais do desenvolvimento dessas economias emergentes.

No que diz respeito à tecnologia e a teoria econômica, a corrente neoclássica observa a tecnologia como um fator estritamente exógeno, tal qual Solow (1956), enquanto Mankiw et al. (1992) postulam que a tecnologia deva ser considerada um bem público e, assim, no longo prazo a taxa de progresso tecnológico seria a mesma em todos os países, fazendo a taxa de crescimento entre as nações convergir (HOWELLS, 2005).

Em contraste, modelos e teorias baseados na interpretação endógena e schumpeteriana introduzem a ideia do progresso técnico como parte da teoria de crescimento econômico.

Modelos neoschumpeterianos introduzem a noção de competição monopolística sobre o direito de propriedade das inovações, definindo, portanto, o conhecimento mais como um bem privado (FAGERBERG, 1987). Dessa forma nascem disparidades pela acumulação dos benefícios da inovação e, portanto, a inovação acaba sendo observada como um fator de desequilíbrio no crescimento econômico.

Existem, ainda, teorias híbridas como a de Uzawa (1965), que tratam a tecnologia como endógena, mas a classificam como bem público não rival e passível de spillovers. 
Assim, estudos têm sugerido a existência de spillovers de conhecimento positivos e negativos, ligados especialmente à tecnologia e seus impactos em outras variáveis relacionadas, como o PIB (LEWISON, 1991; HOWELLS, 2005).

A tecnologia endógena pode ser mais ou menos importante dependendo da perspectiva. Por exemplo, nos Estados Unidos metade da produtividade vem de tecnologia estrangeira, contudo, em um sistema menor é possível que a tecnologia endógena seja mais impactante para o desempenho. De qualquer forma, conhecimento e inovação terão efeitos de spillover, sendo, portanto, a proximidade geográfica um fator de consideração (HOWELLS, 2005)

São inúmeros os estudos sobre conhecimento e inovação como forças de desenvolvimento regional, contudo com múltiplas aproximações e respostas.

Segundo Marshall, o desenvolvimento e crescimento de regiões industriais emergem do processo de especialização produtiva, o qual advém da divisão regional do trabalho. O crescimento econômico tem sido baseado na transformação e criação de conhecimento e inovação, que possui uma forte dimensão regional por sua natureza localizacional (WERKER e ATHREYE, 2004).

A infraestrutura fornecida pelo estado é de suma importância para o fomento da inovação, contudo, intermediários público-privados também possuem relevância. Dessa forma, um dos principais elementos da infraestrutura regional para o fomento da inovação é fornecido na forma de tráfego como links de comunicação e informação, os quais não apenas influenciam os custos de transportes de inputs e outputs, mas também, determinam o quão fácil o acesso a uma região pode ser. Este último, podendo ser compreendido como fax, e-mail, telefone, etc (WERKER e ATHREYE, 2004). 
Não obstante, tráfego e links de comunicação e informação podem diminuir a concentração regional. Isso ocorre, pois firmas podem compartilhar unidades de P\&D, bem como ter grande mobilidade nos fatores de produção, em especial, o fator trabalho (WERKER e ATHREYE, 2004).

Outro importante elemento de infraestrutura é a educação, bem como departamentos e instalações de $\mathrm{P} \& \mathrm{D}$, ambos provedores de conhecimento sobre diferentes tecnologias, bem como criadores de capital humano e capacidades de absorção (WERKER e ATHREYE, 2004).

Assim, a tecnologia é condição necessária, mas não suficiente, para o desenvolvimento econômico regional. São as redes regionais de inovação que transformam tecnologia em competitividade das firmas, que contribuem para o desenvolvimento econômico (RUTTEN e BOEKEMA, 2007).

Firmas inovativas são mais competitivas, criam mais empregos, e pagam maiores salários e impostos, beneficiando assim o desenvolvimento econômico regional. Tal desenvolvimento é uma característica de regiões em que a inovação é um processo inter e intra firmas. Assim, para uma firma coletar os benefícios da inovação, dentre outras condições, deve colaborar na inovação em redes regionais.

Reiterando que a tecnologia é uma condição necessária para desenvolvimento econômico regional, observa-se que são nas redes de inovação que a tecnologia é transformada em prosperidade, sendo o capital social (ativos intangíveis) que define o quão efetiva é essa transformação.

Pesquisadores apontam que a capacidade inovativa tem sido amplamente vista como força crítica para crescimento econômico nacional em países desenvolvidos. Contudo, tal visão não é consensual quando analisadas economias emergentes. 
A despeito disso, a capacidade inovativa contribuiu significativamente para o crescimento econômico de China e Índia no período de 1981 a 2004, em especial, nos anos noventa (PEILEI, 2011).

O output do sistema nacional de inovações, o qual pode ser refletido por patentes e exportações de serviços de alta tecnologia, demonstra o incrível progresso que China e Índia fizeram em sua capacidade inovativa. Tal capacidade ocorreu nas décadas recentes devido a pesados investimentos em inputs inovativos como gastos com P\&D e pessoal para $\mathrm{P} \& \mathrm{D}$, tendo os governos nacionais grande importância e liderança em tais processos (PEILEI, 2011).

Ambos os países conectaram seus setores científicos com o setor de negócios, provendo incentivos à inovação e balanceando importação de tecnologias e esforços de P\&D nativo.

Estudos como Crookes (2012) examinam a estratégia inovativa chinesa como parte de sua política de desenvolvimento econômico para atingir maior modernização de seu mercado doméstico, citando algumas fraquezas estruturais que atuam como inibidores em alguns setores chineses.

Países que possuem programas de inovação tecnológica, normalmente, possuem renda elevada, parques industriais mais avançados, e menor desigualdade social Jensen et al. (2004), o que pode ser verificado na Tabela 1, que demonstra que países com elevado índice de desenvolvimento sócio-econômico como Áustria, Dinamarca e Finlândia possuem proporções do PIB mais elevadas destinadas ao fomento de P\&D, enquanto países em desenvolvimento, como o Brasil, apresentam menores valores para tais proporções. 
Tabela 1- P\&D como porcentagem do PIB.

\begin{tabular}{lc} 
País & P\&D como \% do PIB \\
\hline Áustria & 2.76 \\
Canadá & 1.80 \\
Dinamarca & 3.06 \\
Estonia & 1.62 \\
Finlandia & 3.87 \\
França & 2.26 \\
Alemanha & 2.82 \\
Hungria & 1.16 \\
Irlanda & 1.79 \\
Itália & 1.26 \\
Coreia do Sul & 3.74 \\
Polônia & 0.74 \\
Eslováquia & 0.63 \\
Turquia & 0.84 \\
\hline & \\
BRASIL & 1.16 \\
\hline
\end{tabular}

Fonte: OECD (2012), "Gross domestic expenditure on P\&D", Science and Technology: Key Tables from OECD, No. 1.

No que tange ao desenvolvimento, Hall e Howell-Moroney (2012) examinam a relação entre pobreza e capacidade inovativa nos Estados Unidos por meio de um modelo econométrico que relaciona a performance econômica, mensurada via output econômico de uma localidade (Gross State Product), sendo, portanto, uma medida de PIB em jurisdições menores, e a taxa de pobreza.

O modelo proposto apresentado na Figura 1 apresenta características de endogeneidade e defasagem temporal, nas equações (2.1) e (2.2), bem como acrescenta variáveis de controle, contudo, sem especificá-las. 


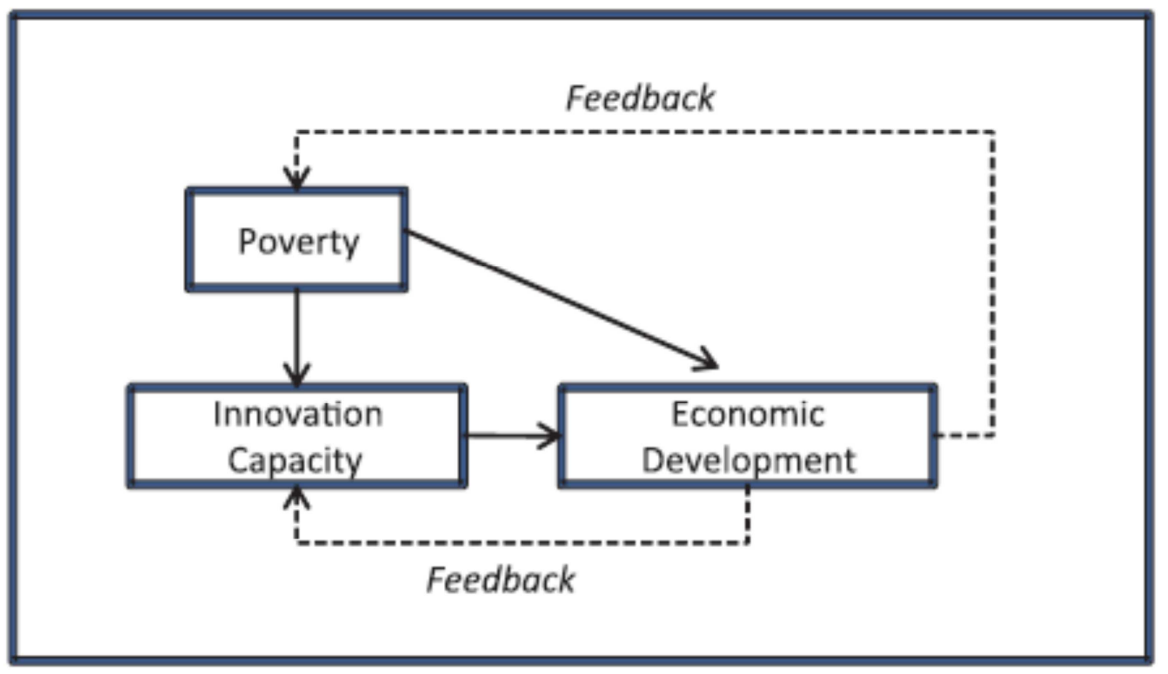

Figura 1 - Modelo de pobreza e performance inovativa.

Fonte: Hall e Howell-Moroney (2012)

O modelo utilizado é,

$$
\text { INOVAÇÃ } O_{i t}=\text { INOVAÇÃ } O_{i t-1}+\alpha P O B R E Z A_{t}+X_{i t} \beta+F e_{i}+u_{i t}
$$

PERFORMANCE ECON EP $_{i t}=\rho$ PRFORMANCE ECON EC $_{i t-1}+$

$$
\alpha I N O V A C ̧ \tilde{A} O_{i t}+X_{i t} \beta+F e_{i}+u_{i t}
$$

O estudo de Hall e Howell-Moroney (2012) encontra que, provavelmente, a pobreza afeta a performance econômica e indiretamente reduz a capacidade inovativa.

Nesse âmbito, universidades têm assumido um papel cada vez maior no desenvolvimento de economias baseadas em ciência e tecnologia, tanto em regiões em processo de catching-up, quanto em localidades de liderança inovativa. Segundo Youtie e Shapiro (2008), a universidade na era pós-industrial atua como um hub (ponto central) tecnológico, isto é, uma instituição integrada em uma região inteligente, promovendo inovações naturais do país e novas capabilidades.

Tal ideia é corroborada por Veugelers et al. (2012), que utilizando dados de patentes, analisa a presença e impacto de universidades em tecnologias para vários países e setores. O estudo revela a grande preponderância das universidades americanas em termos de criação de tecnologias acadêmicas altamente citadas. Já países Europeus e 
Asiáticos variam consideravelmente tem termos de criação e uso de tecnologias acadêmicas.

Ainda, apesar de pouco explorado, existe o estudo da transmissão e transformação de investimentos inovativos, visto que as despesas com atividades de inovação rendem retornos potenciais no futuro, pouco observáveis no período do dispêndio.

Em termos de empresas privadas, para avaliar como a inovação afeta o desempenho geral, sugere-se que sejam considerados alguns dados genéricos da empresa referentes a um período de três anos (OCDE, 2005).

\section{3 - Infraestruturas de transportes}

Juntamente com a tecnologia, as infraestruturas de transportes desempenham um papel crucial para o desempenho de uma nação. Estudos como Ambe (2009) atestam forte relação positiva entre infraestruturas de transporte e desenvolvimento econômico, medido pelo IDH. Seguindo tal hipótese, para Berechman (1994), a crença de que a alocação de recursos públicos em infraestrutura de transportes irá gerar crescimento econômico constitui uma das principais justificativas para tal investimento em países em desenvolvimento.

A visão das infraestruturas de transporte como facilitadoras de crescimento econômico não é questionada, pois infraestruturas de transportes eficientes expandem a capacidade produtiva de uma nação pelo incremento da mobilização de recursos existentes, bem como melhorando sua produtividade (PRADHAN e BAGCHI, 2012).

Muitas vezes, a infraestrutura de transportes pode ser vista com o input direto no processo produtivo, bem como eleva a produtividade de outros inputs pela diminuição 
dos custos de transportes. Ademais, tais infraestruturas podem atrair recursos de outras regiões, gerando crescimento e efeitos de aglomeração (PRADHAN e BAGCHI, 2012).

Ademais, educação e a universalização de serviços de saúde podem ser alcançadas pela provisão de infraestruturas de transportes (PRADHAN e BAGCHI, 2012).

Infraestruturas públicas de transportes, como rodovias, por exemplo, tem sido apontadas como um dos monopólios naturais mais intensivos em capital (GRAMLICH, 1994 apud NJOH, 2012).

Em estudos realizados no âmbito de países desenvolvidos, é unânime a ideia de que infraestruturas de transportes, como rodovias, afetam o desenvolvimento, contudo, não há consenso sobre a natureza de tal efeito. Nesses países, era comum o estímulo à economia em tempos de crise com planos que contemplassem enormes investimentos no setor, especialmente, na construção de rodovias (NJOH, 2012).

Especialmente nos países em desenvolvimento, tais infraestruturas são prioritárias a fim de contemplar necessidades de mobilidade e promover o desenvolvimento e, portanto, fatores como mobilidade melhorada, redução de congestionamentos, e outros benefícios econômicos têm sido utilizados para justificar investimentos em infraestruturas de transportes (KHASNABIS et al., 2010).

Já em países de passado colonial, era comum que as infraestruturas de transportes fossem construídas pela metrópole com a finalidade de escoar a produção de commodities (NJOH, 2012).

A relação entre transportes e desenvolvimento é entendida primordialmente, pelo fato de infraestruturas de transportes serem direta ou indiretamente ligadas a outros setores como construção e manutenção de equipamentos, transporte de força de trabalho, aquisição e distribuição de serviços, facilitação de operações, e gestão. Assim, 
qualquer incremento nas infraestruturas de transporte ocasiona efeitos positivos nessas áreas da economia (NJOH, 2012).

Transportes também são usualmente entendidos como importantes fatores de produção, apesar de terem perdido tal preponderância em economias desenvolvidas pelo advento do outsourcing. Contudo, seu papel e importância permanecem intactos, sendo ainda mais amplificados em termos do desenvolvimento regional (NJOH, 2012).

Em termos de teoria econômica, para os neoclássicos, o desenvolvimento ocorre pelo aumento de eficiência e, portanto, infraestruturas de transportes atuariam no desenvolvimento pela melhoria da produtividade de capital humano e físico, mas também agindo como input direto. Já a vertente teórica do cumulative-causation model postula que o crescimento regional se origina de algum estímulo inicial, como a existência de algum recurso natural. Nesse caso, as infraestruturas de transportes atuariam como atrativo de atividades econômicas, gerando efeitos de aglomeração e escala, servindo assim, de motor para o desenvolvimento econômico regional (NJOH, 2012).

Pradhan (2012) examina o papel das infraestruturas de transportes para o crescimento econômico indiano entre 1970 e 2010. Utilizando o PIB como proxy para o crescimento, e por meio de uma análise que utilizava causalidade de Granger, o trabalho encontra relação bidirecional entre rodovias e crescimento, relação bidirecional entre rodovias e formação bruta de capital, relação unidirecional entre ferrovias e crescimento, e por fim, relação unidirecional entre ferrovias e formação bruta de capital.

Dessa maneira, Pradhan (2012) constrói o modelo de três equações em concordância com a dinâmica de causalidade encontrada. Contudo, relaciona apenas as variáveis de crescimento e infraestruturas de transportes e formação bruta de capital, negligenciando outras possíveis variáveis como trabalho e tecnologia, o que poderia 
causar viés de especificação nos parâmetros estimados para as infraestruturas de transportes. Tal situação corresponderia ao fato dos parâmetros estimados das infraestruturas estarem absorvendo parte do efeito das variáveis omitidas no modelo.

De modo semelhante, Njoh (2012) relaciona infraestruturas de transportes e desenvolvimento na África oriental, relacionando PIB per capita com diferentes formas de transportes na região e confirmando tal relação positiva via modelo econométrico. Porém, utiliza o PIB per capita como medida de desenvolvimento, regredindo tal variável apenas em função de infraestruturas de transportes, omitindo, portanto, outras variáveis relevantes, o que ocasionaria viés de especificação nos parâmetros estimados para as infraestruturas de transportes.

Também, é necessário considerar a existência dos spillovers de infraestruturas associados ao crescimento econômico. Contudo, ainda não existe na literatura um consenso sobre a relação de dependência entre tais variáveis, configurando, possivelmente, em uma relação de dependência bidirecional (HU e LIU, 2010)

Externalidades podem ser definidas como o impacto da produção sobre indivíduos que não participam dela diretamente. Dessa forma, externalidades de infraestruturas de transporte podem ser negativas como poluição, acidentes, e congestionamentos; ou positivas, tais como facilitação de exportações, movimentação espacial de força de trabalho, melhoria da distribuição de renda, bem-estar social pela imigração para localidades com melhores remunerações, e economias de escala, visto o aumento de produção pelo acesso a diferentes mercados (GOODWIN, 2001).

Estudos têm, cada vez mais, comprovado a influência de externalidades decorrentes de infraestruturas de transporte. Mais especificamente $\mathrm{Hu}$ e Liu (2010) encontram que um aumento de $1 \%$ na infraestrutura de transportes causa uma elevação da ordem de $0,28 \%$ no PIB Chinês, sendo que desses, $0,22 \%$ consiste de efeito direto, e 
0,06\% refere-se à externalidade. Nesse mesmo sentido, Baum (1998) afirma que 25\% do PIB Alemão é oriundo de externalidades positivas referentes ao investimento em infraestruturas de transporte.

O desenvolvimento de corredores de transportes configura um grande aspecto e indicador de desenvolvimento econômico e social, pois é o reflexo espacial do processo de circulação de bens.

Xu (2007) encontra elevada e positiva correlação entre o desenvolvimento econômico Chinês e infraestruturas de transportes. Mais especificamente, o estudo revelou séries cointegradas e com relação bidirecional entre as variáveis para os anos de 1992 a 2005.

Fazendo também uso de testes de cointegração, Zhang (2011) encontra uma relação positiva entre desenvolvimento da aviação civil e crescimento econômico, verificando também uma relação bidirecional entre as variáveis e elasticidades de $0,91 \%$ para a expansão do transporte aéreo em relação à variação de $1 \%$ no PIB chinês, e elasticidade de $0,97 \%$ para o oposto.

Tendo em vista a literatura explorada, inovação e infraestruturas de transporte compõem um conjunto de importantes fatores para o crescimento e desenvolvimento econômico, bem como as influências regionais e espaciais, e seus spillovers associados. 


\section{CAPÍTULO 3 - ECONOMETRIA ESPACIAL E O CONCEITO DE SPILLOVER}

O termo "Econometria Espacial" foi, inicialmente, introduzido por Jean Paelinck no início dos anos 70 para denominar a área do conhecimento que lida com a estimação e teste de modelos econométricos de cunho regional (GRIFFITH e PERES-NETO, 2006).

Segundo Anselin (1988a), a variedade de técnicas que lida com peculiaridades causadas pelo espaço em análise estatística regional é conhecida como econometria espacial. O autor argumenta que a principal razão para a existência da econometria espacial como campo separado da econometria usual são os efeitos espaciais, que basicamente configuram-se na dependência e na heterogeneidade espacial.

Assim, a econometria espacial pode ser definida por Anselin (1988a, pág7) como,

"The collection of techniques that deal with the peculiarities caused by space in the statistical analysis of regional Science models."

Portanto, tal campo do conhecimento lida explicitamente com a consideração dos efeitos espaciais que os modelos econométricos tradicionais não abordam, bem como levando em consideração testes de especificação e predição espacial.

Normalmente, dados são organizados em unidades espaciais de observação e, portanto, dados como emprego e atividade econômica são coletados em estados, municípios, países, províncias, etc. Tais dados são habitualmente utilizados para projeções de impactos sócio-econômicos. 
Nesse contexto, a dependência espacial pode ser considerada como a existência de relação funcional entre o que ocorre em um ponto do espaço, em relação ao todo. Isso ocorre em função de erros de medida em unidades espaciais contíguas, bem como da existência de uma variedade de interações espaciais. Isso faz com que os erros de uma unidade espacial $i$ sejam relacionados com os erros de uma unidade $j$, o que leva a perturbações não esféricas, mais precisamente, a autocorrelação (ANSELIN, 1988a).

Quanto à heterogeneidade espacial, vários fatores que afetam as unidades espaciais fazem com que elas sejam não homogêneas, como exemplo, diferentes regiões podem possuir níveis de renda e desenvolvimento tecnológicos distintos. Assim, tal heterogeneidade em termos econométricos acaba sendo refletida em erros de medida resultante de variáveis omitidas ou forma funcional erroneamente especificada, resultando em heteroscedasticidade (ANSELIN, 1988a).

De fato, a heterogeneidade espacial é simplesmente uma instabilidade estrutural de variância não constante dos resíduos (heteroscedasticidade), podendo ser tratada de forma usual. Contudo, tal heterogeneidade ocorre conjuntamente com autocorrelação espacial, e, portanto, técnicas econométricas tradicionais não são mais adequadas (ANSELIN, 1999).

Não obstante, a autocorrelação espacial é expressa por (3.1).

$$
\operatorname{cov}\left[y_{i}, y_{j}\right]=E\left[y_{i} y_{j}\right]-E\left[y_{i}\right] E\left[y_{j}\right] \neq 0 \text { para } i \neq j
$$

Recentemente, alguns estudos têm feito uso da econometria espacial em uma série de aplicações, em especial, estudos envolvendo economia, geografia econômica e ciências sociais aplicadas em geral.

Diferentemente da econometria tradicional, os modelos espaciais tem uma noção de operador de defasagem muito particular, pois no espaço os eventos não estão 
"enfileirados", como ocorrem em séries temporais. Assim, nos modelos espaciais, utiliza-se a noção de matriz de pesos espaciais para denotar a relação entre unidades espaciais.

Assim,

$$
[W y]_{i}=\sum W_{i j} y_{j} \text { para } j=1, \ldots, n
$$

Onde, a localização i = linha, e os vizinhos são elementos não zero nas colunas. Nesse caso, se.

$$
\sum W_{i j}=1
$$

Então a defasagem espacial pode ser interpretada como uma média ponderada dos vizinhos, onde $W_{i j}$ são os pesos (ANSELIN, 1999).

O importante é que os elementos dessa matriz sejam não estocásticos (fixos), e exógenos ao modelo, podendo ser baseados em vizinhança (contiguidade), distância, ou outro critério, como distância econômica (CASE, 1992).

Segundo Anselin (1988a) o conceito de dependência espacial (o qual diz que uma unidade do espaço é influenciada por outras) está intimamente ligado à noção topológica de vizinhos no espaço. Assim, considerando um sistema " $\mathrm{S}$ " de $\mathrm{i}=1, \ldots, \mathrm{n}$ unidades espaciais e uma variável X observada em cada unidade, então, o conjunto de vizinhos para uma unidade espacial $\mathrm{j}$ em que $\mathrm{X}_{\mathrm{j}}$ é contido na forma funcional da probabilidade condicional $\mathrm{X}_{\mathrm{i}}$. Portanto,

$$
P\left(X_{i} \mid X\right)=P\left(X_{i} \mid X_{j}\right)
$$

Onde $\mathrm{X}_{\mathrm{j}}$ é o vetor de observação com os vizinhos de $\mathrm{X}_{\mathrm{i}}$. 
De forma simplificada tudo isto equivale a dizer, por exemplo, que se $\mathrm{X}$ é o PIB de cada unidade $\mathrm{i}$, o PIB de uma unidade $\mathrm{X}_{\mathrm{i}}$ depende do PIB de seus vizinhos cujo vetor é representado por $\mathrm{X}_{\mathrm{j}}$.

Assim, a dependência espacial, ou autocorrelação espacial Moran (1948), pode ser baseada, entre outras, na noção de contiguidade matricial entre unidades. Nesse caso, a fim de expressar a relação de vizinhança entre as entidades no espaço, utiliza-se uma matriz binária (0 ou 1), sendo que duas unidades serão 1 caso tiverem uma "borda" ou região comum (ANSELIN, 1999).

Deste modo, uma matriz de contiguidade binária para ponderação espacial, considerando-se quatro localidades da região genérica $\mathrm{S}$ representada na Figura 2.

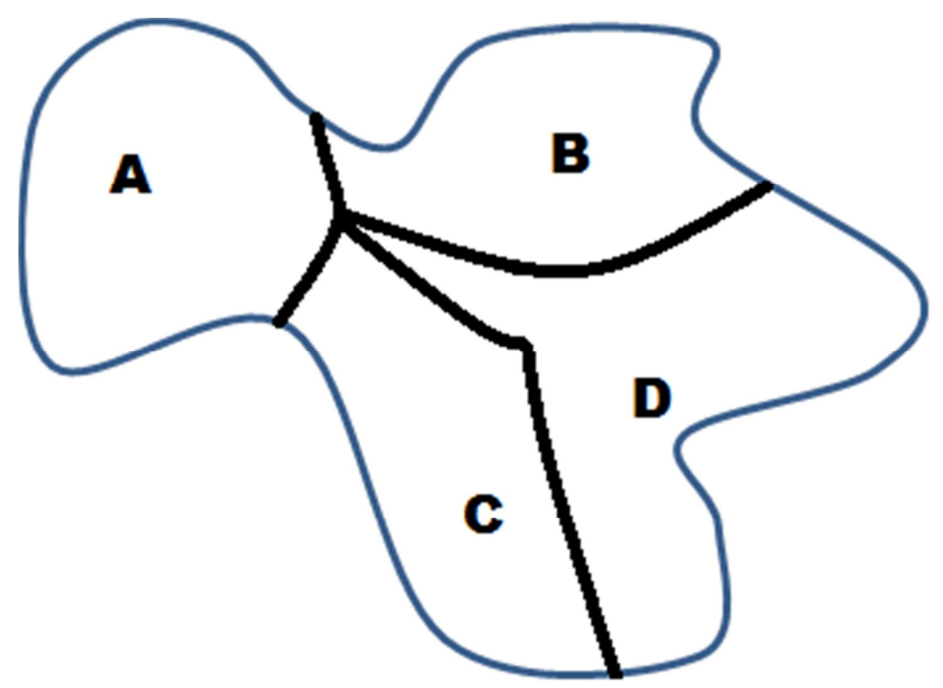

Figura 2 - Região genérica $S$

Onde a Figura 2 correspondente a matriz de ponderação binária de vizinhança (3.5).

$\begin{array}{ccccc} & A & B & C & D \\ A & 0 & 1 & 1 & 0 \\ B & 1 & 0 & 1 & 1 \\ C & 1 & 1 & 0 & 1 \\ D & 0 & 1 & 1 & 0\end{array}$


Nota-se em (3.5) que a diagonal principal da matriz é composta obrigatoriamente por zeros, visto que uma unidade espacial não pode ser vizinha dela mesma, e ademais, tal matriz deve ser obrigatoriamente quadrada. Portanto, os elementos da matriz iguais a 1 denotam que duas localidades compartilham uma mesma "borda" na região $\mathrm{S}$.

Contudo, a simples noção de vizinhança como a existência ou não de borda comum pode ser de certa forma uma pouco mais complexa, visto que na região $S$, as localidades A e D não partilham borda comum, contudo, possuem um vértice que as conecta. Nesse caso seria necessário pré-estabelecer se o vértice é ou não um critério de contiguidade, em que no exemplo de (3.5), o vértice não foi utilizado como critério de vizinhança e, portanto, A e D não foram considerados vizinhos.

Seguindo essa lógica, existem na literatura basicamente cinco critérios de contiguidade que podem ser adotados para a construção de uma matriz de ponderação espacial, baseados na disposição espacial de duas localidades “i” e “j” (ANSELIN, 1999; VITON, 2010).

a) Contiguidade linear: i e j partilham fronteira Leste-Oeste.

b) Contiguidade torre: Como no xadrez, i e j são vizinhos que partilham fronteira nas direções norte, sul, leste e oeste.

c) Contiguidade bispo: i e $\mathrm{j}$ são vizinhos quando se encontram em um ponto, sendo a vizinhança estabelecida pelas coordenadas nordeste, noroeste, sudeste, e sudoeste. Nesse caso, apenas os vértices são considerados como vizinhança, e, portanto, como na Figura 2, apenas A e D seriam consideradas vizinhas. 
d) Contiguidade rainha: i e j são vizinhos se partilharem um ponto comum, não importando a direção, seja como no critério torre ou bispo. Nesse caso, pela Figura 2 , todas as localidades da região $\mathrm{S}$ seriam consideradas vizinhas.

e) Contiguidade radius: Aqui, a contiguidade é baseada em uma distância máxima de um determinado ponto em uma região i, como exibido na Figura 3

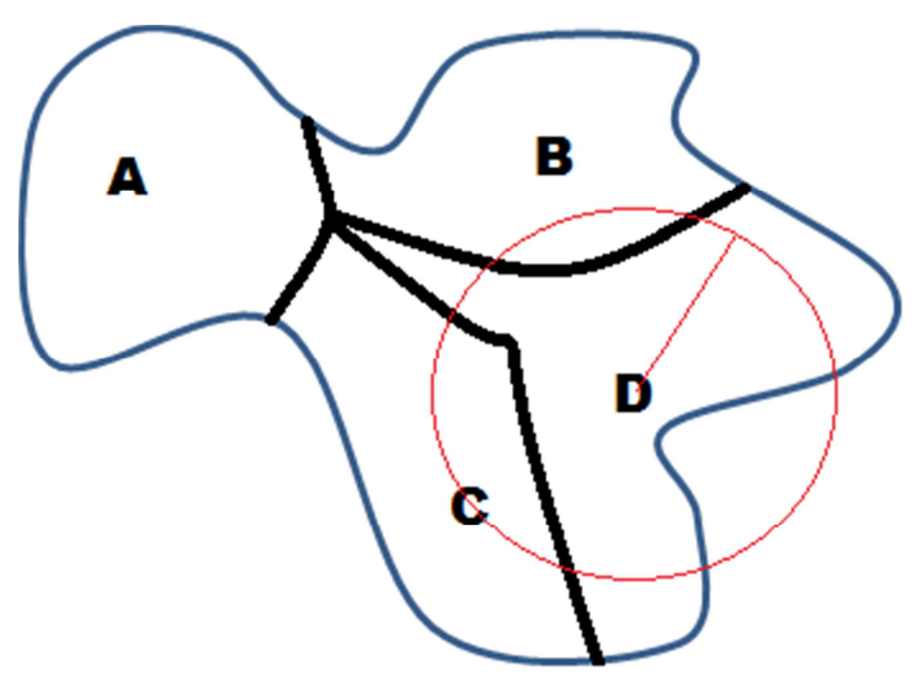

Figura 3 - Critério Radius.

Pelo critério radius, observa-se que existe um raio que emerge de um ponto central na região D, e apenas as localidades dentro desse raio são consideradas vizinhas.

Portanto, será o critério de contiguidade a ser escolhido que irá especificar a relação de vizinhança entre localidades. Por exemplo, A e D são considerados vizinhos pelos critérios rainha e bispo, mas não são vizinhos pelo critério torre e radius.

Há também a contiguidade de segunda ordem, que representa uma localidade ser "vizinha de um vizinho", dado algum dos critérios de contiguidade relacionados anteriormente. Tal relação pode ser visualizada na região genérica da Figura 4. 


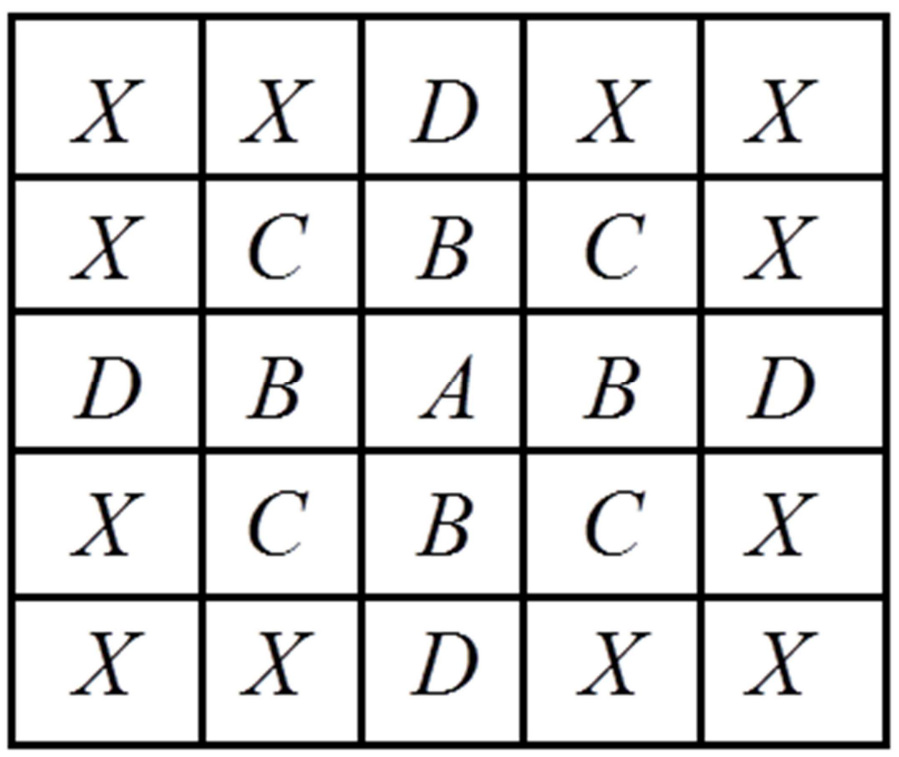

Figura 4 - Contiguidade de segunda ordem.

Na região representada pela Figura 4, pelo critério torre, por exemplo, "A" é vizinho das regiões marcadas por "B", mas também é vizinho de segunda ordem das regiões marcadas por "D”, também seguindo o critério torre.

Assim, é possível observar que serão os critérios de contiguidade que determinarão a forma de vizinhança a ser considerada e, por conseguinte, a matriz de ponderação espacial.

A determinação dos elementos da matriz de ponderação espacial é sem dúvidas a questão mais controversa da econometria espacial, (visto que esta se configura num critério muitas vezes subjetivo, que pode afetar diretamente os resultados a serem obtidos), contudo, normalmente as matrizes de ponderação usualmente são baseadas em contiguidade ou distância. Apesar disso, uma boa matriz de ponderação espacial deve refletir diretamente a estrutura de dependência espacial ao invés de refletir apenas um padrão ad-hoc no espaço (ANSELIN, 1980). 
Existem ainda duas outras formas de se determinar os elementos da matriz de ponderação espacial. São elas a sugestão de Cliff (1973) e de Dacey (1968), ambas encontradas com maior detalhamento em Anselin (1988a).

Segundo a sugestão de Cliff (1973), os elementos da matriz de ponderação espacial, os quais devem refletir a relação de dependência espacial das localidades de uma determinada região podem ser calculados combinando-se o inverso da distância (ou negativo exponencial da distância) e o comprimento da borda comum entre duas unidades espaciais. Tal critério pode ser exemplificado como (3.6)

$W_{i j}=\left|d_{i j}\right|^{-a}\left|\beta_{i j}\right|^{b}$

Onde,

$d_{i j}$ é a distância entre i e j,

$\beta_{i j}$ é a borda entre i e j.

Já a sugestão de Dacey (1968) pode ser demonstrada em (3.7).

$W_{i j}=c_{i j} \alpha_{i j} \beta_{i j}$

Onde,

$c_{i j}$ é fator de contiguidade binário,

$\alpha_{i j}$ é a porcentagem total da unidade i no total do espaço,

$\beta_{i j}$ é novamente a borda entre i e j.

Apesar de tais formas de determinação da matriz de ponderação espacial serem interessantes, novamente, ressalta-se que a matriz de peso deve refletir de fato a relação de dependência entre as localidades, devendo ser, portanto, um fator a ser decidido pelo 
pesquisador, baseado na análise das especificidades do espaço em questão. Assim, outros fatores como, distância (medido em tempo de viagem), redes sociais Gatrell (1979), canais de comunicação entre regiões como rodovias e ferrovias Bodson e Peeters (1975) também podem ser considerados.

\section{1 - Medida de autocorrelação espacial}

A principal medida de autocorrelação espacial encontrada na literatura é o coeficiente de Moran (1948), também conhecido como I de Moran, o qual calcula um coeficiente para a correlação espacial baseada na matriz de contiguidade qualquer de primeira ordem (ANSELIN, 1988a; LESAGE e PACE, 2009).

Uma série temporal naturalmente faz com que os dados sejam perfilados, de modo que uma dada observação possuirá apenas um ou dois vizinhos. Contudo, no espaço, uma unidade pode possuir uma série de vizinhos, e assim, um coeficiente de autocorrelação espacial deverá levar tal característica em consideração.

Desse modo, o coeficiente de I de Moran será,

$$
I=\frac{\sum_{i=1}^{n}\left(x_{i}-\bar{x}\right)\left(V x_{i}-\bar{x}\right)}{\sum_{i=1}^{n}\left(x_{i}-\bar{x}\right)^{2}}
$$

Onde, $V x_{i}$ é a média dos vizinhos de i, o qual corresponde aos termos iguais a um na matriz de ponderação binária.

Nesse caso, se $X$ representar a renda de uma unidade espacial, um coeficiente I positivo indicará que quanto mais próxima uma unidade “j” do centro mais rico “i”, maior será a renda de “j”. Dessa forma, a renda de unidades mais distantes do centro (o qual possui renda mais elevada) irá diminuir. 
Assim, por exemplo, dada uma matriz de vizinhança binária (matriz de pesos espaciais) para um espaço "S" com cinco regiões, caracterizada por (3.9).

$$
W=\left(\begin{array}{lllll}
0 & 1 & 1 & 1 & 0 \\
1 & 0 & 0 & 0 & 1 \\
1 & 0 & 0 & 1 & 1 \\
1 & 1 & 1 & 0 & 1 \\
0 & 0 & 1 & 1 & 0
\end{array}\right) \begin{aligned}
& R_{1} \\
& R_{2} \\
& R_{3} \\
& R_{4} \\
& R_{5}
\end{aligned}
$$

E uma variável X qualquer observável em cada unidade espacial (regiões) de "S".

$$
X=\left(\begin{array}{l}
x_{1} \\
x_{2} \\
x_{3} \\
x_{4} \\
x_{5}
\end{array}\right)
$$

Multiplicando (09) e (10),

$$
W X=\left[\begin{array}{c}
\left(x_{2}+x_{3}+x_{4}\right) \\
\left(x_{1}+x_{4}\right) \\
\left(x_{1}+x_{4}+x_{5}\right) \\
\left(x_{1}+x_{2}+x_{3}+x_{5}\right) \\
\left(x_{3}+x_{4}\right)
\end{array}\right]
$$

Em (3.11), por exemplo, a primeira linha da matriz $W X$ representa o impacto dos vizinhos da região R1 em R1.

É possível ainda considerar uma matriz de pesos $\mathrm{W}$ normalizada, de modo que a soma dos termos de cada linha seja igual a um (LESAGE e PACE, 2009).

$$
W=\left(\begin{array}{ccccc}
0 & 1 / 3 & 1 / 3 & 1 / 3 & 0 \\
1 / 2 & 0 & 0 & 0 & 1 / 2 \\
1 / 3 & 0 & 0 & 1 / 3 & 1 / 3 \\
1 / 4 & 1 / 4 & 1 / 4 & 0 & 1 / 4 \\
0 & 0 & 1 / 2 & 1 / 2 & 0
\end{array}\right) \begin{aligned}
& R_{1} \\
& R_{2} \\
& R_{3} \\
& R_{4} \\
& R_{5}
\end{aligned}
$$


Que resulta em uma matriz WX normalizada,

$$
W X=\left[\begin{array}{c}
\left(x_{2}+x_{3}+x_{4}\right) / 3 \\
\left(x_{1}+x_{4}\right) / 2 \\
\left(x_{1}+x_{4}+x_{5}\right) / 3 \\
\left(x_{1}+x_{2}+x_{3}+x_{5}\right) / 4 \\
\left(x_{3}+x_{4}\right) / 2
\end{array}\right]
$$

Assim, em termos matriciais, o coeficiente de Moran pode ser calculado via (3.14).

$$
I=\frac{X^{\prime} W X}{X^{\prime} X}=\left(X^{\prime} X\right)^{-1} X^{\prime} W X
$$

A equação (14) mostra-se muito semelhante ao cálculo de parâmetros de uma regressão por mínimos quadrados ordinários (MQO), sendo, portanto, o coeficiente angular de uma regressão de $W X$ por $X$. A interpretação gráfica do coeficiente de I pode ser visualizada na Figura 5.
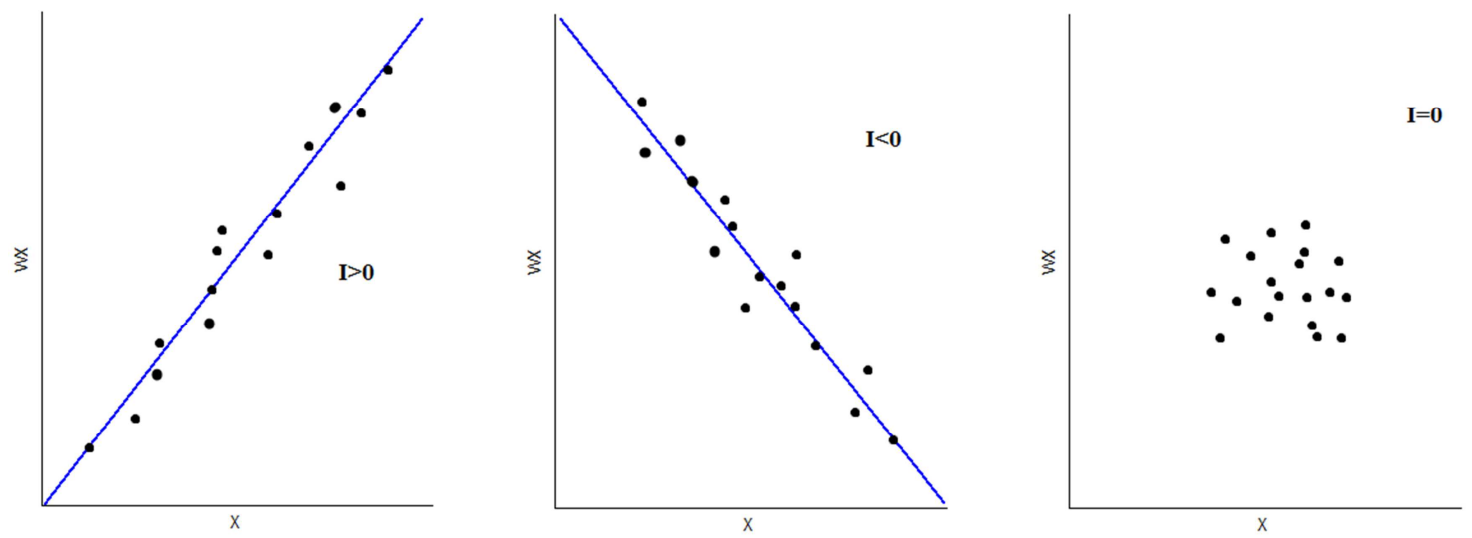

Figura 5 - Coeficiente de I de Moran para mensuração de autocorrelação espacial. 


\section{2 - Principais modelos de econometria espacial}

Existem duas principais formulações para os modelos de econometria espacial, os quais incorporam as características inerentes a interações entre unidades no espaço e, portanto, devem ser

em consideração.

Basicamente as formulações expressam a dependência espacial como uma variável dependente espacialmente defasada ( $W y)$, ou na estrutura do resíduo, $\left(E\left[\varepsilon_{j} \varepsilon_{i}\right] \neq 0\right)$ sendo que outras serão derivadas destas principais.

O primeiro é o modelo de erro espacial (SEM), que incorpora a questão da autocorrelação espacial no resíduo, cuja forma genérica é expressa em notação matricial por (3.15).

$$
Y=X \beta+\varepsilon
$$

Onde, $\varepsilon=\lambda W \varepsilon+u$

E, $W$ é a matriz de ponderação espacial, que pode configurar-se em uma matriz de vizinhança binária, ou uma matriz de distância.

Aqui, é possível dizer que existe correlação entre uma unidade e seus vizinhos. Ocorre, portanto, um problema de autocorrelação entre os resíduos, tornando os estimadores ineficientes apesar de não-viesados, o que invalida os testes de hipóteses (ANSELIN, 1988a; GUJARATI, 2006).

O segundo modelo é o modelo de defasagem espacial (SAR), cuja formulação genérica é dada pela equação matricial (3.16).

$$
Y=\rho W Y+X \beta+\varepsilon
$$


Onde, $W$ é a matriz de ponderação espacial. Tal modelo incorre tanto em viés quanto em inconsistência, tendo em vista a existência de uma variável endógena explicativa (ANSELIN, 1988a; GUJARATI, 2006). A título de exemplo, tal equação diz que uma variável dependente como PIB, por exemplo, em uma cidade A afeta o PIB da cidade B (vizinha de A), bem como o oposto também ocorre.

É considerável também a existência de um modelo completo que considere ambas as características, sendo que, caso os parâmetros estimados $\rho$ e $\lambda$ sejam insignificantes, os modelos espaciais se reduzem a modelos de regressão clássicos (ANSELIN, 1988a). Tal modelo completo pode ser observado em (3.17).

$$
Y=\rho W_{1} Y+X \beta+\varepsilon
$$

Onde,

$$
\varepsilon=\lambda W_{2} \varepsilon+u
$$

Substituindo (3.18) em (3.17),

$$
Y=\left(I_{n}-\rho W_{1}\right)^{-1} X \beta+\left(I_{n}-\rho W_{1}\right)^{-1}\left(I_{n}-\lambda W_{2}\right)^{-1} u
$$

Onde,

$$
u \sim N\left(0, \sigma^{2} I_{n}\right)
$$

Nesse caso, $W_{1}$ e $W_{2}$ podem ser iguais, contudo, podem ocorrer problemas de identificação. Nesse caso, a estimação deve ser realizada com duas matrizes de ponderação espacial distintas (Lesage e Pace, 2009).

Assim sendo, tais modelos se baseiam na premissa de que a localização e a distância são importantes forças sócio-econômicas e de mercado. Todas estas noções 
têm sido formalizadas e consideram as interações espaciais e efeitos de difusão espaciais (spillover), os quais serão investigados pelo trabalho proposto.

\section{3 - Dependência espacial e estimação de modelos de dados em painel}

Dados em painel, também conhecidos como dados longitudinais, referem-se a um conjunto de $N$ entidades observadas cada uma em $T$ períodos no tempo; e nesse caso, observa-se um painel equilibrado. Contudo, se houver a falta de ao menos um período no tempo $T$ para pelo menos uma entidade $N$, tem-se um painel desequilibrado (STOCK e WATSON, 2011).

Para a estimação de dados longitudinais utiliza-se uma técnica especial, pois é necessário levar em conta o efeito da heterogeneidade individual assumida entre as unidades, bem como controlar as variáveis omitidas no modelo quando elas variam de entidade para entidade, mas são constantes ao longo do tempo (GREENE, 2002; STOCK e WATSON, 2011).

Assim sendo, algebricamente, um modelo econométrico para dados em painel pode ser da seguinte forma:

$$
Y_{i t}=\beta_{1}+\beta_{2} X_{i t}+\beta_{3} Z_{i}+\varepsilon_{i t}
$$

Onde,

$$
\begin{aligned}
& i=1,2, \ldots, N \\
& t=1,2, \ldots, T
\end{aligned}
$$

Em Stock e Watson (2011), na equação (3.20), observa-se uma variável $Z_{i}$ a qual varia de uma entidade $N$ para outra, mas não ao longo do tempo. Assim sendo, em um modelo com efeitos fixos, há um intercepto para cada entidade, que podem ser 
representados por um conjunto de variáveis binárias (dummy) que absorvem o efeito das variáveis omitidas de uma entidade para outra.

Portanto, o objetivo é estimar $\beta_{1}$ representativo do efeito fixo de $\mathrm{X}$ sobre $\mathrm{Y}$, mantendo-se constantes as informações não observadas $Z_{i}$, de uma entidade $N$ para outra, e assim, é possível interpretá-lo como dotado de $N$ interceptos. Dessa forma:

$$
\alpha_{i}=\beta_{i}+\beta_{2} Z_{i}
$$

E o modelo modifica-se adquirindo a seguinte especificação:

$$
Y_{i t}=\beta_{2} X_{i t}+\alpha_{i}+\varepsilon_{i t}
$$

Onde $\alpha_{i}$ são interceptos a serem estimados para cada entidade individual.

O coeficiente de declividade da população total é o mesmo para todas as entidades, mas o intercepto varia de entidade para entidade, de acordo com a variável $Z_{i}$.

Assim sendo, os interceptos para cada entidade individual podem ser expressos no modelo por meio de variáveis binárias, que captam os interceptos de cada entidade $N$ individual. Deste modo, obtém-se o seguinte modelo:

$$
Y_{i t}=\beta_{1}+\beta_{2} X_{i t}+\alpha_{1} d 1_{t}+\alpha_{2} d 2_{t}+\alpha_{3} d 3_{t}+\cdots+\alpha_{n} d n_{t}+\varepsilon_{i t}
$$

Onde,

$d 1_{i}=1$, quando a observação referir-se a unidade $i$, e zero, caso contrário (outra unidade $\mathrm{j}$ ).

Em (Greene, 2002), encontra-se a contrapartida matricial da equação (3.24):

$$
Y=X \beta+D \alpha+\varepsilon
$$


Que pode ser indicada por:

$$
Y=\left[\begin{array}{lllll}
X & d 1 & d 2 & \cdots & d n
\end{array}\right]\left[\begin{array}{l}
\beta \\
\alpha
\end{array}\right]+\mathcal{E}
$$

Assim, o estimador dos parâmetros da regressão por efeitos fixos, também conhecidos por mínimos quadrados com variáveis dummy $\left(\mathrm{LSDV}^{2}\right)$ é dado por:

$$
\hat{\beta}_{E F}=\left(X^{\prime} M_{D} X\right)^{-1} X M_{D} Y
$$

Onde, $M_{D}$ é a matriz de projeção dada por (3.27):

$$
M_{D}=I-D\left(D^{\prime} D\right)^{-1} D^{\prime}
$$

Mais especificamente, uma matriz de projeção é aquela que quando prémultiplicada pelo vetor da variável dependente, produz os valores ajustados da regressão por MQO de Y sobre D.

Como exemplo, considere (3.28).

$$
\begin{aligned}
& \hat{Y}=X \beta \\
& \hat{Y}=X\left(X^{\prime} X\right)^{-1} X^{\prime} Y \\
& \hat{Y}=P Y
\end{aligned}
$$

Onde "P" é a matriz de projeção.

Portanto, a eventual omissão da variável binária que identifica as diferentes unidades no painel faria com que os estimadores de mínimos quadrados ordinários fossem viesados, e também inconsistentes, isto é, não convergindo para o seu valor real com o aumento da amostra (GREENE, 2002).

\footnotetext{
${ }^{2}$ Least squares dummy variables
} 
Diferentemente da regressão por efeitos fixos, se a heterogeneidade individual não for correlacionada com as variáveis explicativas do modelo, surgirá no modelo um componente aleatório, similar à perturbação estocástica que é estimada de forma ineficiente por mínimos quadrados ordinários (GREENE, 2002).

Assim, considerando-se um modelo de regressão múltipla:

$$
\begin{aligned}
& Y_{i t}=\alpha_{i}+\beta_{2} X_{2 i t}+\beta_{3} X_{3 i t}+\varepsilon_{i t} \\
& Y_{i t}=\beta_{2} X_{2 i t}+\beta_{3} X_{3 i t}+\left(\alpha_{i}+\varepsilon_{i t}\right)
\end{aligned}
$$

$\operatorname{Se}\left(\alpha_{i}+\varepsilon_{i t}\right)=u_{i t}$

O modelo será:

$$
Y_{i t}=\beta_{2} X_{2 i t}+\beta_{3} X_{3 i t}+u_{i t}
$$

Onde é possível observar que parte do termo de erro é constante para cada unidade e, portanto, não é possível dizer que não haja correlação entre os erros. Disso decorre a ineficiência da estimação por MQO.

Por essa razão, é necessário estimar o modelo de efeitos aleatórios por mínimos quadrados generalizados; mas também é possível que a estimação seja feita por máxima verossimilhança (DAVIDSON, 2004).

A escolha entre qual modelo utilizar pode ser feita pelo teste de Hausman, o qual afirma que o modelo estimado, utilizando-se efeitos fixos, não se diferencia do modelo estimado por efeitos aleatórios; e a estatística do teste segue assintoticamente uma distribuição qui-quadrado (GUJARATI, 2006). Já Greene (2002) afirma que no teste, a covariância de um estimador eficiente e sua diferença para um estimador ineficiente é zero e, portanto: 


$$
\operatorname{Cov}[(b-\hat{\beta}), \hat{\beta}]=\operatorname{Cov}[b, \hat{\beta}]-\operatorname{Var}[\hat{\beta}]=0
$$

$\mathrm{Ou}$

$$
\operatorname{Cov}[b, \hat{\beta}]=\operatorname{Var}[\hat{\beta}]
$$

Inserindo (3.35) na formulação $\operatorname{Var}[b-\hat{\beta}]$ tem-se:

$$
\operatorname{Var}[b-\hat{\beta}]=\operatorname{Var}[b]-\operatorname{Var}[\hat{\beta}]=\psi
$$

Assim, a estatística qui-quadrado do teste será:

$$
W=\chi^{2}[k-1]=[b-\hat{\beta}]^{\prime} \hat{\psi}^{-1}[b-\hat{\beta}]
$$

Onde $\hat{\psi}$ é a declividade da matriz de covariância estimada pelo método LSDV e a matriz de covariância estimada no modelo de efeitos aleatórios excluindo-se a constante; e $k-1$ são os graus de liberdade.

Existe também o teste de Hausman robusto (teta). Contudo, sua aplicabilidade em painéis desbalanceados é bem mais complexa, (sem adicionar grande confiabilidade) (CAMERON, 2009).

Os dados longitudinais, por sua especificidade, possuem algumas vantagens e desvantagens para a análise econométrica, as quais serão citadas a seguir, de acordo com Hsiao (1990).

A primeira e mais clara vantagem na utilização de dados em painel é o aumento do número de observações em uma amostra, onde cada unidade é observada por um período de tempo.

Outra vantagem é que os dados longitudinais podem auxiliar na interpretação de um modelo. Por exemplo, se um modelo diz que as mulheres representam $50 \%$ da força 
de trabalho, os dados em painel respondem se esses $50 \%$ são relativos ao tempo dentro da força de trabalho, ou se não há essa questão temporal.

Considerando agora questões mais próximas do estudo a ser descrito no presente trabalho, como demonstrado em (3.38), geralmente existe o problema da colinearidade entre as variáveis explicativas defasadas. Portanto, a variável explicativa com uma defasagem, terá colinearidade com a variável explicativa com duas defasagens e assim por diante.

$$
Y_{t}=\beta_{0}+\sum_{i=0}^{\infty} \beta_{i} X_{t-i}+u_{t}
$$

Assim, se há apenas a disponibilidade de dados cross-section ou de séries temporais, não é possível obter estimadores eficientes para o modelo proposto.

A partir da disponibilidade de dados em painel, as diferenças entre indivíduos reduzem a colinearidade entre as variáveis explicativas. Ademais, a extensão do tempo no painel (usualmente tratado como "T" do painel) impõe uma restrição ao número de parâmetros de defasagem a serem estimados, o que impossibilita a estimação ad hoc da extensão da defasagem.

Portanto, o uso de dados em painel é interessante para a diminuição da magnitude de problemas econômicos encontrados em estudos empíricos, bem como possibilita predições mais corretas em nível individual.

A principal desvantagem no uso de técnicas como efeitos fixos e aleatórios para dados em painel é a heterogeneidade dos coeficientes angulares estimados. Isso ocorre quando fatores peculiares e importantes de um dado indivíduo são esquecidos, a função de distribuição de probabilidade utilizada para a geração da variável dependente não é mais realista. Assim, a não captura de tais efeitos individuais existentes nas unidades 
cross-section e temporais pelas variáveis explicativas pode levar à heterogeneidade dos parâmetros estimados. Dado (3.39).

$$
y_{i t}=\alpha_{i}^{*}+\beta_{i} x_{i t}+\mu_{i t}
$$

Onde,

$$
i=1,2, \cdots, N
$$$$
t=1,2, \cdots, T
$$

Os parâmetros $\alpha_{i}^{*}$ e $\beta_{i}$ são constantes no tempo, mas diferentes entre unidades. Seguindo esse pressuposto, dois casos podem distorcer a estimação por mínimos quadrados:

Intercepto heterogêneo e coeficiente angular homogêneo:

$$
\left(\alpha_{i}^{*} \neq \alpha_{j}^{*}\right) \mathrm{e}\left(\beta_{i}^{*}=\beta_{j}^{*}\right)
$$

Ou intercepto heterogêneo e coeficiente angular heterogêneo:

$$
\left(\alpha_{i}^{*} \neq \alpha_{j}^{*}\right) \mathrm{e}\left(\beta_{i}^{*} \neq \beta_{j}^{*}\right)
$$

Desse modo, uma forma alternativa para a estimação de dados longitudinais é a utilização de regressões aparentemente não relacionadas (SUR) ${ }^{3}$.

Neste tipo de estimação, os coeficientes de regressão de todas as equações do sistema são estimados simultaneamente por MQG (ZELLNER, 1962) ${ }^{4}$. Essa técnica pode ser utilizada quando em um conjunto de equações suas perturbações estocásticas são contemporâneas, mas não serialmente correlacionadas (CONNIFFE, 1982).

A hipótese de correlação contemporânea, isto é, erros correlacionados no mesmo instante, é razoável caso duas empresas, por exemplo, sejam parecidas em vários

\footnotetext{
${ }^{3}$ Seemingly unrelated regressions

${ }^{4}$ Zellnner foi o percurssor de tal técnica.
} 
aspectos. Nesse caso, os efeitos dos fatores omitidos para a variável a ser explicada devem ser similares para as duas empresas (HILL, 2003).

Quando isso ocorre, observa-se:

$$
\operatorname{Cov}\left(e_{A}, e_{B}\right)=\sigma_{A B}
$$

Mais especificamente, se considerarmos a função investimento de duas empresas (A e B, por exemplo), os estimadores de MQO individuais para cada equação mantém suas propriedades MELNV (melhor estimador linear não-viesado). Mas quando unificamos as duas equações no mesmo modelo utilizando variáveis binárias, estamos admitindo que a variância dos erros seja constante para as observações combinadas das duas empresas, quando na verdade, se as regressões individuais fossem rodadas, seriam observadas variâncias distintas dos erros para cada uma das empresas (HILL, 2003). Portanto, reconhecendo-se a heteroscedasticidade dada por $\sigma_{A}^{2} \neq \sigma_{B}^{2}$, é possível estimar o modelo por MQG, e assim, Zellner (1962) demonstrou que a estimação conjunta por MQG é melhor do que a estimação de MQO com uma única equação. Tal fato evidencia-se, pois os erros-padrão encontrados em uma estimação por SUR são menores do que aqueles encontrados pelo MQO individual (HILL, 2003).

Isso ocorre, pois o MQG equivale ao MQO nas variáveis transformadas que satisfazem as hipóteses usuais do modelo clássico de regressão linear (MCRL), sendo, em outras palavras, MELNV (GUJARATI, 2006).

Observado isso, é possível prosseguir com a construção do estimador. Portanto considere o modelo de regressão linear com erros iid abaixo:

$$
y_{i}=X_{i} \beta_{i}+\varepsilon_{i} \quad i=1,2, \ldots, M
$$


Aqui, na equação $y_{i}$ é um vetor de n linhas na i-ésima variável dependente. E, $X_{i}$ denota a matrix $\mathrm{n} \times k_{i}$ matriz de regressores na i-ésima equação. Já $\beta_{i}$ denota o vetor $k_{i}$ de parâmetros. Similarmente, o termo $\varepsilon_{i}$ é um vetor de n linhas representativas do termo de erro (DAVIDSON, 2004).

Com relação às perturbações, é possível observar que,

$$
\varepsilon_{i} \sim N\left(0, \sigma^{2}\right)
$$

$$
E\left(\varepsilon_{i} \varepsilon_{i}^{\prime}\right)=\sigma_{i i} I_{n}
$$

Onde,

$i_{n}$ é uma matriz identidade $\mathrm{n} \mathrm{x}$.

$\sigma_{i i}$ é a variância do termo de erro.

e,

$$
E\left[\varepsilon \mid X_{1}, X_{2}, \ldots, X_{M}\right]=0
$$

$E\left[\varepsilon \mathcal{E}^{\prime} \mid X_{1}, X_{2}, \ldots, X_{M}\right]=\Omega$

Segundo Greene (2002), assume-se que as perturbações não são serialmente correlacionadas, e, portanto:

$$
E\left[\varepsilon_{i j} \varepsilon_{j s} \mid X_{1}, X_{2}, \ldots, X_{M}\right]=\sigma_{i j}
$$

Assim,

$$
E\left[\varepsilon \mathcal{E}^{\prime} \mid X_{1}, X_{2}, \ldots, X_{M}\right]=\Omega=\left[\begin{array}{cccc}
\sigma_{11} I & \sigma_{12} I & \ldots & \sigma_{1 M} I \\
\sigma_{21} I & \sigma_{22} I & & \sigma_{2 M} I \\
\vdots & & \ddots & \\
\sigma_{M 1} I & \sigma_{M 2} I & \ldots & \sigma_{M M} I
\end{array}\right]
$$


Em Greene (2002), observa-se que cada equação do sistema é uma regressão clássica. Contudo, os parâmetros podem ser estimados consistentemente, mas com perda eficiência por MQO. Assim sendo, Zellner (1962) demonstra que há um ganho de eficiência na estimação dos parâmetros quando utilizado o método de $\mathrm{MQG}^{5}$. Adicionalmente, é interessante salientar que a estimação por regressões aparentemente não relacionadas apresenta um viés quando se utiliza um número pequeno de observações na amostra, como é demonstrado no artigo original de Zellner (1962).

Dessa forma, a estimação dos parâmetros por MQG é, segundo Zellner (1962), descrita pelo seguinte modelo matricial:

$$
\left[\begin{array}{c}
y_{1} \\
y_{2} \\
\vdots \\
y_{M}
\end{array}\right]=\left[\begin{array}{cccc}
X_{1} & 0 & \cdots & 0 \\
0 & X_{2} & \cdots & 0 \\
\vdots & \vdots & \ddots & \vdots \\
0 & 0 & \cdots & X_{M}
\end{array}\right]\left[\begin{array}{c}
\beta_{1} \\
\beta_{2} \\
\vdots \\
\beta_{M}
\end{array}\right]+\left[\begin{array}{c}
\varepsilon_{1} \\
\varepsilon_{2} \\
\vdots \\
\varepsilon_{M}
\end{array}\right]=X \beta+\varepsilon
$$

Lançando mão da matriz de covariância M x M das perturbações:

$$
\Sigma=\left[\begin{array}{cccc}
\sigma_{11} & \sigma_{12} & \ldots & \sigma_{1 M} \\
\sigma_{21} & \sigma_{22} & & \sigma_{2 M} \\
\vdots & & \ddots & \\
\sigma_{M 1} & \sigma_{M 2} & \ldots & \sigma_{M M}
\end{array}\right]
$$

E, considerando a matriz (50) exibida anteriormente, encontra-se a matriz $\Omega$ :

$$
\Omega=\Sigma \otimes I
$$

Assim sendo, em Greene (2002), encontra-se o estimador de MQG considerando-se:

$$
\Omega^{-1}=\Sigma^{-1} \otimes I
$$

\footnotetext{
${ }^{5}$ Zellnner refere-se ao MQG como "Aitken estimator"
} 
Portanto,

$$
\hat{\beta}=\left[X^{\prime} \Omega^{-1} X^{\prime}\right]^{-1} X^{\prime} \Omega^{-1} y=\left[X^{\prime}\left(\Sigma^{-1} \otimes I\right) X\right]^{-1} X^{\prime}\left(\Sigma^{-1} \otimes I\right) y
$$

Onde, (52) é o estimador dos parâmetros da regressão por SUR.

Segundo Anselin (1999), existem basicamente quatro modelos que consideram diferentes combinações de defasagem espacial e temporal para dados longitudinais. São eles:

a) Pure space-recursive: A dependência espacial pertence à vizinhança em períodos distintos.

$$
y_{i t}=\gamma\left[W y_{t-1}\right]_{i}+f(z)+\varepsilon_{i t}
$$

Onde,

$f(z)$ é designação de outros regressores genéricos.

$\left[W y_{t-1}\right]_{i}$ é o i-ésimo elemento da defasagem especial em um período anterior.

b) Time-Space recursive: Dependência se relaciona simultaneamente com a mesma localidade e com os vizinhos em outro período.

$$
y_{i t}=\lambda y_{i t-1}+\gamma\left[W y_{t-1}\right]_{i}+f(z)+\varepsilon_{i t}
$$

c) Time-space simultaneous: Com defasagem temporal e espacial contemporãnea.

$$
y_{i t}=\lambda y_{i t-1}+\rho\left[W y_{t}\right]_{i}+f(z)+\varepsilon_{i t}
$$

d) Space-Time Dynamic: Com todas as formas de dependência.

$$
y_{i t}=\lambda y_{i t-1}+\rho\left[W y_{t}\right]_{i}+\gamma\left[W y_{t-1}\right]_{i}+f(z)+\varepsilon_{i t}
$$


Quanto à estimação de dados em painel para modelos espaciais, em muitas formulações, adota-se uma heterogeneidade não observada, que se configura basicamente em uma variável constante no tempo $\left(\alpha_{i}\right)$.

Se $\alpha_{i}$ for correlacionada com os regressores $x_{i t}$, então, não é possível absorver $\alpha_{i}$ no termo de erro, o que induziria correlação entre os resíduos e os regressores (VITON, 2010).

Assim, um modelo de efeitos fixos espacial seria (57)

$$
y_{i t}=\lambda \sum_{j} w_{i t j} y_{i t}+\alpha_{i}+x_{i t} \beta+\varepsilon_{i t}
$$

Onde,

$w_{i t}$ são elementos da $i, t$ linha de w; e $x_{i t}$ são elementos da $i, t$ linha de x, exceto a constante.

Portanto, o problema do efeito fixo espacial reside no número de dummy que funcionem como interceptos específicos para cada região, o que poderia causar um efeito negativo sobre os graus de liberdade (VITON, 2010).

Dessa forma, para uma amostra com, por exemplo, 500 regiões no espaço, seriam necessárias 500 dummys, o que inviabilizaria a estimação do modelo, tendo em vista os graus de liberdade. Contudo, para algumas dúzias, ou até 50 regiões, o modelo pode ser estimado sem problemas por meio do uso de dummys representativas da heterogeneidade não observada. Dessa forma, é possível inferir que o efeito fixo espacial é mais indicado para dados com poucas regiões ( $\mathrm{N}$ pequeno) e grande série temporal (T grande) (VITON, 2010). 
Contudo, segundo Anselin (1999), a estimação dos modelos espaciais com dados de painel deve ser realizada por efeitos aleatórios, visto que o uso de efeitos fixos (dummys para cada entidade do painel) sofre de causalidade incidental de parâmetros (ou problema do parâmetro incidental), não havendo estimador consistente nesse caso.

Não obstante, se $\alpha_{i}$ não for correlacionado com os regressores $x_{i t}$, então $\alpha_{i}$ pode ser absorvido pelo termo de erro, e a estimação por efeitos aleatórios espaciais é indicada.

O problema do parâmetro incidental ocorre quando somente os coeficientes de declividade do modelo podem ser estimados de forma consistente. Tal fato ocorre usualmente com painéis pequenos ( $\mathrm{T}$ pequeno e $\mathrm{N}$ grande), pois o número de informações disponíveis para ser estimar $\alpha_{i}$ é limitado pelo número de informações na série temporal do painel (ELHORST, 2003).

Porém, se o painel possuir muitas regiões, uma forma interessante para a estimativa do modelo é o rebaixamento pela média dos dados ${ }^{6}$. Tal procedimento elimina a heterogeneidade individual, pois dados (3.60) a (3.61),

$$
y_{i t}=\beta_{i} x_{i t}+\alpha_{i}+\varepsilon_{i t}
$$

Calculando a média ao longo do tempo para cada i,

$$
\bar{y}_{i t}=\beta_{i} \bar{x}_{i t}+\alpha_{i}+\bar{\varepsilon}_{i t}
$$

Subtraindo (60) de (61),

$$
y_{i t}-\bar{y}_{i t}=\beta_{i}\left(x_{i t}-\bar{x}_{i t}\right)+\varepsilon_{i t}-\bar{\varepsilon}_{i t}
$$

Obtém-se,

\footnotetext{
${ }^{6}$ Em inglês se utiliza a expressão demean.
} 


$$
\ddot{y}_{i t}=\beta_{i} \ddot{x}_{i t}+\ddot{\varepsilon}_{i t}
$$

Como é possível observar em (3.62), a subtração dos dados pela média ao longo do tempo para cada $i$ elimina a heterogeneidade individual não observada $\alpha_{i}$ (WOOLDRIDGE, 2008).

Elhorst (2003) faz um dos poucos estudos que tratam das formas de estimação de dados longitudinais para modelos espaciais abordando tanto modelos de efeitos fixos, aleatórios, e regressões aparentemente não relacionadas (SUR), demonstrando que de fato, ainda não existe consenso sobre a melhor forma de estimativa dos modelos espaciais para dados em painel.

De fato, o artigo aborda os trabalhos de Quah (1995), o qual argumenta que o coeficiente angular constante para todas as unidades espaciais somente contabiliza o comportamento médio entre as variáveis espaciais, não demonstrando os diferentes comportamentos das unidades no espaço, mesmo com intercepto variável.

Contudo, a heterogeneidade de coeficientes angulares, tal qual ocorre no modelo SUR também é criticada, pois seus estimadores resultam em estimativas menos plausíveis do que o painel estimado com coeficiente angular homogêneo (BALTAGI e GRIFFIN, 1997). Ademais, tal modelo é factível apenas quando a série temporal do painel for grande o suficiente para justificar uma regressão para cada unidade espacial (ELHORST, 2003).

Dessa forma, apesar dos modelos de efeitos fixos acomodarem a heterogeneidade espacial (específicas do espaço, invariantes no tempo, e difíceis de capturar), muitas vezes tal fator não é completamente capturado pelas dummys, de modo que o modelo pode ser modificado de forma a permitir que os parâmetros de declividade também variem como no modelo SUR. 
O modelo com interceptos variáveis para dados em painel é apresentado em (3.64).

$$
y_{i t}=x_{i t} \beta_{i}+\alpha_{i}+\varepsilon_{i t}
$$

A extensão espacial para dados em painel nos modelos de erro espacial (SEM) e defasagem espacial (SAR), serão respectivamente,

$$
y_{i t}=\beta_{i} x_{i t}+\alpha_{i}+u_{i t}
$$

$$
\text { Onde, } u_{i t}=\delta W u_{t}+\varepsilon_{t}
$$

$$
\text { Onde, } \varepsilon_{t} \sim N\left(0, \sigma^{2} I\right)
$$

$$
y_{i t}=\delta W y_{t}+x_{i t} \beta_{i}+\alpha_{i}+u_{i t}
$$

$$
\text { Onde, } \varepsilon_{t} \sim N\left(0, \sigma^{2} I\right)
$$

Para o modelo SEM, $\delta$ é o de coeficiente de autocorrelação espacial, já para o modelo SAR, $\delta$ é o coeficiente autoregressivo espacial.

Novamente, segundo Elhorst (2003), uma forma de se estimar os modelos espaciais é pelo rebaixamento pela média dos valores temporais de cada entidade do painel, com posterior estimação por máxima verossimilhança.

Quando utilizadas s variáveis rebaixadas pela média, os estimadores não são função de $\alpha_{i}$, não havendo inconsistência nas estimativas de declividade, e as propriedades de grandes amostras para efeitos fixos se aplicam. Isso significa que se utilizando o rebaixamento pela média, o problema do parâmetro incidental apontado por Anselin (1988a) não se aplica. 
Outra peculiaridade da econometria espacial para dados em painel é que a matriz de ponderação espacial nesses casos se torna diagonal em blocos. Por exemplo, considerando-se a matriz de vizinhança binária de três localidades genéricas A, B, e C para dados cross-section na Figura 6.

$\begin{array}{llll} & \text { A } & \text { B } & \text { C } \\ \text { A } & 0 & 1 & 0 \\ \text { B } & 1 & 0 & 1 \\ \text { C } & 0 & 1 & 0\end{array}$

Figura 6 - Matriz de vizinhança binária para dados cross-section.

Agora, para dados em painel, levando em conta uma série temporal de três anos para cada entidade, obtém-se a matriz binária diagonal em blocos da Figura 7.

\begin{tabular}{lccc|cccccc} 
& A1 & A2 & A3 & B1 & B2 & B3 & C1 & C2 & C3 \\
A1 & 0 & 0 & 0 & 1 & 0 & 0 & 0 & 0 & 0 \\
A2 & 0 & 0 & 0 & 0 & 1 & 0 & 0 & 0 & 0 \\
A3 & 0 & 0 & 0 & 0 & 0 & 1 & 0 & 0 & 0 \\
\hline B1 & 1 & 0 & 0 & 0 & 0 & 0 & 1 & 0 & 0 \\
B2 & 0 & 1 & 0 & 0 & 0 & 0 & 0 & 1 & 0 \\
B3 & 0 & 0 & 1 & 0 & 0 & 0 & 0 & 0 & 1 \\
\hline C1 & 0 & 0 & 0 & 1 & 0 & 0 & 0 & 0 & 0 \\
C2 & 0 & 0 & 0 & 0 & 1 & 0 & 0 & 0 & 0 \\
C3 & 0 & 0 & 0 & 0 & 0 & 1 & 0 & 0 & 0
\end{tabular}

Figura 7 - Matriz de vizinhança binária para dados em painel.

É verificável, portanto, que, para cada entidade, a matriz para dados em painel cresce com a extensão da série temporal em linhas e colunas; observando-se ainda que os blocos da diagonal são inteiramente compostos por elementos nulos.

Assim, de maneira análoga, é possível demonstrar graficamente a estrutura de contiguidade e quão esparsa é esta matriz para dados cross-section e painel via Figuras 8 e 9, em que os pontos representam elementos não nulos da matriz. 


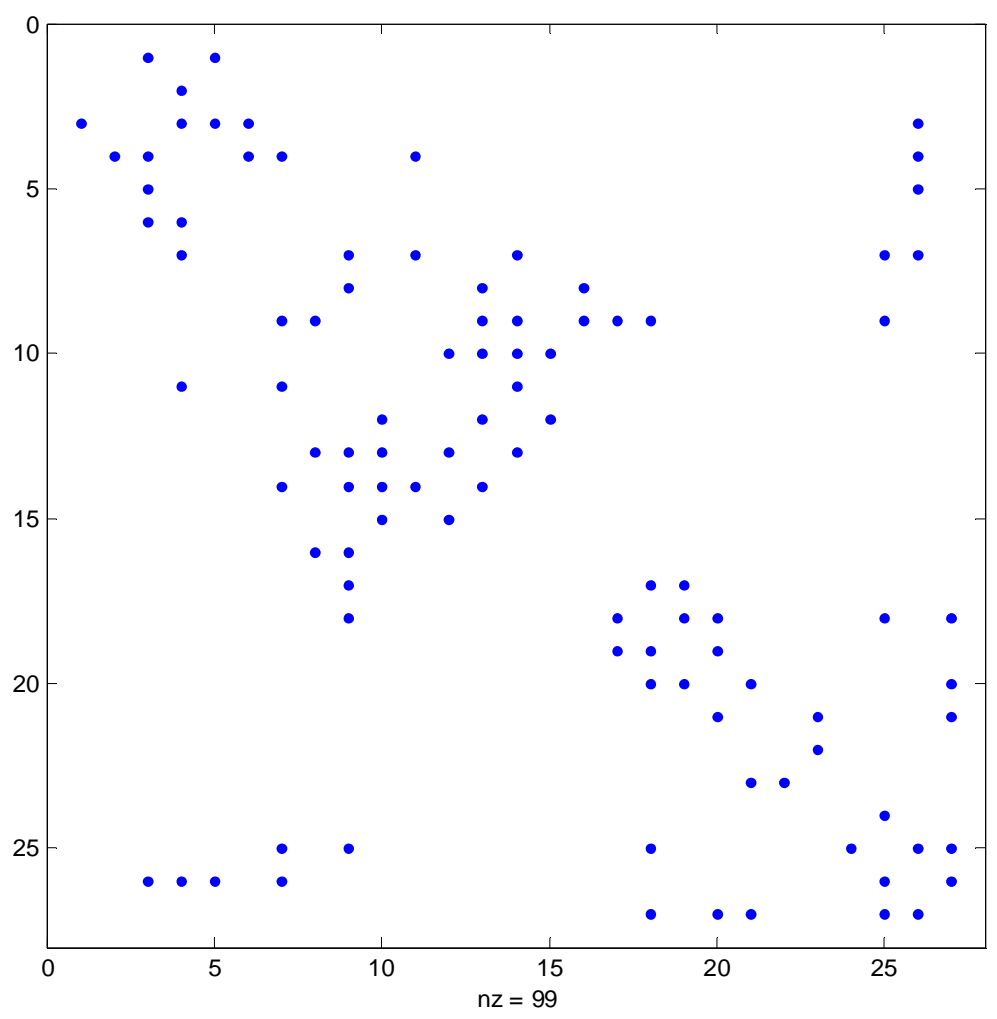

Figura 8 - Estrutura de contiguidade cross-section

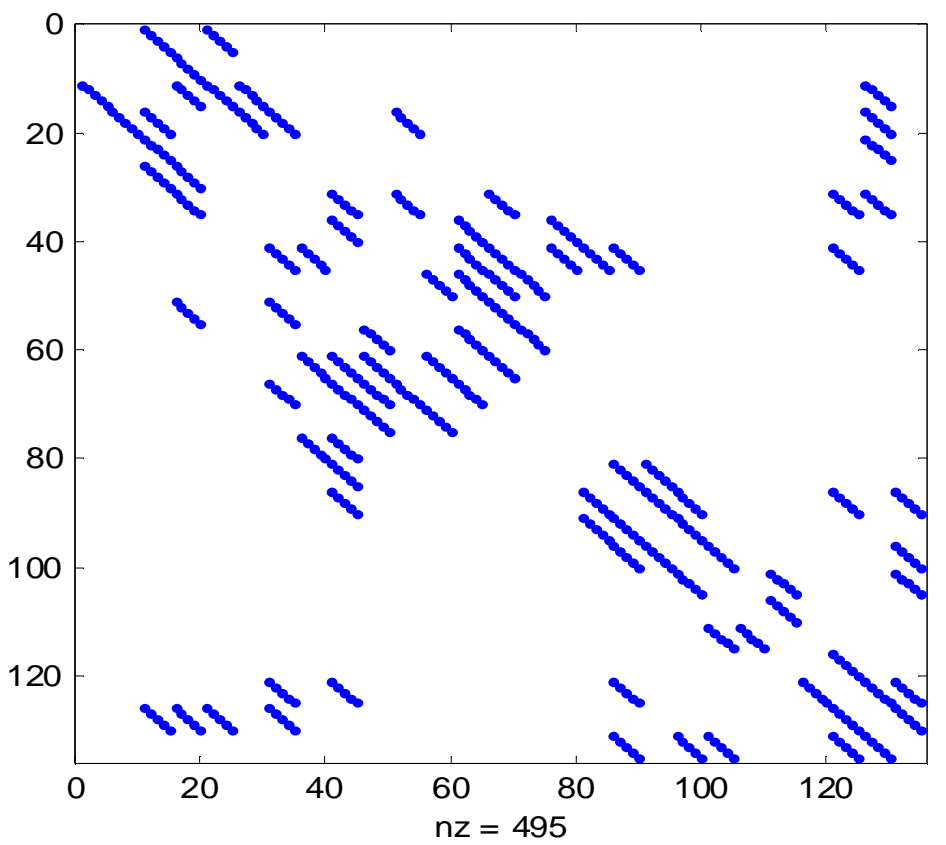

Figura 9 - Estrutura de contiguidade para dados em painel 
Assim, as Figuras 8 e 9 representam a contrapartida gráfica das matrizes de ponderação representadas pelas Figuras 6 e 7.

\section{4 - Modelo Espacial de Durbin (SDM) para dados em painel}

Apenas atualmente, a questão das externalidades agindo nas variáveis explicativas, tal qual ocorre no SDM tem recebido atenção da literatura, diferentemente do que ocorre com relação à medição de spillovers nas variáveis dependentes, tal qual ocorre no modelo SAR.

A partir de 2005 com Brasington e Hite (2005), e Ertur e Koch (2007) o modelo passa a receber maior preponderância para a medição de spillover. Contudo, apenas em 2010 se intensificaram as publicações que faziam uso do SDM para mensuração de externalidades, sendo possível citar trabalhos como Autant-Bernard e Lesage (2011), Lesage e Dominguez (2012) e Beer e Riedl (2011).

O SDM foi encontrado inicialmente em Anselin (1988a) via sugestão de (Durbin, 1960), para o caso de correlação serial em séries temporais. Aqui, uma variável adicional representativa do efeito médio de localidades vizinhas em uma, ou um conjunto de variáveis independentes (LESAGE e PACE, 2009). Tal especificação pode ser exemplificada em forma matricial como (3.70).

$$
Y=\rho W Y+X \beta+W X \gamma+\varepsilon
$$

Onde, $\beta, \rho$ e $\gamma$ são parâmetros. Especificamente, $\gamma$ parâmetro de $W X$ computa o impacto médio da variável X referente aos vizinhos de uma unidade i para a variável Y de i. Assim, por exemplo, seria equivalente a dizer que o investimento em inovação tecnológica (variável X) dos vizinhos de i, afeta o crescimento econômico (Y) de i. 
A forma geral apresentada em (3.70) pode se reduzir a outros modelos dependendo da significância estatística dos parâmetros. Assim, se $\gamma=0$ (3.70) se reduz a um modelo SAR, se $\gamma=-\rho \beta$, observa-se um modelo SEM, e por fim, se $\rho=0$, temse um modelo econométrico tradicional (BURRIDGE, 1981; BEER e RIEDL, 2011).

Não obstante, se os parâmetros forem significantes, o modelo (3.70) computa tanto $W X \gamma$ (impacto dos vizinhos) quanto $X \beta$ (impacto próprio), isto é, o crescimento econômico (Y) resultante do investimento próprio em inovação tecnológica (X).

A única consideração a respeito deste modelo é que algumas vezes este pode sofrer de multicolinearidade, sendo assim, por vezes recomendável a retirada de $X \beta$ a fim de evitar a colinearidade (VITON, 2010; BEER e RIEDL, 2011; LESAGE e DOMINGUEZ, 2012).

A extensão natural para dados em painel do SDM permite aumento dos graus de liberdade e variabilidade da amostra, bem como a contabilização as variáveis constantes omitidas no modelo, o que melhora as estimativas dos parâmetros.

Dessa forma, uma maneira proposta por Beer e Riedl (2011) para se controlar a heterogeneidade individual para painéis no contexto do SDM pode ser realizada via efeitos fixos, permitindo assim que a heterogeneidade individual seja correlacionada com o regressor. Portanto, considera-se o modelo de (3.71).

$Y=\rho W Y+X \beta+W X \gamma+\psi D+\varepsilon$

Onde,

D é matriz de dummys para contabilização do efeito fixo,

$\varepsilon \sim N\left(0, \sigma^{2} \Omega\right)$

$\Omega=\Sigma_{n} \otimes w_{t}$ 
Como generalização, supõe-se que o termo de erro siga um processo $\operatorname{AR}(1)$, de acordo com (3.72).

$$
\varepsilon_{i t}=\hat{\rho} \varepsilon_{i t-1}+u_{i t}
$$

Onde, $u_{i t} \sim N(0,1)$; e $\rho$ é parâmetro autoregressivo.

Assim, a correlação serial pode ser contabilizada pela matriz $w_{t}$.

$$
w_{t}=\frac{1}{1-\phi^{2}}\left(\begin{array}{ccccc}
1 & \phi & \phi^{2} & \cdots & \phi^{T-1} \\
\phi & 1 & \phi & \cdots & \phi^{T-2} \\
\phi^{2} & \phi & \ddots & \ddots & \vdots \\
\vdots & \ddots & \ddots & \ddots & \phi \\
\phi^{T-1} & \phi^{T-2} & \cdots & \phi & 1
\end{array}\right)
$$

É possível ainda permitir heteroscedasticidade considerando-se que a matriz de variância-covariância possui diagonal $\Omega=\operatorname{diag}\left(\sigma_{1} w_{t}, \cdots, \sigma_{N} w_{t}\right)$.

Portanto, nesse contexto de perturbações não-esféricas, Beer e Riedl (2011) propõem duas formas alternativas de estimação do painel com efeitos fixos lidando com autocorrelação serial. A primeira, utiliza o procedimento de Cochrane e Orcutt (1949), enquanto a segunda, faz uso do procedimento de Prais-Winsten (1954) sendo uma abordagem direta que evita a perda de uma observação. Ambos os estimadores mostram-se não-viesados de acordo com simulações de Monte Carlo realizadas, apesar dos testes usuais de significância se mostrarem problemáticos, tendo em vista que existe grande probabilidade de rejeição errônea da existência de spillovers.

Salienta-se ainda que o procedimento configura-se em um método que diferencia as variáveis do modelo utilizando um coeficiente $\hat{\rho}$ derivado da regressão (3.72) dos resíduos obtidos por MQO (DOWRICK e TANI, 2011).

Com o coeficiente $\hat{\rho}$ estimado, faz-se a transformação onde, 
$\tilde{Y}=Y_{t}-\rho Y_{t-1}$ e $\tilde{X}=X_{t}-\rho X_{t-1}$, para $t=2, \cdots, n$

Já para $t=1$,

$$
\left(1-\rho^{2} Y_{1}\right)^{1 / 2}=\beta_{1}\left(1-\rho^{2}\right)^{1 / 2}+\beta_{2}\left(1-\rho^{2} X_{1}\right)^{1 / 2}+\left(1-\rho^{2}\right)^{1 / 2} \varepsilon_{1}
$$

Em (3.74) reside a razão pelo qual o método de Prais-Winsten conserva a primeira observação, diferentemente do método de Cochrane-Orcutt, onde a primeira observação é omitida. Na prática, ambos os métodos são usualmente calculados em um esquema iterativo, de modo que uma vez encontrado $\hat{\rho}$, é possível encontrar um novo conjunto de resíduos e obter um novo $\hat{\rho}$. Tal procedimento é repetido até que a diferença dos $\hat{\rho}$ estimados em duas etapas subsequentes do processo iterativo seja menor do que um nível de tolerância, ou algum critério de convergência (WOOLDRIDGE, 2008).

\section{5 - O conceito de spillover}

O conceito de spillover basicamente advém do interesse teórico de desenvolver modelos que contemplem interações entre os agentes, não os vendo como tomadores de decisão isolados (ANSELIN, 1999).

Assim, o conhecimento de spillovers ou externalidades ocupa um papel central em vários campos da economia, sendo possível considerar, por exemplo, tanto em modelos espaciais quanto tradicionais, spillovers de conhecimento afetando $\mathrm{o}$ crescimento econômico, spillovers de tributação, e spillovers de poluição (BEER e RIEDL, 2011).

O efeito de spillover de vizinhança já é conhecido na literatura desde Jaffe (1986) e Cohen e Levinthal (1989), com relação à externalidades de conhecimento. 
Mais tarde, Durlauf (1994); Borjas (1995); Glaeser et al. (1996) elaboraram os primeiros trabalhos que mensuravam efeitos de spillover num contexto de modelos espaciais.

Além da questão de precisão de estimativas, o conhecimento dos efeitos de spillover (efeitos indiretos ou de externalidades) no contexto de modelos econométricos espaciais é de grande uso para o planejamento público (LESAGE e DOMINGUEZ, 2012).

\section{6 - Spillovers de conhecimento}

Desde Griliches (1979) é sabido que parte do output não é explicado por variações nos inputs não tradicionais, sendo o investimento em $\mathrm{P} \& \mathrm{D}$ reconhecido na literatura como um desses fatores, observando que seus retornos sociais são de impacto considerável. Sendo que acumulação de P\&D é um importante motor de crescimento econômico nos modelos teóricos em nível micro e macro (ROMER, 1986; LUCAS, 1988).

Nesse sentido, os governos encorajam a colaboração entre cientistas acadêmicos e companhias do setor privado a fim de extrair benefícios sociais, econômicos e spillovers associados, mesmo que a dinâmica do investimento inovativo não garanta tais efeitos (BENJAMIN, 2011).

Segundo Gittelman (2006), novas ideias são mais rapidamente absorvidas e aplicadas por firmas dentro de um grupo específico de condições. Tais condições podem ser, por exemplo, uma indústria pertencer a um setor intensivo em ciência como biotecnologia e bens de capital. 
Em nível macroeconômico é de interesse dos governos a promoção dos outputs sócio-econômicos resultantes da inovação tecnológica e dos investimentos em infraestrutura, bem como as vantagens competitivas associadas.

O entendimento de externalidades (spillovers) de conhecimento e tecnológicas é crucial para o conhecimento dos mecanismos de inovação e a dinâmica do crescimento econômico. Nesse contexto emergem modelos como o MAR (Marshall-Arow-Romer) e de Jacobs que buscam explicar a forma de difusão do conhecimento entre as firmas (AUTANT-BERNARD e LESAGE, 2011).

A intercomunicação entre entidades econômicas impulsionadas por TI e globalização resultam em spillovers com importantes implicações e produtividade (TSAI e LIN, 2005). De fato, Griffith e Peres-Neto (2006), por exemplo, reconhecem que empresas do Reino Unido localizadas nos Estados Unidos se beneficiam de mais spillover do que aquelas localizadas no Reino Unido.

Grande parte da literatura de crescimento endógeno trata não apenas do impacto do P\&D para a própria firma inovadora, mas também, o spillover para o restante da economia (O'MAHONY e VECCHI, 2009). Assim, é possível verificar o conhecimento tecnológico como um bem público que afeta todas as empresas operantes em um ambiente intensivo em P\&D (ARROW, 1962).

Os efeitos de spillover podem ocorrer de diversas formas, como por acumulação de capital humano (UZAWA, 1965), ou a aquisição de inputs melhorados e de alta qualidade Goto e Suzuki (1989) apesar de Griliches (1992) não considerá-lo spillover de conhecimento, sendo o puro spillover de conhecimento a troca de ideias entre firmas de um mesmo campo. De fato, segundo Verspagen (1997) a aquisição de inputs melhorados insumos no processo produtivo de outra empresa, fará a receptora receber 
algum spillover. Tal processo também é chamado de rent-spillovers (MONTOROSÁNCHEZ, 2011).

Spillovers de atividades de P\&D ocorrem porque o conhecimento tecnológico não pode ser completamente apropriado por firmas e indivíduos que desenvolvem o conhecimento (VERSPAGEN e LOO, 1999).

Ademais o conhecimento também pode ser transferido via publicações, engenharia reversa e troca de cientistas e colaboradores (VERSPAGEN e LOO, 1999; MONTORO-SÁNCHEZ, 2011). Contudo, existem limites para o spillover como patentes, skill, ou conhecimento tácito para a absorção do conhecimento (VERSPAGEN e LOO, 1999).

Os efeitos de spillover também podem ocorrer por meio da proximidade tecnológica, sendo passível de mensuração, segundo Goto e Suzuki (1989), pela distância entre a indústria eletrônica e o resto do setor manufatureiro baseado em dados de P\&D.

Jaffe (1986) foi o primeiro economista a estimar spillover de P\&D em inovação, utilizando uma função de produção de conhecimento; encontrando um efeito de concentração local de $\mathrm{P} \& \mathrm{D}$ na produtividade de patentes.

Jaffe (1986) afirma que a essência do efeito spillover é que o P\&D de outras empresas auxilia uma firma individual a conseguir resultados com menor dificuldade. Contudo, Cohen e Levinthal (1989) apontam a importância do investimento em P\&D para potencialidade da absorção da informação existente.

Assim, na teoria do crescimento endógeno, uma firma pode se beneficiar dos achados de pesquisa de outras firmas (AUTANT-BERNARD et al., 2011). Assim, a inovação e as externalidades e difusão do conhecimento são de grande importância na 
dinâmica de crescimento econômico de uma nação. Não obstante, spillovers de conhecimento exercem influência positiva na propensão das firmas a inovar como em Montoro-Sánchez (2011), visto que a inovação é altamente relacionada com a habilidade da firma de absorver informação externa, conhecimento e tecnologia (SEGARRA-BLASCO e ARAUZO-CAROD, 2008).

Num estudo na indústria francesa, Autant-Bernard et al. (2011) estudam os efeitos de clusterização para calcular os efeitos de spillover intra e inter-firma. De fato, encontram que o investimento de outras indústrias em P\&D melhora o componente tecnológico de produtividade de firmas individuais. Encontram também que o capital humano é o maior determinante da produtividade.

De fato Autant-Bernard et al. (2011) observam ser muito difícil desembaraçar os retornos internos do investimento em $\mathrm{P} \& \mathrm{D}$ dos efeitos de spillover advindos de outras firmas da mesma região.

Contudo, alguns autores como Lynne et al. (2003) chegam a refutar ou minimizar os efeitos de spillover de conhecimento de universidades para as firmas, argumentando que o principal fator determinante para a tecnologia da firma é a existência dos "star scientists", os quais são responsáveis pela maior parte das descobertas.

Para Liu et al. (2010), as atividades inovativas induzem externalidades de produção que formam uma base para que a função de produção agregada não enfrente retornos decrescentes, fazendo com que o output da sociedade cresça perpetuamente.

O conceito de spillovers pode ser classificado como horizontal ou vertical, dependendo da entidade emissora e receptora do conhecimento. O spillover vertical é aquele que ocorre entre elos da cadeia de suprimentos ou por parcerias entre empresas, 
enquanto o horizontal está ligado às universidades e outros institutos de pesquisa emissores de conhecimento para as firmas (MONTORO-SÁNCHEZ, 2011; KAISER, 2002; DE FARIA et al., 2010).

Existem na literatura de crescimento endógeno, basicamente três formas de calcular os efeitos de spillover de conhecimento, baseados na estimação de funções de produção. A primeira simplesmente endogeiniza na função de produção das firmas de uma região específica, os valores de $\mathrm{P} \& \mathrm{D}$ agregado de firmas em localidades próximas, como em (LIU et al., 2010). A segunda utiliza o SDM para computar tais externalidades e será tratado com maior detalhamento adiante.

Por fim, existe a técnica utilizada por O'mahony e Vecchi (2009); e Black e Lynch (2001) que utilizam um método em que os resíduos de uma regressão prévia da função de produção de empresas, um setor ou localidade, são utilizados para verificar efeitos de spillover. Mais especificamente, os resíduos irão conter a produtividade explicada por fatores externos à firma, caso a regressão prévia esteja bem especificada.

O investimento do governo em inovação tem um importante papel na produtividade das firmas. Kang e Park (2011) examinam os efeitos da colaboração intra-firma bem como os efeitos diretos e indiretos de P\&D governamental nos outputs de inovação, encontrando que o suporte governamental em financiamento de projetos afeta direta e indiretamente a inovação das firmas estimulando o P\&D interno e a colaboração à montante e a jusante.

As universidades desempenham um papel importante para a inovação das firmas, especialmente para aquelas empresas impedidas de inovar em função dos altos custos envolvidos com as atividades de P\&D. Isso faz com que muitas firmas impedidas de inovar por restrições econômicas se tornem inovadoras pelos subsídios e costshare fornecidos pelas universidades (VEUGELERS e CASSIMAN, 2005). 
Nem todas as empresas são aptas a realizar o processo inovativo de forma isolada devido à recente complexidade, riscos e custos das atividades de $\mathrm{P} \& \mathrm{D}$, como resultado, parcerias e cooperação tem se tornado importante (MONTORO-SÁNCHEZ, 2011).

Ademais, as universidades são os principais fornecedores de capital humano inovativo para o setor privado (LYNNE et al., 2003; STUART et al., 2007). Isso pode ser interpretado como um dos fatores de transferência de conhecimento, visto que relações inter-organizacionais, bem como aquelas com universidades elevam o estoque de conhecimento da empresa promovendo o output inovativo, o qual pode ser explicitado, dentre outras formas, como aumento de receitas (BAUM et al., 2000).

Setores intensivos em ciência como o de biotecnologia e bens de capital são pontos centrais nas redes de firmas, pois servem como intermediários e agregadores de valor entre universidade e outras instituições de pesquisa, em suas relações com empresas possuidoras de capabilidades financeiras e de marketing. Nesse contexto, tais setores intensivos em ciência possuem grande interação com universidades e outras instituições públicas de pesquisa (KANG e PARK, 2011). De fato, tais linkages fazem com que tais setores sejam grandes promotores de externalidades de inovação, sendo responsáveis por parte relevante do desenvolvimento de uma nação (NASSIF, 2008).

Também, cumpre pontuar que o setor mais estudado na literatura do crescimento e colaboração é o setor de biotecnologia, tendo em vista sua grande incidência na formação de alianças com universidades, especialmente quando se observam fundadores acadêmicos proeminentes (STUART et al., 2007).

Quanto à mensuração de spillovers via modelos espaciais, é possível citar exemplos de estudos sobre políticas industriais baseadas em clusters para melhora da performance econômica (AUTANT-BERNARD e LESAGE, 2011). Tais estudos têm 
feito uso do modelo espacial de Durbin (SDM) para computar o efeito de spillover espacial, sendo possível citar Lesage e Dominguez (2012) e Beer e Riedl (2011). Assim, são comuns estudos que buscam identificar efeitos de spillover em uma determinada área ou região como Liu et al. (2010) que mensuram as externalidades de conhecimento entre firmas da área metropolitana de Taiwan.

Estudos como o de Autant-Bernard e Lesage (2011), e outros menos recentes como Bottazzi e Peri (2003) computam o efeito de spillovers de conhecimento via função de produção de conhecimento.

Basicamente a ideia é a produção de mensuração estatística do efeito médio do investimento inovativo de uma região específica em outras localidades. Nessa dinâmica, verificam-se, portanto, inputs não mensuráveis no processo de função de produção de conhecimento que levam a um modelo espacial que inclui as características de defasagem espacial tanto na variável dependente quanto nas variáveis independentes, tal qual ocorre nos modelos SAR e SDM.

A quantificação de spillovers de conhecimento é por definição muito difícil, dado sua natureza de intangibilidade. Alguns estudos apontam o papel positivo de proximidade espacial em externalidades de conhecimento. Porém, o fluxo de conhecimento varia de acordo com contextos institucionais e tecnológicos, sendo assim possível a inexistência de spillovers mesmo com proximidade geográfica (AUTANTBERNARD e LESAGE, 2011). Assim, numa regressão convencional, os coeficientes representam medidas diretas da resposta de $Y_{i u}$ com relação às variações em $X_{i u}$ onde $u$ representa uma dada unidade espacial, na função de produção de conhecimento. Nesse caso, não há spillover espacial, visto que as variações em uma unidade "j”" não afetam uma unidade " $i$ ", o que é demonstrado matematicamente em (3.76). 


$$
\frac{\partial Y_{i u}}{\partial X_{j v}}=0
$$

Contudo, para o SDM,

$$
\frac{\partial Y_{i u}}{\partial X_{j v}} \neq 0 \text { paratodo } i \neq j
$$

Em (3.77) mudanças nos inputs $X_{i j}$ causam impacto em uma região $Y_{i}$. De fato, as derivadas parciais tomam a forma de uma matriz $\mathrm{n} \times \mathrm{n}$, em que a diagonal principal reflete os efeitos diretos, enquanto os outros elementos refletem os efeitos indiretos (spillover espacial), podendo ser chamados também de "cross regional spatial derivatives" (AUTANT-BERNARD e LESAGE, 2011).

Assim, um exemplo de função de produção de conhecimento que faz uso do SDM pode ser vista em Autant-Bernard and Lesage (2010), a qual relaciona o output inovativo (patentes) com o investimento de uma amostra de indústrias e o investimento público.

$$
\begin{aligned}
& Y=\psi W Y+R D_{i} \gamma_{1}+R D_{k} \gamma_{2}+P U B_{i} \theta_{1}+P U B_{k} \theta_{2}+W R D_{1} \gamma_{3}+ \\
& W R D_{k} \gamma_{4}+W P U B_{i} \theta_{3}+W P U B_{k} \theta_{4}+E S_{i} \lambda+\varepsilon
\end{aligned}
$$

Onde,

$R D_{i}$ input privado de $\mathrm{P} \& \mathrm{D}$ próprio (mesma indústria),

$R D_{k}$ input privado de $\mathrm{P} \& \mathrm{D}$ de outras indústrias,

$P U B_{i}$ input público de $\mathrm{P} \& \mathrm{D}$ próprio,

$P U B_{k}$ input público de $\mathrm{P} \& \mathrm{D}$ de outras indústrias,

$E S_{i}$ variável de controle para o tamanho de uma indústria de cada região. 
Aqui, a dependência espacial é capturada pela variável espacialmente defasada, $W Y$, enquanto os efeitos de spillover são capturados pelas variáveis dependentes multiplicadas pela matriz de ponderação espacial $W$.

\section{7 - Spillovers de infraestrutura}

Apenas recentemente foram realizados estudos com modelos espaciais que fazem uso do SDM para a avaliação de efeitos de spillover. Contudo, a maioria desses trabalhos trata de funções de produção de conhecimento, inovação e spillovers inovativos, no âmbito da teoria do crescimento endógeno.

Assim, são escassos ainda, estudos como o de Cohen e Monaco (2009) que utilizando dados de condados, avaliam o impacto da infraestrutura portuária para o comércio varejista da Califórnia por meio de um modelo econométrico espacial, o qual mensura o efeito de spillover, observando que o aumento de $1 \%$ nos investimentos em infraestrutura de transportes de um condado causa uma adição da ordem de $0,22 \%$ nas exportações varejistas dos condados vizinhos.

Zhang (2008) desenvolve um modelo empírico que testa spillovers espaciais de infraestrutura de transportes no crescimento econômico, encontrando um spillover positivo da ordem de 0,0287 para o crescimento econômico chinês dado o investimento em transportes. Para tanto, desenvolve um modelo espacial com dados em painel baseado em função de produção para o crescimento econômico local, diferenciando a infraestrutura local e externa, tal qual em (3.79).

$$
\begin{aligned}
& Y_{i t}=\alpha_{0}+\alpha_{1} \ln \left(L_{i t}\right)+\alpha_{2} \ln \left(K_{i t}\right)+\alpha_{3} \ln \left(K t_{i t}\right)+\alpha_{4} \ln \left(K g_{i t}\right)+ \\
& \alpha_{5} \ln \left(O k_{i t}\right)+\gamma_{1} \text { year1993 }+\cdots+\gamma_{1} \text { year } 2003+u_{i}+\varepsilon_{i t}
\end{aligned}
$$

Onde,

$Y_{i t}$ é o output (crescimento econômico), 
$L_{i t}$ é o trabalho,

$K_{i t}$ é o estoque de capital,

$\alpha_{i t}$ são as elasticidades do output em relação às infraestruturas de transporte,

$K t_{i t}$ é a infraestrutura de transporte local,

$K g_{i t}$ é a infraestrutura de transporte pública local,

$O k_{i t}$ é a infraestrutura de transporte externa, mais especificamente,

$$
O k_{i t}=\sum_{i=1}^{n} W_{i} K t_{i}
$$

Onde,

$W_{i}$ é a matriz de ponderação espacial, no qual três distintas são testadas:

Binária, porcentagem do total nacional de rodovias em uma província, e PIB per capita.

Em (3.80) observa-se a presença de dummys temporais com a utilidade de remover autocorrelação temporal nos dados.

Em Zhang (2008) é encontrada uma revisão de alguns estudos que encontraram altas elasticidades entre infraestrutura de transportes e crescimento econômico, contudo, alguns autores argumentam que tais valores podem ser resultado de correlação espúria, como Kelejian e Robinson (1997).

Estudos como Zhang (2008) apontam que a elasticidade de infraestrutura de transportes para o crescimento econômico pode ser até negativa, dado o fato de tal infraestrutura promover a migração de atividade econômica de uma região para outra.

Nesse contexto, a infraestrutura de transporte age como uma rede que interliga regiões, permitindo efeitos de difusão, sejam eles positivos ou negativos, uma vez que a 
migração de fatores faz com que seja possível o crescimento econômico de uma região acarretar o decréscimo de outras, por efeitos de aglomeração, por exemplo. Isso ocorre, pois, por criar vantagens para a região investidora, existe a migração de fatores produtivos de regiões vizinhas para a investidora (ZHANG, 2008).

É comum em muitos países, especialmente naqueles em desenvolvimento, a clusterização da atividade econômica em certas áreas, formando um gradiente de crescimento econômico e infraestrutura de transportes, como ocorre de leste para oeste no caso da China (ZHANG, 2008).

Dessa forma, no contexto de externalidades espaciais de infraestruturas de transporte, tendo em vista as redes formadas por tais infraestruturas, a consideração dos spillovers espaciais torna-se de extrema importância para que sejam evitados problemas de estimativa como o viés de especificação.

\section{8 - O princípio da máxima verossimilhança}

O principal objetivo desta seção é demonstrar o conceito de máxima verossimilhança e as formas de estimação de modelos econométricos via tal técnica. Para tanto, serão abordados, adicionalmente, uma revisão de métodos numéricos iterativos, os quais são necessários para a maximização da função de verossimilhança.

A máxima verossimilhança é uma técnica que permite a estimação de modelos econométricos (bem como a estimação de parâmetros de distribuições de probabilidade) e a realização de testes de hipóteses relativos a restrições lineares e não lineares ao vetor de parâmetros.

A máxima verossimilhança possui as propriedades de ser assintóticamente eficiente e consistente, contudo, apenas a partir dos anos 90 passou a ser utilizada amplamente, dada a necessidade de otimização numérica para o cálculo dos parâmetros. 
Mais especificamente, o princípio da máxima verossimilhança consiste em encontrar os parâmetros desconhecidos que maximizem a chance (verossimilhança) dos valores amostrais pertencerem a uma distribuição de probabilidade pré-estabelecida; em econometria, usualmente é utilizada a distribuição normal (PORTUGAL, 1995).

Portanto, dada uma amostra aleatória $y_{1} \ldots y_{n}$ retirada de uma população com função densidade de probabilidade $(\operatorname{fdp}) f\left(y_{i}, \theta\right)$, a qual é dependente do vetor de parâmetros $\theta$, tal amostra aleatória possui a fdp de (30).

$$
\prod_{i=1}^{n} f\left(y_{i}, \theta\right)
$$

Onde, após a amostragem, $\theta$ é vetor de parâmetros variáveis, e $y_{i}$ é fixo.

O produtório de (2.30) representa simplesmente o produto das densidades de cada observação. Portanto, antes da amostragem, $y_{i}$ é uma variável aleatória com fdp populacional e os parâmetros da fdp são também populacionais, e, portanto, fixos, isto é, $\theta$ fixo e $y_{i}$ variável. Contudo, após a amostragem a situação se inverte, $y_{i}$ se torna fixo e a função pode ser reinterpretada como sendo uma função do vertor de parâmetros $\theta$, que se tornam variáveis (PORTUGAL, 1995).

Assim, o problema consiste em calcular as estimativas dos parâmetros populacionais desconhecidos encontrando-se um vetor $\hat{\theta}$ que maximize a chance (verossimilhança) de se obter a amostra em questão. Isto é, obter o $\hat{\theta}$ que maximize a função de verossimilhança. Contudo, na prática, o cálculo envolve maximizar o logaritmo natural da função de verossimilhança, pois tal procedimento é mais simples e produz os mesmos resultados do procedimento original (PORTUGAL, 1995). 
O procedimento pode ser mais bem entendido por meio de um exemplo em que se estima o parâmetro de uma variável aleatória com 10 observações seguindo uma distribuição Poisson.

Assim, dados $\mathrm{y}=(5,0,1,1,0,3,2,3,4,1)$

Cuja fdp Poisson é exibida em (3.82).

$$
\frac{e^{-\theta} \theta^{y_{i}}}{y_{i} !}
$$

Assim, aplicando-se a densidade conjunta, e utilizando-se logaritmos naturais tem-se (3.83).

$\ln L(\theta \mid y)=\ln \left(\frac{e^{-n \theta} \theta^{\sum_{i=1}^{n} y_{i}}}{\prod_{i=1}^{n} y_{i} !}\right)$

$\ln L(\theta \mid y)=\ln _{e} e^{-n \theta}+\sum_{i=1}^{n} y_{i} \ln \theta-\ln \left(\prod_{i=1}^{n} y_{i} !\right)$

$\ln L(\theta \mid y)=-n \theta+\ln \theta \sum_{i=1}^{n} y_{i}-\ln \left(\prod_{i=1}^{n} y_{i} !\right)$

Maximizando (3.85),

$\frac{\partial \ln L}{\partial \theta}=-n+\frac{1}{\theta} \sum_{i=1}^{n} y_{i}=0$

Portanto,

$$
\hat{\theta}=\frac{\sum_{i=1}^{n} y_{i}}{n}
$$

Assim, para a amostra em questão, 


$$
\hat{\theta}=\frac{\sum_{i=1}^{n} y_{i}}{n}=20 / 10=2
$$

Dessa forma, $\hat{\theta}=2$ é a estimativa de máxima verossimilhança para o parâmetro theta $(\hat{\theta})$ da distribuição Poisson.

A máxima verossimilhança também está relacionada com as definições de score eficiente, que simplesmente é a derivada primeira da função de verossimilhança em relação ao vetor de parâmetros (3.89), e o conceito de matriz de informação, que está relacionado à derivada segunda da função de verossimilhança (3.90).

$$
\begin{aligned}
& \frac{\partial \ln L}{\partial \theta}=S(\theta) \\
& E\left(-\frac{\partial^{2} \ln L}{\partial \theta \partial \theta^{\prime}}\right)=I(\theta)
\end{aligned}
$$

Basicamente, a estimativa por máxima verossimilhança será a solução do conjunto de equações $S(\theta)=0$, bem como a matriz de informação estará relacionada com a variância do score eficiente. Mais especificamente, $[I(\theta)]^{-1}$ será a variância do score, onde $\hat{\theta}$ é consistente e assintóticamente normalmente distribuído e eficiente. Este é o conhecido limite inferior do teorema de Cramer-Rao, pois não existe outro estimador consistente de que tenha variância menor.

O mais comum é a utilização da distribuição normal para a maximização de uma variável aleatória, a fim de calcular seus parâmetros. É possível então verificar um exemplo do cálculo dos parâmetros média e variância para uma variável $y$ distribuição normal em (3.91).

$$
y \sim N\left(\mu, \sigma^{2}\right)
$$


Nesses termos, é possível verificar a fdp:

$$
f\left(y_{t}, \mu, \sigma^{2}\right)=\frac{1}{\left(2 \pi \sigma^{2}\right)} \exp \left(-\frac{1}{2 \sigma^{2}}\left(y_{t}-\mu\right)^{2}\right)
$$

E a função densidade conjunta é:

$$
\prod_{t=1}^{T} f\left(y_{t}, \mu, \sigma^{2}\right)
$$

Logo, a função de verossimilhança é:

$$
L=\prod_{t=1}^{T} f\left(y_{t}, \mu, \sigma^{2}\right)
$$

Assim,

$$
L\left(\mu, \sigma^{2} \mid y_{1}, y_{2}, y_{3}, \ldots, y_{T}\right)=\left(2 \pi \sigma^{2}\right)^{-t / 2} \exp \left(-\frac{\sum\left(y_{t}-\mu\right)^{2}}{2 \sigma^{2}}\right)
$$

Aplicando o logaritmo natural na equação (3.95),

$\ln L\left(\mu, \sigma^{2} \mid y_{t}\right)=-\frac{T}{2} \ln 2 \pi-\frac{T}{2} \ln \sigma^{2}-\left(\frac{\sum\left(y_{t}-\mu\right)^{2}}{2 \sigma^{2}}\right)$

Que é resultado das propriedades de logaritmos de (3.96) abaixo,

$$
\ln (2 \pi \sigma)^{-T / 2}=-\frac{T}{2}\left(\ln 2 \pi \sigma^{2}\right)=-\frac{T}{2} \ln 2 \pi-\frac{T}{2} \ln \sigma^{2}
$$

Observa-se que o uso de logaritmos não modifica o máximo pois o logaritmo é função sempre crescente. Assim, os estimadores de MV para os parâmetros o vetor de $\left(\mu, \sigma^{2}\right)$ que maximiza $\ln L$. Para tanto, é necessário encontrar a derivada de (3.97), isto é, igualar o score eficiente a zero $\left(S\left(\mu, \sigma^{2}\right)=0\right)$.

Assim, derivando (3.97) em relação à $\mu$. 


$$
\frac{\partial \ln L}{\partial \mu}=-\frac{T}{2} \ln 2 \pi-\frac{T}{2} \ln / \sigma^{2}-\frac{1}{2 \sigma^{2}} \sum_{t=1}^{T}\left(y_{t}-\mu\right)^{2}=0
$$

Os dois primeiros termos da equação possuem derivada parcial igual à zero, e assim, basta aplicar a técnica de derivação de produtos no último termo da equação.

$$
\frac{\partial \ln L}{\partial \mu}=\left(-\frac{1}{2 \sigma^{2}}\right)^{\prime}\left(\sum_{t=1}^{T}\left(y_{t}-\mu\right)^{2}\right)+\left(-\frac{1}{2 \sigma^{2}}\right)\left(\sum_{t=1}^{T}\left(y_{t}-\mu\right)^{2}\right)^{\prime}=0
$$

Novamente o primeiro termo possui derivada igual a zero, e aplica-se a regra da cadeia no segundo termo,

$$
\frac{\partial \ln L}{\partial \mu}=-\frac{1}{2 \sigma^{2}}\left(2 \sum_{t=1}^{T}\left(y_{t}-\mu\right)(-1)\right)=0
$$

Eliminando as constantes e rearranjando,

$$
\begin{aligned}
& \frac{\partial \ln L}{\partial \mu}=-\frac{1}{\sigma^{2}}\left(\sum_{t=1}^{T} y_{t}-\sum_{t=1}^{T} \mu\right)=0 \\
& -\frac{1}{\sigma^{2}} \sum_{t=1}^{T} y_{t}=-\frac{1}{\sigma^{2}} \sum_{t=1}^{T} \mu=0
\end{aligned}
$$

Eliminando os termos iguais em ambos os lados, e adicionalmente identificando

$$
\begin{gathered}
\text { que } \sum_{t=1}^{T} \mu=T \mu \text {, então, } \\
\sum_{t=1}^{T} y_{t}=T \mu \\
\hat{\mu}=\frac{\sum_{t=1}^{T} y_{t}}{T}
\end{gathered}
$$

Onde (3.104) é o estimador para a média aritmética de $y$.

Agora, derivando (3.97) em relação à $\sigma$, 


$$
\frac{\partial \ln L}{\partial \sigma}=-\frac{T}{2} \ln 2 \pi-\frac{T}{2} \ln \sigma^{2}-\frac{1}{2 \sigma^{2}} \sum_{t=1}^{T}\left(y_{t}-\mu\right)^{2}=0
$$

O primeiro termo novamente é igual a zero, e aplica-se a derivada do produto ao segundo e ao terceiro termo.

$$
\begin{aligned}
& \frac{\partial \ln L}{\partial \sigma}=\left[\left(-\frac{T}{2}\right)^{\prime}\left(\ln \sigma^{2}\right)+\left(-\frac{T}{2}\right)\left(\ln \sigma^{2}\right)^{\prime}\right]- \\
& {\left[\left(\frac{1}{2 \sigma^{2}}\right)^{\prime}\left(\sum_{t=1}^{T}\left(y_{t}-\mu\right)^{2}\right)+\left(\frac{1}{2 \sigma^{2}}\right)\left(\sum_{t=1}^{T}\left(y_{t} /-\mu\right)^{2}\right)^{\prime}\right]=0}
\end{aligned}
$$

Rearranjando,

$$
\begin{aligned}
& \frac{\partial \ln L}{\partial \sigma}=\left(-\frac{T}{2} \frac{1}{\sigma^{2}}\right)-\left[\frac{(1)^{\prime}\left(2 \sigma^{2}\right)-(1)\left(2 \sigma^{2}\right)^{\prime}}{\left(2 \sigma^{2}\right)^{2}}\left(\sum_{t=1}^{T}\left(y_{t}-\mu\right)^{2}\right)\right]=0 \\
& \frac{\partial \ln L}{\partial \sigma}=\left(-\frac{T}{2 \sigma^{2}}\right)-\left[-\frac{2}{\left(2 \sigma^{2}\right)^{2}}\left(\sum_{t=1}^{T}\left(y_{t}-\mu\right)^{2}\right)\right]=0 \\
& \frac{\partial \ln L}{\partial \sigma}=-\frac{T}{2 \sigma^{2}}+\frac{1}{2\left(\sigma^{2}\right)^{2}} \sum_{t=1}^{T}\left(y_{t}-\mu\right)^{2}=0 \\
& \frac{1}{2\left(\sigma^{2}\right)^{2}} \sum_{t=1}^{T}\left(y_{t}-\mu\right)^{2}=\frac{T}{2 \sigma^{2}} \\
& \frac{1}{2\left(\sigma^{2}\right)^{2}} \sum_{t=1}^{T}\left(y_{t}-\mu\right)^{2}=\frac{T}{2 \sigma^{2}}
\end{aligned}
$$

Dividindo ambos os lados da equação por $2 \sigma^{2}$, e, rearranjando,

$$
\begin{aligned}
& \sum_{t=1}^{T}\left(y_{t}-\mu\right)^{2}=T \sigma^{2} \\
& \hat{\sigma}^{2}=\frac{\sum_{t=1}^{T}\left(y_{t}-\mu\right)^{2}}{T}
\end{aligned}
$$


Onde, (3.113) é o estimador de máxima verossimilhança para a variância da variável $y_{t} \cdot y_{t} y_{t}$.

Agora, para obter a matriz de informação $I(\theta)$, é necessário encontrar as derivadas segundas de $\ln L$. Portanto,

$$
\begin{aligned}
& \frac{\partial^{2} \ln L}{\partial \mu^{2}}=\frac{1}{\sigma^{2}} \sum_{t=1}^{T} y_{t}-\frac{1}{\sigma^{2}} \sum_{t=1}^{T} \mu \\
& \frac{\partial^{2} \ln L}{\partial \mu^{2}}=\left(-\frac{1}{\sigma^{2}}\right)^{\prime}\left(\sum_{t=1}^{T} y_{t}\right)+\left(-\frac{1}{\sigma^{2}}\right)\left(\sum_{t=1}^{T} \mu\right)^{\prime} \\
& \frac{\partial^{2} \ln L}{\partial \mu^{2}}=\left(-\frac{1}{\sigma^{2}}\right)^{\prime}\left(\sum_{t=1}^{T} y_{t}\right)+\left(-\frac{1}{\sigma^{2}}\right)\left(\sum_{t=1}^{T} \mu\right)^{\prime} \\
& \frac{\partial^{2} \ln L}{\partial \mu^{2}}=-\frac{1}{\sigma^{2}} T
\end{aligned}
$$

Encontrando agora a derivada segunda em relação à $\sigma$,

$$
\frac{\partial^{2} \ln L}{\partial\left(\sigma^{2}\right)^{2}}=-\frac{T}{2 \sigma^{2}}+\frac{1}{2\left(\sigma^{2}\right)^{2}} \sum_{t=1}^{T}\left(y_{t}-\mu\right)^{2}
$$

Utilizando as regras de derivação,

$$
\begin{aligned}
& \frac{\partial^{2} \ln L}{\partial\left(\sigma^{2}\right)^{2}}=-\frac{(T)^{\prime}\left(2 \sigma^{2}\right)-(T)\left(2 \sigma^{2}\right)^{\prime}}{\left(2 \sigma^{2}\right)^{2}}+\left(\frac{1}{2\left(\sigma^{2}\right)^{2}}\right)^{\prime}\left(\sum_{t=1}^{T}\left(y_{t}-\mu\right)^{2}\right)+ \\
& \left(\frac{1}{2\left(\sigma^{2}\right)^{2}}\right)\left(\sum_{t=1}^{T}\left(y_{t}-\mu\right)^{2}\right)^{\prime} \\
& \frac{\partial^{2} \ln L}{\partial\left(\sigma^{2}\right)^{2}}=-\left(-\frac{2 T^{\prime}}{\left(2 \sigma^{2}\right)^{2}}\right)-\frac{4 \sigma}{\left[2\left(\sigma^{2}\right)^{2}\right]^{2}}\left(\sum_{t=1}^{T}\left(y_{t}-\mu\right)^{2}\right)
\end{aligned}
$$

Rearranjando, obtém-se a expressão final. 


$$
\frac{\partial^{2} \ln L}{\partial\left(\sigma^{2}\right)^{2}}=+\frac{T}{2\left(\sigma^{2}\right)^{2}}-\frac{1}{\left(\sigma^{2}\right)^{3}}\left(\sum_{t=1}^{T}\left(y_{t}-\mu\right)^{2}\right)
$$

Para a matriz de informação, é necessário encontrar ainda, os elementos fora da diagonal principal da matriz de informação, as quais, pelo teorema de Clariout, não dependem da ordem de derivação.

Portanto,

$$
\begin{aligned}
& \frac{\partial^{2} \ln L}{\partial \mu \partial \sigma^{2}}=\frac{\partial}{\partial \sigma^{2}}\left(\frac{\partial \ln L}{\partial \mu}\right) \\
& \frac{\partial^{2} \ln L}{\partial \mu \partial \sigma^{2}}=\frac{\partial}{\partial \sigma^{2}}\left(\frac{1}{\sigma^{2}} \sum_{t=1}^{T}\left(y_{t}-\mu\right)\right)
\end{aligned}
$$

Derivando em relação a $\sigma$

$$
\begin{aligned}
& \frac{\partial^{2} \ln L}{\partial \mu \partial \sigma^{2}}=\left(\frac{1}{\sigma^{2}}\right)^{\prime}\left(\sum_{t=1}^{T}\left(y_{t}-\mu\right)\right)+\left(\frac{1}{\sigma^{2}}\right)\left(\sum_{t=1}^{T}(y /-\mu)\right)^{\prime} \\
& \frac{\partial^{2} \ln L}{\partial \mu \partial \sigma^{2}}=-\frac{1}{\left(\sigma^{2}\right)^{2}} \sum_{t=1}^{T}\left(y_{t}-\mu\right)
\end{aligned}
$$

Assim, a matriz de informação é formada pelas derivadas segundas do logaritmo da função de verossimilhança avaliadas no ponto de máximo, isto é, relativo à $\hat{\mu}$ e $\hat{\sigma}^{2}$. Portanto, para construir a matriz de informação, e posteriormente a variância dos estimadores, é necessário avaliar a esperança matemática de cada um dos termos relativos a matriz, são eles os já calculados:

$$
\begin{aligned}
& \frac{\partial^{2} \ln L}{\partial \mu^{2}}=-\frac{1}{\sigma^{2}} T \\
& \frac{\partial^{2} \ln L}{\partial\left(\sigma^{2}\right)^{2}}=+\frac{T}{2\left(\sigma^{2}\right)^{2}}-\frac{1}{\left(\sigma^{2}\right)^{3}}\left(\sum_{t=1}^{T}\left(y_{t}-\mu\right)^{2}\right)
\end{aligned}
$$




$$
\frac{\partial^{2} \ln L}{\partial \mu \partial \sigma^{2}}=-\frac{1}{\left(\sigma^{2}\right)^{2}} \sum_{t=1}^{T}\left(y_{t}-\mu\right)
$$

Visto que o primeiro elemento é não estocástico, este permanece inalterado. Já o terceiro elemento possui esperança igual a zero, sendo, portanto nulo. Isso ocorre pois a variância assintótica necessita da esperança das derivadas cruzadas, as quais possuem esperança igual a zero. Por fim o segundo elemento será modificado, visto que a esperança $E\left(y_{t}\right)=\mu$, a esperança deste segundo elemento será $T /\left(2 \sigma^{4}\right)$.

Verifica-se então a matriz de informação,

$$
I[\theta]=\left[\begin{array}{cc}
\frac{T}{\hat{\sigma}^{2}} & 0 \\
0 & \frac{T}{2 \hat{\sigma}^{2}}
\end{array}\right]
$$

Assim, a inversão da matriz de informação resulta na matriz de variância dos estimadores de máxima verossimilhança. E, portanto,

$$
[I(\theta)]^{-1}=\left[\begin{array}{cc}
\frac{\hat{\sigma}^{2}}{T} & 0 \\
0 & \frac{2 \hat{\sigma}^{4}}{T}
\end{array}\right]
$$

Isso se deve ao teorema de Crámer-Rao, o qual afirma que o inverso da matriz de informação é o limite inferior para a variância de qualquer estimador não-viesado de $\theta$ por máxima verossimilhança, equivalente a,

$$
\operatorname{Var}(\hat{\theta}) \geq \frac{1}{I(\theta)}
$$

Em outras palavras, a precisão da estimativa da $\theta$ é limitada fundamentalmente pela matriz de informação da função de verossimilhança. Assim, em termos genéricos, a estimativa da variância dos estimadores é dada por, 


$$
[I(\theta)]^{-1}=\left\{-E\left[\frac{\partial^{2} \ln L}{\partial \theta \partial \theta^{\prime}}\right]\right\}^{-1}=\left\{E\left[\left(\frac{\partial \ln (\theta)}{\partial \theta}\right)\left(\frac{\partial \ln (\theta)}{\partial \theta}\right)^{\prime}\right]\right\}^{-1}
$$

Um exemplo mais completo do cálculo do score eficiente e da matriz de variância dos estimadores (matriz de informação) pode ser realizado por meio do cálculo dos parâmetros de uma regressão linear simples.

Assim, pressupondo-se normalidade dos resíduos da regressão, e partindo-se do modelo de regressão usual.

$$
y_{i}=\beta x_{i}+u_{i}
$$

Onde,

$$
u_{i} \sim N\left(0, \sigma^{2}\right)
$$

Agora, arranjando em função do resíduo,

$$
u_{i}=y_{i}-\beta x_{i}
$$

Portanto, dado que o resíduo é normalmente distribuído,

$$
f\left(u_{i}\right)=\frac{1}{\left(2 \pi \sigma^{2}\right)^{1 / 2}} \exp \left(-\frac{u_{i}^{2}}{2 \sigma^{2}}\right)
$$

Para todo $\mathrm{i}=1,2,3, \ldots, \mathrm{n}$.

Visto que $u_{i}$ é normalmente distribuído, $y_{i}$ também será, tendo em vista que qualquer função linear de variável com distribuição normal também é normalmente distribuída. Portanto,

$$
f\left(y_{i}\right)=\frac{1}{\sqrt{2 \pi \sigma^{2}}} \exp \left(-\frac{\left(y_{i}-\beta x_{i}\right)^{2}}{2 \sigma^{2}}\right)
$$

E deste modo o logaritmo natural da função de verossimilhança será dado por: 
$\ln L\left(\beta, \sigma^{2} \mid y_{i}\right)=\sum_{i=1}^{n} \ln f\left(y_{i}\right)$

Assim, pela aplicação de logaritmos naturais,

$$
\begin{aligned}
& \ln L\left(\beta, \sigma^{2} \mid y_{i}\right)=\sum_{i=1}^{n}\left[\ln \left(\sqrt{2 \pi \sigma^{2}}\right)^{-1} \ln \exp \left(-\frac{\left(y_{i}-\beta x_{i}\right)^{2}}{2 \sigma^{2}}\right)\right] \\
& \ln L\left(\beta, \sigma^{2} \mid y_{i}\right)=\sum_{i=1}^{n}\left[-\ln \left(2 \pi \sigma^{2}\right)^{1 / 2}-\frac{1}{2 \sigma^{2}}\left(y_{i}-\beta x_{i}\right)^{2}\right] \\
& \ln L\left(\beta, \sigma^{2} \mid y_{i}\right)=\sum_{i=1}^{n}\left[-\frac{1}{2}\left(\ln 2 \pi+\ln \sigma^{2}\right)-\frac{1}{2 \sigma^{2}}\left(y_{i}-\beta x_{i}\right)^{2}\right] \\
& \ln L\left(\beta, \sigma^{2} \mid y_{i}\right)=\sum_{i=1}^{n}\left[-\frac{1}{2} \ln (2 \pi)-\frac{1}{2} \ln \sigma^{2}-\frac{1}{2 \sigma^{2}}\left(y_{i}-\beta x_{i}\right)^{2}\right]
\end{aligned}
$$

Aplicando o somatório,

$$
\ln L\left(\beta, \sigma^{2} \mid y_{i}\right)=-\frac{n}{2} \ln (2 \pi)-\frac{n}{2} \ln \sigma^{2}-\frac{1}{2 \sigma^{2}} \sum_{i=1}^{n}\left(y_{i}-\beta x_{i}\right)^{2}
$$

Para obter os estimadores de máxima verossimilhança, aplica-se a derivada primeira e igualando-a a zero (score eficiente).

Aplicando-se a regra da derivada do produto no terceiro termo, e zerando os dois primeiros (derivada de constante),

$$
\begin{aligned}
& \frac{\partial \ln L}{\partial \beta}=\left(-\frac{1}{2 \sigma^{2}}\right)^{\prime}\left(\sum_{i=1}^{n}\left(y_{i}-\beta x_{i}\right)^{2}\right)+\left(-\frac{1}{2 \sigma^{2}}\right)\left(\sum_{i=1}^{n}\left(y_{i}-\beta x_{i}\right)^{2}\right)^{\prime}=0 \\
& \frac{\partial \ln L}{\partial \beta}=-\frac{1}{2 \sigma^{2}} 2 \sum_{i=1}^{n}\left(y_{i}-\beta x_{i}\right)\left(-x_{i}\right)=0
\end{aligned}
$$


Multiplicando ambos os lados da equação pela variância $\sigma^{2}$ e distribuindo o somatório, é possível encontrar o estimador do parâmetro de declividade por máxima verossimilhança.

$$
\begin{aligned}
& -\sum_{i=1}^{n} y_{i} x_{i}+\sum_{i=1}^{n} \hat{\beta} x_{i}^{2}=0 \\
& \hat{\beta}=\frac{\sum_{i=1}^{n} y_{i} x_{i}}{\sum_{i=1}^{n} x_{i}^{2}}
\end{aligned}
$$

Nota-se que o estimador de declividade por máxima verossimilhança é idêntico ao estimador de mínimos quadrados ordinários.

Agora, aplicando a derivada primeira em relação à $\sigma^{2}$, tendo em vista que o primeiro termo é eliminado,

$$
\begin{aligned}
& \frac{\partial \ln L}{\partial \sigma^{2}}=\left(-\frac{h{ }^{\prime}}{2}\right)^{\prime}\left(\ln \sigma^{2}\right)+\left(-\frac{n}{2}\right)\left(\ln \sigma^{2}\right)^{\prime}+ \\
& \left(-\frac{1}{2 \sigma^{2}}\right)^{\prime}\left(\sum_{i=1}^{n}\left(y_{i}-\beta x_{i}\right)^{2}\right)+\left(-\frac{1}{2 \sigma^{2}}\right)\left(\sum_{i=1}^{n}\left(y_{i} /-\beta x_{i}\right)^{2}\right)^{\prime}=0 \\
& \frac{\partial \ln L}{\partial \sigma^{2}}=\left(-\frac{n}{2}\right)\left(\frac{1}{\sigma^{2}}\right)^{\prime}-\left(-\frac{1}{\left(2 \sigma^{2}\right)^{2}}\right)^{\prime}\left(\sum_{i=1}^{n}\left(y_{i}-\beta x_{i}\right)^{2}\right)=0
\end{aligned}
$$

O estimador de variância por máxima verossimilhança será:

$$
\begin{aligned}
& \frac{\partial \ln L}{\partial \sigma^{2}}=-\frac{n}{2} \frac{1}{\sigma^{2}}+\frac{1}{\left(2 \sigma^{2}\right)^{2}} \sum_{i=1}^{n}\left(y_{i}-\beta x_{i}\right)^{2}=0 \\
& \frac{1}{\left(2 \hat{\sigma}^{2}\right)^{2}} \sum_{i=1}^{n}\left(y_{i}-\beta x_{i}\right)^{2}=\frac{n}{2 \hat{\sigma}^{2}}+
\end{aligned}
$$




$$
\hat{\sigma}^{2}=\frac{\sum_{i=1}^{n}\left(y_{i}-\beta x_{i}\right)^{2}}{n}
$$

Onde, (3.126) é um estimador de variância viesado, contudo é assintóticamente não-viesado. Isso equivale a dizer que o aumento do tamanho amostral torna tal viés sucessivamente insignificante.

É interessante notar, ainda, que tal expressão corresponde à soma dos quadrados dos resíduos (SQR) sobre o tamanho amostral, diferente do estimador de variância de mínimos quadrados ordinários o qual subtrai os graus de liberdade (número de parâmetros a serem estimados) do tamanho amostral. Portanto,

$$
\hat{\sigma}^{2}=\frac{S Q R^{M V}}{n} \neq \frac{S Q R^{M Q O}}{n-k}
$$

Agora, para calcular a matriz de informação, são necessárias as derivadas segundas.

$$
\begin{aligned}
& \frac{\partial^{2} \ln L}{\partial \beta^{2}}=-\frac{1}{2 \sigma^{2}} 2 \sum_{i=1}^{n}\left(y_{i} x_{i}-\beta x_{i}\right)\left(-x_{i}\right)=0 \\
& \frac{\partial^{2} \ln L}{\partial \beta^{2}}=\left(-\frac{1}{\sigma^{2}}\right)^{\prime}\left(\sum_{i=1}^{n}\left(-y_{i} x_{i}+\beta x_{i}^{2}\right)\right)+\left(-\frac{1}{\sigma^{2}}\right)\left(\sum_{i=1}^{n}\left(-y_{i} x_{i}+\beta x_{i}^{2}\right)\right)^{\prime}=0 \\
& \frac{\partial^{2} \ln L}{\partial \beta^{2}}=\frac{1}{\sigma^{2}} \sum_{i=1}^{n} x_{i}^{2}
\end{aligned}
$$

Encontrando agora a derivada segunda em relação à $\sigma^{2}$,

$$
\begin{aligned}
& \frac{\partial^{2} \ln L}{\partial\left(\sigma^{2}\right)^{2}}=-\frac{n}{2 \sigma^{2}}+\frac{1}{\left(2 \sigma^{2}\right)^{2}} \sum_{i=1}^{n}\left(y_{i}-\beta x_{i}\right)^{2} \\
& \frac{\partial^{2} \ln L}{\partial\left(\sigma^{2}\right)^{2}}=\left(-\frac{n}{2 \sigma^{2}}\right)^{\prime}+\left(\frac{1}{\left(2 \sigma^{2}\right)^{2}}\right)^{\prime}\left(\sum_{i=1}^{n}\left(y_{i}-\beta x_{i}\right)^{2}\right)+\left(\frac{1}{\left(2 \sigma^{2}\right)^{2}}\right)\left(\sum_{i=1}^{n}\left(y_{i}-\beta x_{i}\right)^{2}\right)^{\prime}
\end{aligned}
$$




$$
\begin{aligned}
& \frac{\partial^{2} \ln L}{\partial\left(\sigma^{2}\right)^{2}}=\frac{2 n}{\left(2 \sigma^{2}\right)^{2}}-\frac{4}{4\left(\sigma^{2}\right)^{4}}\left(\sum_{i=1}^{n}\left(y_{i}-\beta x_{i}\right)^{2}\right) \\
& \frac{\partial^{2} \ln L}{\partial\left(\sigma^{2}\right)^{2}}=\frac{n}{2\left(\sigma^{2}\right)^{2}}-\frac{4}{\left(\sigma^{2}\right)^{3}} \sum_{i=1}^{n}\left(y_{i}-\beta x_{i}\right)^{2}
\end{aligned}
$$

A derivada cruzada será,

$$
\begin{aligned}
& \frac{\partial^{2} \ln L}{\partial \beta \partial \sigma^{2}}=\frac{\partial}{\partial \sigma^{2}}\left(\frac{\partial \ln L}{\partial \beta}\right) \\
& \frac{\partial^{2} \ln L}{\partial \beta \partial \sigma^{2}}=\frac{\partial}{\partial \sigma^{2}}\left(\frac{1}{\sigma^{2}} \sum_{i=1}^{n}\left(-y_{i} x_{i}+\beta x_{i}^{2}\right)\right) \\
& \frac{\partial^{2} \ln L}{\partial \beta \partial \sigma^{2}}=\left(\frac{1}{\sigma^{2}}\right)^{\prime}\left(\sum_{i=1}^{n}\left(-y_{i} x_{i}+\beta x_{i}^{2}\right)\right)+\left(\frac{1}{\sigma^{2}}\right)\left(\sum_{i=1}^{n}\left(y_{i} x_{i}+\beta x_{i}^{2}\right)\right)^{\prime} \\
& \frac{\partial^{2} \ln L}{\partial \beta \partial \sigma^{2}}=-\frac{1}{\left(\sigma^{2}\right)^{2}} \sum_{i=1}^{n}\left(y_{i}-\beta x_{i}\right) x_{i}
\end{aligned}
$$

Novamente, tomando a esperança das derivadas segundas, e lembrando que $E\left(x_{i} u_{i}\right)=0$, dado que são não-correlacionados, e que $E\left(\sum_{i=1}^{n} u_{i}^{2}\right)=n \sigma^{2}$, obtém-se a matriz de informação.

Portanto,

$$
E\left[-\frac{\partial^{2} \ln L}{\partial \theta \partial \theta^{\prime}}\right]=I(\theta)=\left[\begin{array}{cc}
\frac{\sum_{i=1}^{n} x_{i}}{\sigma^{2}} & 0 \\
0 & \frac{n}{2\left(\sigma^{2}\right)^{2}}
\end{array}\right]
$$

Invertendo a matriz de informação a fim de obter as variâncias dos estimadores, dado o teorema de Cramer-Rao, 


$$
[I(\theta)]^{-1}=\left[\begin{array}{cc}
\frac{\hat{\sigma}^{2}}{\sum_{i=1}^{n} x_{i}} & 0 \\
0 & \frac{2 \hat{\sigma}^{4}}{n}
\end{array}\right]=\left[\begin{array}{cc}
\operatorname{Var}(\hat{\beta}) & 0 \\
0 & \operatorname{Var}\left(\hat{\sigma}^{2}\right)
\end{array}\right]
$$

\subsubsection{Maximização da verossimilhança}

Muitas vezes a condição de primeira ordem (score eficiente) não permite uma solução explícita para os estimadores em questão, como quando são geradas equações não lineares ou muito complexas.

Nesses casos a maximização da verossimilhança é realizada por meio de algum método numérico, em especial, os métodos interativos, como o método de NewtonRaphson.

Contudo, antes de apresentar o método de Newton-Raphson é necessário introduzir alguns conceitos matemáticos relativos à expansão de funções em séries de Taylor.

Também conhecidas como "séries de potências", é a expansão de uma série de funções ao redor de um ponto. Isto é, é a expansão de $f(x)$ ao redor do ponto em que $x$ assume um valor qualquer " $a$ " por exemplo. Portanto, a expansão de Taylor de forma genérica assume a seguinte forma:

$$
f(x)=\sum a_{n}(x-a)^{n}, \quad \text { onde } \quad a_{n}=\frac{f^{(n)}(a)}{n !}
$$

Especificamente, se $x=a$ :

$$
f(x)=f(a)(x-a)^{0}+\frac{f^{\prime}(a)(x-a)^{1}}{1 !}+\frac{f^{\prime}(a)(x-a)^{2}}{2 !}+\cdots
$$

Se $a=0$, observa-se a série de MacLaurin, ou expansão em torno de $x=0$. 
Assim, expandir uma função $f(x)$ em torno de um ponto "a" significa transformar tal função em um polinômio no qual os coeficientes dos vários termos são expressos em termos dos valores das derivadas $f^{\prime}(a), f^{\prime \prime}(a)$, etc, todas calculadas no ponto de expansão " $a$ ".

Tal método é interessante para verificar extremos relativos que podem ser aplicados mesmo quando a derivada segunda seja zero no ponto estacionário. Assim, a série de Taylor (ou MacLaurin) são utilizadas para aproximação e convergência de funções. Isso significa que o crescimento do grau de polinômio de aproxima-se faz com que ele se aproxime da função correta.

Exemplo 1 - Série de MacLaurin para a função:

$$
\begin{aligned}
& f(x)=2+4 x+3 x^{2} \\
& f^{\prime}(x)=4+6 x \\
& f^{\prime \prime}(x)=6
\end{aligned}
$$

De modo que,

$$
\begin{aligned}
& f^{\prime}(0)=4 \\
& f^{\prime \prime}(0)=6
\end{aligned}
$$

A série de MacLaurin então será:

$$
\begin{aligned}
& f(x)=\frac{f(0)}{0 !}+\frac{f^{\prime}(0) x}{1 !}+\frac{f^{\prime \prime}(0) x^{2}}{2 !} \\
& f(x)=\frac{2}{1}+\frac{(4) x}{1 !}+\frac{(6) x^{2}}{2 !} \\
& f(x)=2+4 x+3 x^{2}
\end{aligned}
$$

Onde (3.127) é idêntico a função original. 


\section{Exemplo 2:}

$$
e^{x}=1+\frac{x^{1}}{1 !}+\frac{x^{2}}{2 !}+\frac{x^{3}}{3 !}+\frac{x^{4}}{4 !}+\cdots
$$

É possível também expandir uma série em função arbitrária, não necessariamente um polinômio. Isso é possível desde que a função arbitrária $\phi(x)$ seja diferenciável (com derivadas contínuas e finitas até o grau desejado) no ponto de expansão $a$.

Exemplo 3: Expandir a função (3.128) em torno de $a=1$, com $n=4$.

$$
\begin{aligned}
& e^{x}=\phi(x)=\frac{1}{1+x} \\
& \phi^{\prime}(x)=-(1+x)^{-2} \\
& \phi^{\prime \prime}(x)=2(1+x)^{-3} \\
& \phi^{\prime \prime \prime}(x)=-6(1+x)^{-4} \\
& \phi^{(4)}(x)=24(1+x)^{-5}
\end{aligned}
$$

Assim,

$$
\begin{aligned}
& \phi(1)=\frac{1}{2} \\
& \phi^{\prime}(1)=-\frac{1}{4} \\
& \phi^{\prime \prime}(1)=\frac{1}{4} \\
& \phi^{\prime \prime \prime}(1)=-\frac{3}{8} \\
& \phi^{(4)}(1)=\frac{3}{4}
\end{aligned}
$$

Portanto,

$$
\phi(x)=\frac{1}{2}-\frac{1}{4}(x-1)+\frac{1}{8}(x-1)^{2}-\frac{1}{16}(x-1)^{3}+\frac{1}{32}(x-1)^{4}+R_{4}
$$


Onde, $R_{4}$ representa um resto, pois no exemplo foi escolhida uma expansão arbitrária para a extensão do polinômio.

\subsubsection{Séries de Taylor para extremos relativos}

Pode ser utilizada quando a derivada segunda não é capaz de responder se existe um mínimo ou máximo relativo, ou seja, $f^{\prime \prime}(x)=0$.

Isso é possível, pois, quando $f(x)=0$ atinge um máximo relativo em $x_{0}$ se $f(x)-f\left(x_{0}\right)$ é negative para valores de $x$ na sua vizinhança imediata tanto à esquerda quanto à direita.

Assim, expandindo $f(x)$ em torno de $x_{0}$, para o caso em que:

$f^{\prime}(x)-f^{\prime \prime}\left(x_{0}\right)=0$

Mas,

$f^{\prime \prime \prime}\left(x_{0}\right) \neq 0$

Assim, para $\mathrm{n}=2$,

$f(x)-f\left(x_{0}\right)=f^{\prime}\left(x_{0}\right)-f\left(x-x_{0}\right)+\frac{1}{2 !} f^{\prime \prime}\left(x_{0}\right)\left(x-x_{0}\right)^{2}+\frac{1}{3 !} f^{\prime \prime \prime}(p)\left(x-x_{0}\right)^{3}$

Como,

$f^{\prime}(x)=f^{\prime \prime}\left(x_{0}\right)=0$

$f(x)-f\left(x_{0}\right)=\frac{1}{6} f^{\prime \prime \prime}(p)\left(x-x_{0}\right)^{3}$

Que é um ponto de inflexão.

Assim, se: 
$f^{(n)}\left(x_{0}\right)<0$ e " $n$ " é par, observa-se um máximo relativo.

$f^{(n)}\left(x_{0}\right)>0$ e " $n$ " é par, observa-se um mínimo relativo.

Para os casos em que " $n$ " é impar, observa-se um ponto de inflexão.

Exemplo numérico relativo à forma de se encontrar extremos relativos em funções pode ser encontrado em (3.129).

$$
\begin{aligned}
& f(x)=(7-x)^{4} \quad \text { em } x=7, \text { para } n=4 \\
& f^{\prime}(x)=-4(7-x)^{3} \\
& f^{\prime \prime}(x)=-12(7-x)^{2} \\
& f^{\prime \prime \prime}(x)=-24(7-x) \\
& f^{(4)}(x)=24
\end{aligned}
$$

Assim,

$f^{\prime}(7)=0$

$f^{\prime \prime}(7)=0$

$f^{\prime \prime \prime}(7)=0$

$f^{(4)}(7)=24$

Assim, como $f^{(4)}(7)>0$ e 4 é par, encontra-se um mínimo relativo. 


\subsubsection{O método de Newton-Raphson}

O método de Newton-Raphson é um método numérico iterativo utilizado para encontrar as raízes de uma equação ou seus pontos extremos (máximos e mínimos), em uma formulação alternativa, a qual será explorada adiante.

Tal método pode ser deduzido a partir de uma expansão de Taylor de $f(x)$ em torno de $x_{1}$.

$$
f(x)=\left(x_{1}\right)+\left(x-x_{1}\right) f^{\prime}(x)+\frac{1}{2 !}\left(x-x_{1}\right)^{2} f^{\prime \prime}\left(x_{1}\right)+\cdots
$$

Se $x_{2}$ é a solução aproximada considerando os dois primeiros termos observa-se,

$$
f\left(x_{2}\right)=0+f\left(x_{1}\right)+\left(x_{2}-x_{1}\right) f^{\prime}(x)+\frac{1}{2 !}\left(x_{2}-x_{1}\right)^{2}+\cdots
$$

Assim, a solução aproximada considerando os dois primeiros termos será,

$$
x_{2}=x_{1}-\frac{f\left(x_{1}\right)}{f^{\prime}\left(x_{1}\right)}
$$

Genericamente,

$$
x_{i+1}=x_{i}-\frac{f\left(x_{i}\right)}{f^{\prime}\left(x_{i}\right)}
$$

Observa-se, portanto, em (3.130), a lógica do processo iterativo do método de Newton, o qual utiliza valores passados para atualizar os futuros, dado um "chute" inicial.

Tendo em vista tais características, o processo pode ser repetido indefinidamente, contudo, normalmente métodos numéricos iterativos exigem um critério de parada, para a interrupção do processo. Um desses critérios é o erro relativo 
o qual encerra o processo iterativo quando existir uma diferença menor do que um valor pré-estabelecido entre uma iteração $i$ e uma subsequente $i+1$. Portanto,

$$
\left|\frac{x_{i+1}-x_{i}}{x_{i}}\right| \leq \varepsilon
$$

Onde, $\varepsilon$ é um valor previamente especificado.

Isso significa, por exemplo, se $\varepsilon=0,001$, então quando a diferença relativa entre uma iteração $i$ e uma subsequente $i+1$ for menor que tal valor, o processo iterativo é finalizado.

Existem também outros critérios de parada, como o estabelecimento ad hoc de um número limite de iterações, ou mesmo a utilização de um erro absoluto como em

$$
x_{i+1}-x_{i} \leq \varepsilon
$$

Um exemplo pode se visualizado no processo de determinar a solução da equação (3.131), utilizando uma estimativa inicial de $x=0,4$ e um critério de parada de um máximo de 3 iterações. A solução exata para o problema é de 0,5.

$$
\begin{aligned}
& y=\frac{1}{x}-2=0 \\
& f^{\prime}(x)=-\frac{1}{x^{2}} \\
& x_{i+1}=x_{i}-\frac{f\left(x_{i}\right)}{f^{\prime}\left(x_{i}\right)}=x_{i}-\frac{\left(1 / x_{i}-2\right)}{-\frac{1}{\left(x_{i}\right)^{2}}}=x_{i}-\left(\frac{1}{x_{i}}-2\right)\left(-\frac{x_{i}^{2}}{1}\right)=2\left(x_{i}-x_{i}^{2}\right)
\end{aligned}
$$

Portanto,

$$
x_{i+1}=2\left(x_{i}-x_{i}^{2}\right)
$$


Assim, aplicando o chute inicial a (3.132),

$$
\begin{aligned}
& x_{1}=0,4 \\
& x_{2}=2\left(x_{i}-x_{i}^{2}\right)=2\left[0,4-(0,4)^{2}\right]=0,48 \\
& x_{3}=2\left[(0,48)-(0,48)^{2}\right]=0,4992 \\
& x_{3}=2\left[(0,4992)-(0,4992)^{2}\right]=0,499999
\end{aligned}
$$

É possível observar assim, que o valor encontrado em (3.132) é uma solução aproximada para a função após apenas 3 iterações.

Salienta-se que em algumas funções o método de Newton-Raphson é muito sensível ao chute inicial, pois dependendo do formato da função, este método pode divergir ou, caso esteja buscando um valor otimizado (máximo ou mínimo), o método pode encontrar extremos locais ao invés de globais.

Contudo, para o caso da maximização da verossimilhança, o uso do Método de newton não é um problema. Isso ocorre, pois, tal qual visto anteriormente, é usual a utilização do logaritmo natural da verossimilhança; e tendo em vista que a função log é monotonicamente crescente, os problemas de máximos locais e divergência não se aplicam.

3.8.4. Encontrando o máximo da verossimilhança via método de NewtonRaphson

O método de Newton aplicado à maximização segue a mesma lógica, contudo, utilizará uma razão entre a derivada primeira e a segunda de uma função.

$$
x_{i+1}=x_{i}-\frac{f^{\prime}\left(x_{i}\right)}{f^{\prime \prime}\left(x_{i}\right)}
$$


Contudo, agora, a ideia básica é maximizar um parâmetro ou um vetor de parâmetros, cuja lógica fundamental se baseia novamente na expansão de Taylor. Assim, aqui, observa-se que uma função pode ser suficientemente aproximada de forma quadrática como demonstrado em (3.134), onde a função $Q(\theta)$ é expandida ao redor de $\hat{\theta}_{1}$

$$
Q(\theta) \cong Q\left(\hat{\theta}_{1}\right)+g_{1}{ }^{\prime}\left(\theta-\hat{\theta}_{1}\right)+\frac{1}{2}\left(\theta-\hat{\theta}_{1}\right)^{\prime} H_{1}\left(\theta-\hat{\theta}_{1}\right)
$$

Onde,

$\hat{\theta}_{1}$ é uma estimativa inicial.

$$
\begin{aligned}
& g_{1}=\frac{\partial Q}{\partial \theta} \hat{\theta}_{1} \\
& H_{1}=\left.\frac{\partial^{2} Q}{\partial \theta \partial \theta^{\prime}}\right|_{\hat{\theta}_{1}}
\end{aligned}
$$

A segunda iteração é obtida maximizando-se o lado direito da equação (3.134), portanto,

$$
\hat{\theta}_{2}=\hat{\theta}_{1}-H_{1}^{-1} g_{1}
$$

Assim, de forma genérica,

$$
\hat{\theta}_{i+1}=\hat{\theta}_{i}-H_{1}^{-1} g_{1}
$$

De modo análogo, o processo é repetido até $\hat{\theta}_{n}$ atingir um critério de convergência especificado.

Caso $\hat{\theta}$ for um vetor de parâmetros ao invés de um único parâmetro, 


$$
\begin{aligned}
g_{1} & =\left[\begin{array}{c}
\frac{\partial Q}{\partial \theta_{1}} \hat{\theta}_{i} \\
\left.\frac{\partial Q}{\partial \theta_{2}}\right|_{\hat{\theta}_{i}} \\
\left.\frac{\partial Q}{\partial \theta_{3}}\right|_{\hat{\theta}_{i}} \\
\vdots
\end{array}\right] \\
H & =\left[\begin{array}{c|c|c}
\frac{\partial^{2} Q}{\partial \theta_{1}^{2}} \mid \hat{\theta}_{i} & \frac{\partial^{2} Q}{\partial \theta \partial \theta^{\prime}} \mid \hat{\theta}_{1} & \cdots \\
\frac{\partial^{2} Q}{\partial \theta \partial \theta^{\prime}} \hat{\theta}_{1} & \frac{\partial^{2} Q}{\partial \theta_{2}^{2}} \mid \hat{\theta}_{i} & \cdots \\
\vdots & \vdots & \ddots \\
& &
\end{array}\right]
\end{aligned}
$$

Onde, observa-se que $H$ é a matriz Hessiana.

Agora, a nova iteração inserida na aproximação quadrática expandida será:

$$
Q\left(\hat{\theta}_{2}\right) \cong Q\left(\hat{\theta}_{1}\right)-\frac{1}{2}\left(\hat{\theta}_{2}-\hat{\theta}_{1}\right)^{\prime} H_{1}\left(\hat{\theta}_{2}-\hat{\theta}_{1}\right)
$$

A equação (3.135) denota a principal fraqueza de tal método, visto que a não ser que $H_{1}$ seja matriz definida negativa, não se pode garantir que $Q\left(\hat{\theta}_{2}\right)>Q\left(\hat{\theta}_{1}\right)$.

Se, $X^{\prime} A X \operatorname{com} A$ simétrica,

$X^{\prime} A X>0$, com $X \neq 0$, é definida positiva.

$X^{\prime} A X<0$, com $X \neq 0$, é definida negativa.

Especificamente, uma matriz definida positiva é aquela cuja qualquer submatriz possua determinante maior que zero.

Contudo, mesmo que (3.135) seja matriz definida negativa, caso,

$\hat{\theta}_{2}-\hat{\theta}_{1}$ for muito grande, o método tende a ultrapassar o alvo. 
$\hat{\theta}_{2}-\hat{\theta}_{1}$ for muito pequeno, o método tende a convergir de forma lenta.

Porém tal fragilidade pode ser superada via a transformação de GoldfeldQuandt-Troter,

$$
\hat{\theta}_{2}=\hat{\theta}_{1}-\left(H_{1}-\alpha_{1} I\right)^{-1} g_{1}
$$

Onde,

I é matriz identidade,

$\alpha_{1}$ é escalar escolhido pelo pesquisador que faça $H_{1}-\alpha_{1} I$ ser definida negativa.

O método de Newton-Raphson pode ser melhor exemplificado através do exemplo a seguir para casos de Aids na Bélgica com os dados da Tabela 10 (WOOD, 2009)

Tabela 10 - Dados para exemplo

$\begin{array}{llllllllllllll}\text { Ano } & 81 & 82 & 83 & 84 & 85 & 86 & 87 & 88 & 89 & 90 & 91 & 92 & 93 \\ \text { Novos casos } & 12 & 14 & 33 & 50 & 67 & 74 & 123 & 141 & 165 & 204 & 253 & 246 & 240\end{array}$

A formulação geral da função é o número de novos casos $\left(\mu_{i}\right)$ em função do ano de apuração $\left(t_{i}\right)$.

$$
\mu_{i}=\alpha e^{\beta t_{i}}
$$

Aqui, $E\left(y_{i}\right)=\mu_{i}=\alpha e^{\beta t_{i}}$ segue uma distribuição Poisson.

$$
\begin{aligned}
& f\left(y_{i}\right)=\frac{\mu_{i}^{y_{i}} e^{-\mu_{i}}}{y_{i}} \\
& \ln L\left(y_{i} \mid \alpha, \beta\right)=\prod_{I=1}^{n}\left(\frac{\mu_{i}^{y_{i}} e^{-\mu_{i}}}{y_{i}}\right)
\end{aligned}
$$


Por propriedades de logaritmo, o produtório torna-se um somatório.

$$
\begin{aligned}
& \ln L\left(y_{i} \mid \alpha, \beta\right)=\sum_{i=1}^{n}\left[\ln \mu_{i}^{y_{i}}+\ln e^{-\mu_{i}}-\ln \left(y_{i} !\right)\right] \\
& \ln L\left(y_{i} \mid \alpha, \beta\right)=\sum_{i=1}^{n}\left[y_{i} \ln \mu_{i}-\mu_{i}-\ln \left(y_{i} !\right)\right] \\
& \ln L\left(y_{i} \mid \alpha, \beta\right)=\sum_{i=1}^{n}\left[y_{i} \ln \left(\alpha e^{\beta t_{i}}\right)-\alpha e^{\beta t_{i}}-\ln \left(y_{i} !\right)\right] \\
& \ln L\left(y_{i} \mid \alpha, \beta\right)=\sum_{i=1}^{n}\left[y_{i}\left(\ln \alpha+\ln e^{\beta t_{i}}\right)-\alpha e^{\beta t_{i}}\right] \\
& \ln L\left(y_{i} \mid \alpha, \beta\right)=\sum_{i=1}^{n}\left[y_{i}\left(\ln \alpha+\beta t_{i}\right)-\alpha e^{\beta t_{i}}\right] \\
& \ln L\left(y_{i} \mid \alpha, \beta\right)=\sum_{i=1}^{n} y_{i}\left(\ln \alpha+\beta t_{i}\right)-\sum_{i=1}^{n} \alpha e^{\beta t_{i}}
\end{aligned}
$$

A partir de (3.136), calcula-se o score eficiente (condição de primeira ordem).

$$
\begin{aligned}
& \frac{\partial \ln L}{\partial \alpha}=\sum_{i=1}^{n} y_{i}\left[\ln \alpha+\beta t_{i}\right]-\sum_{i=1}^{n} \alpha e^{\beta t_{i}}=0 \\
& \left.\frac{\partial \ln L}{\partial \alpha}=\sum_{i=1}^{n} y_{i} \ln \alpha+\sum_{i=1}^{n} y_{i} \beta t_{i}\right]-\sum_{i=1}^{n} \alpha e^{\beta t_{i}}=0 \\
& \frac{\partial \ln L}{\partial \alpha}=\sum_{i=1}^{n}\left[(y /)^{\prime}(\ln \alpha)+\left(y_{i}\right)(\ln \alpha)^{\prime}\right]+\sum_{i=1}^{n}\left(y_{i} \beta t_{i}\right)^{\prime}-\sum_{i=1}^{n}\left[(\alpha)^{\prime}\left(e^{\beta t_{i}}\right)+(\alpha)\left(e^{\beta t_{i}}\right)^{\prime}\right]=0 \\
& \frac{\partial \ln L}{\partial \alpha}=\sum_{i=1}^{n} \frac{y_{i}}{\alpha}-\sum_{i=1}^{n} e^{\beta t_{i}}
\end{aligned}
$$

Derivando agora em relação a $\beta$,

$$
\frac{\partial \ln L}{\partial \beta}=\sum_{i=1}^{n} y_{i}\left(\ln \alpha+\beta t_{i}\right)-\sum_{i=1}^{n} \alpha e^{\beta t_{i}}=0
$$




$$
\begin{aligned}
& \frac{\partial \ln L}{\partial \beta}=\sum_{i=1}^{n}\left[y_{j} \ln \alpha\right]+\sum_{i=1}^{n}\left[\left(y_{i}\right)^{\prime}\left(\beta t_{i}\right)+\left(y_{i}\right)\left(\beta t_{i}\right)^{\prime}\right]-\sum_{i=1}^{n}\left[(\alpha)^{\prime}\left(e^{\beta t_{i}}\right)+(\alpha)\left(e^{\beta t_{i}}\right)^{\prime}\right]=0 \\
& \frac{\partial \ln L}{\partial \beta}=\sum_{i=1}^{n} y_{i} t_{i}-\sum_{i=1}^{n} \alpha t_{i} e^{\beta t_{i}}
\end{aligned}
$$

Assim, o vetor de score (gradiente) será,

$$
\left(\begin{array}{c}
\frac{\partial \ln L}{\partial \alpha} \\
\frac{\partial \ln L}{\partial \beta}
\end{array}\right)=\left(\begin{array}{c}
\sum_{i=1}^{n} \frac{y_{i}}{\alpha}-\sum_{i=1}^{n} e^{\beta t_{i}} \\
\sum_{i=1}^{n} y_{i} t_{i}-\sum_{i=1}^{n} \alpha t_{i} e^{\beta t_{i}}
\end{array}\right)
$$

Agora, deriva-se novamente o score a fim de encontrar a matriz de informação (Matriz Hessiana).

$$
\begin{aligned}
& \frac{\partial^{2} \ln L}{\partial^{2} \alpha}=\sum_{i=1}^{n} \frac{y_{i}}{\alpha}-\sum_{i=1}^{n} e^{\beta t_{i}} \\
& \frac{\partial^{2} \ln L}{\partial^{2} \alpha}=\sum_{i=1}^{n} \frac{\left(y_{i}\right)^{\prime}(\alpha)-\left(y_{i}\right)(\alpha)^{\prime}}{\left(\alpha^{2}\right)}-\sum_{i=1}^{n}\left(e^{\beta t_{i}}\right)^{\prime} \\
& \frac{\partial^{2} \ln L}{\partial^{2} \alpha}=-\sum_{i=1}^{n} \frac{y_{i}}{\alpha^{2}}
\end{aligned}
$$

Encontrando a derivada segunda em relação a $\beta$,

$$
\begin{aligned}
& \frac{\partial^{2} \ln L}{\partial^{2} \beta}=\sum_{i=1}^{n}\left(y_{i} t_{i}\right)^{\prime}-\sum_{i=1}^{n}\left(\alpha t_{i}\right)^{\prime}\left(e^{\beta t_{i}}\right)+\left(\alpha t_{i}\right)\left(e^{\beta t_{i}}\right)^{\prime} \\
& \frac{\partial^{2} \ln L}{\partial^{2} \beta}=\sum_{i=1}^{n} \alpha t_{i}{ }^{2} e^{\beta t_{i}}
\end{aligned}
$$


Por fim, é necessário encontrar a derivada cruzada, a fim de encontrar os elementos externos à diagonal principal.

$$
\begin{aligned}
& \frac{\partial^{2} \ln L}{\partial \alpha \partial \beta}=\frac{\partial}{\partial \beta}\left(\frac{\partial \ln L}{\partial \alpha}\right) \\
& \frac{\partial^{2} \ln L}{\partial \alpha \partial \beta}=\frac{\partial}{\partial \beta}\left(\sum_{i=1}^{n} \frac{y_{i}}{\alpha}-\sum_{i=1}^{n} e^{\beta t_{i}}\right) \\
& \frac{\partial^{2} \ln L}{\partial \alpha \partial \beta}=\sum_{i=1}^{n}\left(\frac{y / \gamma^{\prime}}{\alpha}\right)^{\prime}-\sum_{i=1}^{n}\left(e^{\beta t_{i}}\right)^{\prime} \\
& \frac{\partial^{2} \ln L}{\partial \alpha \partial \beta}=-\sum_{i=1}^{n} t_{i} e^{\beta t_{i}}
\end{aligned}
$$

Assim, a matriz de informação será,

$$
\left[\begin{array}{cc}
\frac{\partial^{2} \ln L}{\partial^{2} \alpha} & \frac{\partial^{2} \ln L}{\partial \beta \partial \alpha} \\
\frac{\partial^{2} \ln L}{\partial \alpha \partial \beta} & \frac{\partial^{2} \ln L}{\partial^{2} \beta}
\end{array}\right]=\left[\begin{array}{cc}
-\sum_{i=1}^{n} \frac{y_{i}}{\alpha^{2}} & -\sum_{i=1}^{n} t_{i} e^{\beta t_{i}} \\
-\sum_{i=1}^{n} t_{i} e^{\beta t_{i}} & \sum_{i=1}^{n} \alpha t_{i}^{2} e^{\beta t_{i}}
\end{array}\right]
$$

\subsubsection{Processo iterativo}

O processo iterativo do método de Newton-Raphson baseia-se na atualização de cálculos via a equação apresentada (3.137), tendo em vista um "chute inicial".

$$
\hat{\theta}_{i+1}=\hat{\theta}_{i}-H_{1}^{-1} g_{1}
$$

Assim, considerando um chute inicial de,

$$
\begin{aligned}
& \hat{\alpha}_{0}=4 \\
& \hat{\beta}_{0}=0,35
\end{aligned}
$$


Substituindo os valores do chute inicial na matriz $g$,

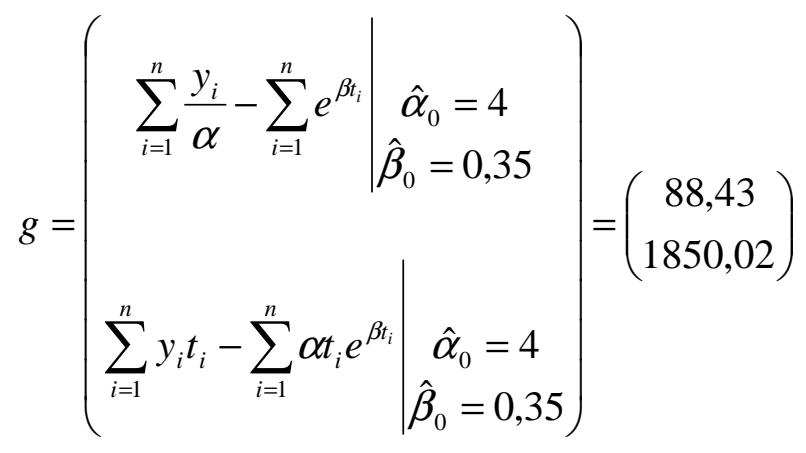

Realizando o mesmo procedimento para $H$,

$$
H=\left(\begin{array}{cc}
-101,375 & -3409,25 \\
-3409,25 & 154567
\end{array}\right)
$$

Realizando a multiplicação matricial $H^{-1} g$,

$$
H^{-1} g=\left(\begin{array}{c}
-1,820 \\
0,028
\end{array}\right)
$$

Assim, de forma genérica, o passo 1 será,

$\hat{\theta}_{1}=\hat{\theta}_{0}-H^{-1} g$

Portanto,

$$
\left(\begin{array}{c}
\hat{\alpha}_{1} \\
\hat{\beta}_{1}
\end{array}\right)=\left(\begin{array}{c}
\hat{\alpha}_{0} \\
\hat{\beta}_{0}
\end{array}\right)-\left(\begin{array}{c}
-1,820 \\
0,028
\end{array}\right)=\left(\begin{array}{c}
5,82 \\
0,322
\end{array}\right)
$$

Deste modo, o processo iterativo prossegue utilizando no passo 2, os resultados do passo 1 de (3.138), e assim sucessivamente, até algum critério ode parada préestabelecido.

De forma geral, o método de Newton-Raphson utiliza além do gradiente da função, a derivada de segunda ordem para determinar a direção da busca, convergindo quadraticamente, configurando, portanto, um método de rápida resolução. 
Contudo o método requer que o chute inicial seja próximo a solução para garantir a convergência, além do custo computacional elevado, especialmente quando as derivadas são mais complexas do que a função original.

No que diz respeito ao chute inicial, infelizmente não existe muita teoria sobre tal tópico na literatura. Alguns citam a possibilidade de estimação preliminar da função a fim de melhorar a velocidade da convergência, prática conhecida como score the function.

Outra técnica consiste em plotar a função, se possível, a fim de fornecer uma ideia da forma da função e dos valores iniciais a serem utilizados.

\subsubsection{Testes de hipótese baseados na máxima verossimilhança}

Testar uma hipótese equivale a testar um vetor $\theta$ de restrição nos parâmetros, dada a função de verossimilhança $L(x, \theta)$, onde $x$ é matriz (Tx1), e $\theta$ é matriz $(\mathrm{kx} 1)$. Assim, é possível testar restrições lineares, como os parâmetros individuais $\theta_{1}+\theta_{2}=1$, ou $h(\theta)=0$, isto é, se os elementos do vetor de parâmetros $h(\theta)$ são iguais a zero; respeitando sempre a condição de que o número de restrições lineares seja menor do que o número de parâmetros estimados. É possível também testar restrições não-lineares como $\theta_{1}+\theta_{2} \theta_{3}=0$.

Existem basicamente três testes baseados na máxima verossimilhança, são eles, a razão de Verossimilhança, o teste de Wald, Multiplicador de Langrange (também conhecido como score teste de Rao). Aqui, contudo, será dada maior atenção ao teste de razão de verossimilhança pelo fato de aproximar-se de um teste F simples. 
Tal teste requer a estimação de um modelo restrito e de outro sem restrição. Considerando $\hat{\theta}$ o vetor de parâmetros sem restrição, e $\tilde{\theta}$ o parâmetro restrito, testa-se $h(\tilde{\theta})=0$, por meio do cálculo da função de verossimilhança com e sem restrição.

Assim, caso a restrição seja verdadeira, os valores da verossimilhança calculados com $\hat{\theta}$ e $\tilde{\theta}$ devem estar próximos, indicando que a restrição é válida. Portanto, tal teste aproxima-se de um teste de restrição.

De maneira geral, o teste de razão de verossimilhança é expresso por,

$$
\begin{aligned}
& L R=-2 \log \left(\frac{L(\hat{\theta})}{L(\tilde{\theta})}\right) \\
& L R=-2[\ln L(\hat{\theta})-\ln L(\tilde{\theta})] \sim \chi_{g}^{2}
\end{aligned}
$$

Em que (3.139) segue uma distribuição qui-quadrado com $n-k$ graus de liberdade.

Sendo um teste de restrição, o teste de razão de verossimilhança aproxima-se de um teste $\mathrm{F}$, podendo ser expresso em termos as soma dos quadrados dos resíduos $(\mathrm{SQR})$.

$$
F=\frac{[\operatorname{SQRR}(\tilde{\theta})-\operatorname{SQR}(\hat{\theta})\rfloor / r}{\operatorname{SQR}(\hat{\theta}) /(n-k)}
$$

Onde, r é o número de parâmetros restritos.

SQRR é a soma dos quadrados dos resíduos do modelo estimado com restrição.

Portanto,

$$
L R=-2[\ln L(\hat{\theta})-\ln L(\tilde{\theta})]=2\left[\frac{n}{2} \ln S Q R R(\hat{\theta})-\frac{n}{2} \ln S Q R(\tilde{\theta})\right]
$$


$L R=n \ln \left[\frac{\ln S Q R R(\hat{\theta})}{\ln S Q R(\tilde{\theta})}\right] \sim \chi_{g}^{2}$

Assim, se,

$L R<\chi_{g}^{2}$, aceita-se a hipótese nula, isto é, a restrição é válida.

$L R>\chi_{g}^{2}$, rejeita-se a hipótese nula, isto é, a restrição não é válida. 


\section{CAPÍTULO 4 - MÉTODO}

O presente trabalho classifica-se na categoria de desenho de estudo transversal retrospectivo; visto que não há intervenção do pesquisador, caracterizando-se, portanto, como pesquisa descritiva.

\section{1 - Modelo proposto}

Tendo em vista o objetivo declarado, o presente trabalho propõe a construção e posterior estimação de um modelo econométrico com duas equações, com variáveis em notação matricial, que visará responder às perguntas de pesquisa declaradas.

Aqui, o modelo a ser estimado será um modelo espacial completo e, portanto, engloba de erro e defasagem espacial (SEM e SAR), juntamente com as variáveis que computam o spillover via modelo espacial de Durbin (SDM).

Dado isso, o modelo será baseado na lógica da função de produção, controlando o modelo para efeitos espaciais, visto que estudos como os de Aiyar e Dalgaard (2009) têm mostrado que a Cobb-Douglas permanece uma aproximação interessante.

Obviamente, funções de produção não lineares são estimadas utilizando-se a linearização do modelo Cobb-Douglas via utilização de logaritmos (modelo log-log), que entre outros subprodutos, possibilita que os parâmetros estimados sejam interpretados em termos de elasticidades (GUJARATI, 2006).

Quanto à utilização de funções de produção modificadas, é possível citar Griliches (1968), Mundlak (1961), Doll (1974), Ulveling e Fletcher (1970), Mefford (1986) e, mais recentemente, Gartner et al. (2009). Em termos da econometria espacial, 
é possível citar ainda estudos como os de Cohen e Monaco (2009), que fazem uso de funções de produção.

Contudo, autores como Bitzer et al. (2008) argumentam que muitas vezes os inputs podem ser considerados endógenos, pois a produtividade total dos fatores pode influenciar a escolha da combinação dos fatores no mesmo período, levando a correlação contemporânea do termo do erro. Porém, tal hipótese é rebatida via testes de endogeneidade realizado pelo autor, bem como a exogeneidade dos fatores é apoiada por Zellner et al. (1966) os quais argumentam que o output é estocástico. Ademais, dada à natureza macroeconômica do presente trabalho, tal hipótese não será levada em consideração.

Adicionalmente, o modelo econométrico espacial irá propor a defasagem temporal do painel dos investimentos inovativos, a fim de estimar o tempo de transmissão e transformação de tais dispêndios, visto que as despesas com atividades de inovação rendem retornos potenciais no futuro, pouco observáveis no período do dispêndio (OCDE, 2005).

Assim, a série temporal do painel impõe uma restrição ao número de parâmetros de defasagem a serem estimados, o que impossibilita a estimação ad hoc da extensão da defasagem (HSIAO, 1990). Nesses termos, foi utilizada uma extensão máxima de três defasagens para o painel, configurando-se, portanto, em um modelo Space-Time Dynamic (com todas as formas de dependência).

O modelo a ser estimado é descrito pelas equações (4.1) e (4.2) 
$\ln C_{i t}=\rho W_{1} \ln C_{i t}+\alpha_{1} \ln K_{i t}+\alpha_{2} \ln L_{i t}+\alpha_{3} \ln P o p_{i t}+\alpha_{4} \ln I n_{i t-T}+\alpha_{5} \ln T_{i t}+$ $\alpha_{6} W_{1} \ln I n_{i t-T}+\alpha_{7} W_{1} \ln T_{i t}+F e_{i}+\varepsilon_{1}$

Onde,

$\varepsilon_{1}=\lambda_{1} W_{2} \varepsilon_{1}+u_{1}$

E,

$\ln D s e_{i t}=\rho W_{1} \ln D s e_{i t}+\beta_{1} \ln C_{i t}+\beta_{2} \ln K_{i t}+\beta_{3} \ln L_{i t}+\beta_{4} \ln P o p_{i t}+$

$\beta_{5} \ln I n_{i t-T}+\beta_{6} \ln T_{i t}+\beta_{7} W_{1} \ln C_{i t}+\beta_{8} W_{1} \ln I n_{i t-T}+\beta_{9} W_{1} \ln T_{i t}+$

$F e_{i}+\varepsilon_{2}$

Onde,

$\varepsilon_{2}=\lambda_{2} W_{2} \varepsilon_{2}+u_{2}$

Em que,

$K$ : Estoque de capital;

L: Trabalho;

Pop: População;

$C$ : Crescimento econômico (variável endógena que exige a consideração de técnicas de variáveis instrumentais);

Dse: Desenvolvimento sócio-econômico;

T: Matriz de aporte de capital público em infraestrutura de transportes;

In: Investimento em inovação tecnológica;

$W$ : Matriz de ponderação espacial;

T: É a extensão da defasagem a ser utilizada;

$F e$ : É efeito fixo. 
O modelo de equações proposto, responderá às perguntas de pesquisa, sendo que, os parâmetros das variáveis em interação $W^{*} T, W^{*} C, e W^{*} \operatorname{In}$ fornecerão o efeito de spillover de estados vizinhos, em média, para o Brasil.

Quanto à escolha da matriz de ponderação espacial $(W)$, serão utilizadas duas formas: inverso da distância, e vizinhança binária.

De maneira geral, o modelo a ser estimado é dinâmico em termos espaciais e temporais, visto que, por exemplo, o investimento em inovação de uma unidade espacial $i$ em um tempo $t$ - $k$, ocasionaria crescimento econômico em um tempo posterior $t$ para a unidade investidora $i$, assim como para suas unidades vizinhas $j$.

Tal dinâmica pode ser mais bem visualizada na Figura 10.

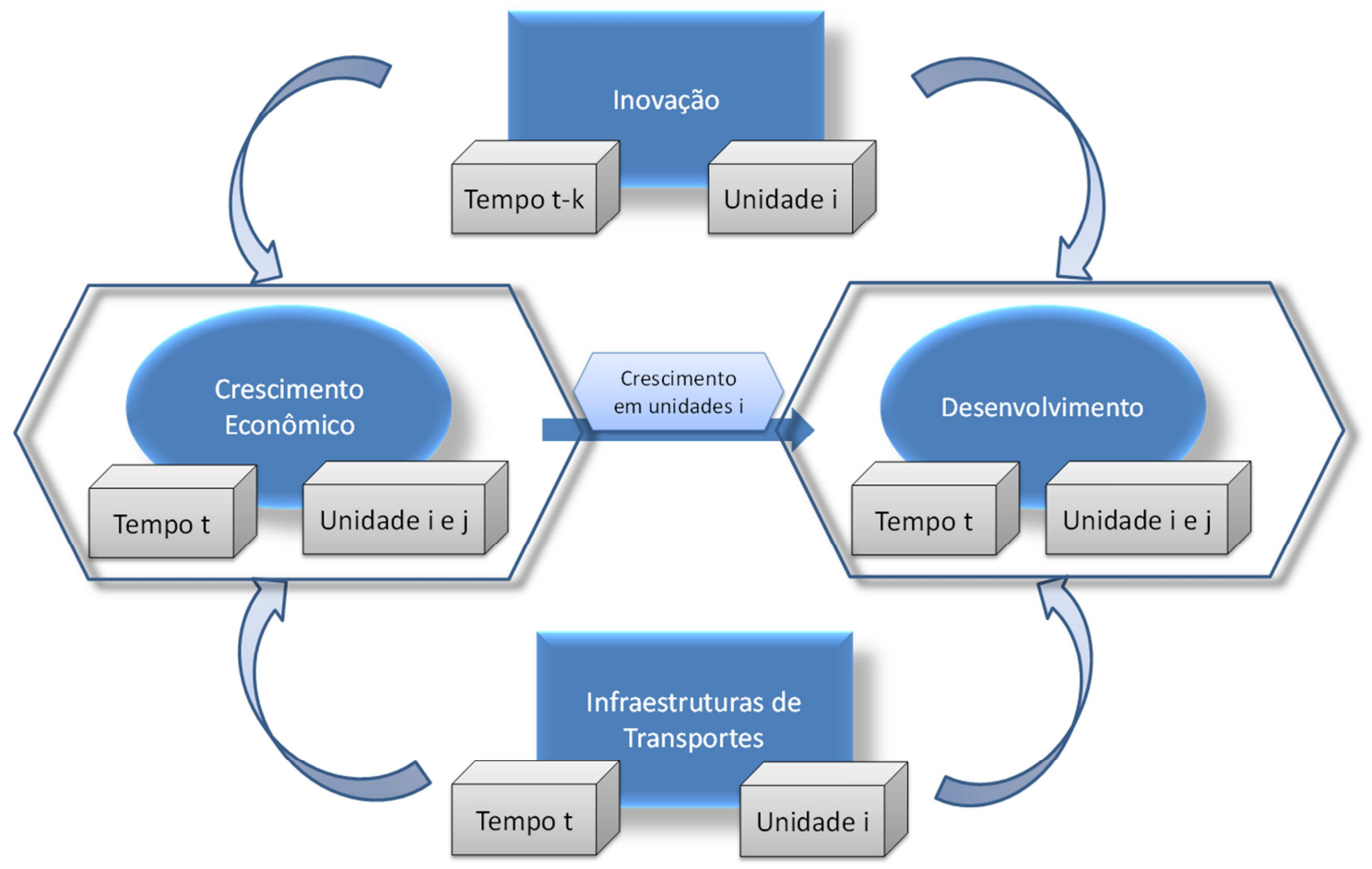

Figura 10 - Esquema de inter-relacionamento das variáveis do modelo proposto.

É importante notar na Figura 10 que não existe defasagem temporal nos relacionamentos entre crescimento, desenvolvimento, e investimentos em infraestruturas de transportes. Assim, o crescimento em uma unidade $i$, por exemplo, 
acarreta o desenvolvimento desta unidade $i$ e em suas vizinhas $j$, mas no mesmo tempo t. Portanto, este bloco do modelo é dinâmico apenas em termos espaciais.

Contudo, a fim de testar formas funcionais alternativas, respeitando o interrelacionamento observado na Figura 10, serão propostas três especificações alternativas, que exibem, também, o cômputo dos efeitos de spillover para as variáveis de controle capital e trabalho, tendo em vista o escopo Cobb-Douglas.

Ademais, será demonstrado adiante que a especificação inicial representada pela Figura 10 apresentou alguns problemas para estimação, sendo de fato, necessária a consideração de especificações alternativas.

\section{2 - MODELO A - Sem defasagem na variável de inovação}

O “MODELO A" é similar à formulação inicialmente proposta, com exceção da hipótese de defasagem temporal para a variável relativa à inovação.

$\ln C_{i t}=\rho W_{1} \ln C_{i t}+\alpha_{1} \ln K_{i t}+\alpha_{2} \ln L_{i t}+\alpha_{3} \ln I n_{i t}+\alpha_{4} \ln T_{i t}+\alpha_{5} W_{1} \ln K_{i t}+$
$\alpha_{6} W_{1} \ln L_{i t}+\alpha_{7} W_{1} \ln I n_{i t}+\alpha_{8} W_{1} \ln T_{i t}+F e_{i}+\varepsilon_{1}$

Onde,

$\varepsilon_{1}=\lambda_{1} W_{2} \varepsilon_{1}+u_{1}$

$\mathrm{E}$

$\ln D s e_{i t}=\rho W_{1} \ln D s e_{i t}+\beta_{1} \ln C_{i t}+\beta_{2} \ln K_{i t}+\beta_{3} \ln L_{i t}+\beta_{4} \ln I n_{i t}+\beta_{5} \ln T_{i t}$

$+\beta_{6} \ln E d_{i t}+\beta_{7} W_{1} \ln C_{i t}+\beta_{8} W_{1} \ln K_{i t}+\beta_{9} W_{1} \ln L_{i t}+\beta_{10} W_{1} \ln I n_{i t}+\beta_{11} W_{1} \ln T_{i t}$

$+\beta_{12} W_{1} \ln E d_{i t}+F e_{i}+\varepsilon_{2}$

Onde,

$\varepsilon_{2}=\lambda_{2} W_{2} \varepsilon_{2}+u_{2}$ 


\section{3 - MODELO B - Sem defasagem e com inércia}

Esta formulação é similar ao "MODELO A", contudo, introduz uma variável dependente temporalmente defasada na equação de crescimento do modelo, com o objetivo de captar quaisquer efeitos de inércia que porventura sejam fonte de viés de especificação em caso de omissão de tal variável.

$\ln C_{i t}=\rho W_{1} \ln C_{i t}+\alpha_{1} \ln \hat{C}_{i t-1}+\alpha_{2} \ln K_{i t}+\alpha_{3} \ln L_{i t}+\alpha_{4} \ln I n_{i t}+\alpha_{5} \ln T_{i t}$
$+\alpha_{6} W_{1} \ln K_{i t}+\alpha_{7} W_{1} \ln L_{i t}+\alpha_{8} W_{1} \ln \hat{C}_{i t-1}+\alpha_{9} W_{1} \ln I n_{i t}+\alpha_{10} W_{1} \ln T_{i t}+F e_{i}+\varepsilon_{1}$

Onde,

$\varepsilon_{1}=\lambda_{1} W_{2} \varepsilon_{1}+u_{1}$

A fim de evitar problemas decorrentes de variáveis endógenas, a equação (4.5) faz uso dos valores estimados da variável $\hat{C}_{i t-1}$, a qual é regredida em função das variáveis de $\mathrm{K}$ e L defasadas em uma unidade temporal, juntamente com a variável de consumo de cimento Portland, também defasada um ano, a fim de assegurar a confiabilidade dos valores estimados. Tal regressão prévia para o cômputo da variável instrumental é demonstrada em (4.6)

$\ln \hat{C}_{i t-1}=\phi_{1}+\phi_{2} \ln K_{i t-1}+\phi_{3} \ln L_{i t-1}+\phi_{4} \ln C p_{i t}+\mu_{i t}$

E,

$\ln D s e_{i t}=\rho W_{1} \ln D s e_{i t}+\beta_{1} \ln \hat{C}_{i t-1}+\beta_{2} \ln K_{i t}+\beta_{3} \ln L_{i t}+\beta_{4} \ln I n_{i t}+$ $\beta_{5} \ln T_{i t}+\beta_{6} \ln E d_{i t}+\beta_{7} W_{1} \ln \hat{C}_{i t-1}+\beta_{8} W_{1} \ln K_{i t}+\beta_{9} W_{1} \ln L_{i t}+$ $\beta_{10} W_{1} \ln I n_{i t}+\beta_{11} W_{1} \ln T_{i t}+\beta_{12} W_{1} \ln E d_{i t}+F e_{i}+\varepsilon_{2}$

$$
\varepsilon_{2}=\lambda_{2} W_{2} \varepsilon_{2}+u_{2}
$$




\section{4 - MODELO C - Modelo de Ulvelling \& Fletcher}

Este modelo pressupõe uma relação de interação entre a variável de inovação e as variáveis de inputs tradicionais, capital e trabalho. De fato, Ulveling e Fletcher (1970), propõem a adição de uma variável e assumem retornos variáveis de escala de acordo com o modelo (4.8).

$$
Y=A X_{1}^{B_{1}} X_{2}^{B_{2}} X_{3}^{B_{3}}
$$

Onde,

$$
B_{i}=B_{i}(I)
$$

Em que "I" é uma variável que influencia hipoteticamente retornos de escala e elasticidades parciais de produção, devendo ser escolhida caso a caso, de acordo com o problema estudado. Assim, rearranjando (4.9) com a utilização de logaritmos tem-se:

$$
\ln Y=\ln A+B_{1}(I) \ln X_{1}+B_{2}(I) \ln X_{2}+B_{3}(I) \ln X_{3}
$$

Observando-se (4.9), a diferença básica em relação o modelo Cobb-Douglas tradicional é a interação entre as variáveis "X" e "I", a qual afetará a elasticidade de produção e os retornos de escala (ULVELING e FLETCHER, 1970).

Nesses termos é possível entender a variável de inovação como um fator que modifica o impacto das elasticidades de capital e trabalho no modelo proposto que após a linearização se configura em (4.10).

$$
\begin{aligned}
& \ln C_{i t}=\rho \ln W_{1} C_{i t}+\alpha_{1} \ln K_{i t} I n_{i t}+\alpha_{2} \ln L_{i t} I n_{i t}+\alpha_{3} \ln T_{i t}+ \\
& \alpha_{4} W_{1} \ln K_{i t} I n_{i t}+\alpha_{5} W_{1} \ln L_{i t} I n_{i t}+\alpha_{6} W_{1} \ln T_{i t}+F e_{i}+\varepsilon_{1}
\end{aligned}
$$

Onde,

$$
\varepsilon_{1}=\lambda_{1} W_{2} \varepsilon_{1}+u_{1}
$$

$\mathrm{E}$, 


$$
\begin{aligned}
& \ln D s e_{i t}=\rho \ln W_{1} D s e_{i t}+\beta_{1} \ln \hat{C}_{i t}+\beta_{2} \ln K_{i t} I n_{i t}+\beta_{3} \ln L_{i t} \operatorname{In}_{i t} \\
& +\beta_{4} \ln T_{i t}+\beta_{5} \ln E d_{i t}+\beta_{6} W_{1} \ln \hat{C}_{i t}+\beta_{7} W_{1} \ln K_{i t} I n_{i t} \\
& +\beta_{8} W_{1} \ln L_{i t} I n_{i t}+\beta_{9} W_{1} \ln T_{i t}+\beta_{10} W_{1} \ln E d_{i t}+F e_{i}+\varepsilon_{1} \\
& \varepsilon_{2}=\lambda_{2} W_{2} \varepsilon_{2}+u_{2}
\end{aligned}
$$

\section{5 - Matrizes de ponderação espacial}

É interessante observar que, em todos os modelos propostos, a ordem entre as variáveis em logaritmos iteradas com a matriz de ponderação espacial, como em $W_{1} \ln X_{i t}$, possui relevância. Isso ocorre, pois, caso a matriz de ponderação possua obrigatoriamente elementos nulos, a multiplicação pela variável de interesse e consequentemente o cálculo do logaritmo não será possível, como em $\ln W_{1} X_{i t}$.

Adicionalmente, a variável $W_{1}$ utilizada nas equações representativa do inverso da distância entre as capitais das unidades federativas também apresenta seus valores transformados em logaritmos, a fim de possibilitar a interpretação dos resultados em termos de elasticidades.

Quanto à escolha das matrizes de peso, optou-se pela utilização de uma matriz de inverso da distância para o cômputo dos efeitos de spillover por dois motivos. Primeiramente, a utilização de uma matriz binária acarretou em elevado grau de singularidade na matriz de inputs, o que prejudicava a acurácia da maximização da verossimilhança no modelo completo. Em segundo lugar, as grandes distâncias e as condições de isolamento de alguns polos populacionais nas regiões norte e centro-oeste fazem com que a simples consideração da vizinhança como critério de ponderação espacial seja inadequada. 
Por exemplo, apesar de Mato Grosso e Pará serem estados vizinhos, as distâncias entre suas capitais (principais polos populacionais) é em torno de $1.778 \mathrm{~km}$, em região de difícil acesso por terra. Tal conjuntura geográfica levou a presente investigação a empregar a matriz de inverso da distância entre as capitais.

Contudo, a necessidade da utilização de duas matrizes de pesos distintas para a estimação do modelo completo (com erro e defasagem espacial) fez com que fosse necessário empregar uma segunda matriz de ponderação para a estrutura do resíduo. Em decorrência disso, foi empregada a matriz de contiguidade binária rainha para tais fins.

\section{6 - Fontes de dados}

Os dados foram coletados no período de 2004 a 2009 para as variáveis em questão, nos Anuários de Infraestrutura da Revista Exame®, IPEA DATA, e Ministério da Ciência e Tecnologia (MCT) de modo que serão consideradas as variáveis descritas a seguir.

K: Consumo Industrial de energia como proxy para estoque de capital. Fonte: Anuário Exame.

L: População economicamente ativa (PEA) representativa da variável trabalho. Fonte: IPEA DATA.

Pop: População Absoluta. Fonte: IPEA DATA.

C: Produto Interno Bruto (PIB) como Crescimento econômico (variável endógena que exige a consideração de técnicas de variáveis instrumentais). Fonte: IPEA DATA. 
Dse: Índice de FIRJAN (IFDM) como proxy de desenvolvimento. Fonte: IPEA DATA.

T: Matriz de infraestrutura de transportes, levando em conta malha rodoviária, ferroviária, portos, e aeroportos. Fonte: Anuário Exame.

In: Dispêndio em atividades de C\&T com o objetivo de promover inovação tecnológica. Fonte: Ministério da Ciência e Tecnologia (MCT).

$E d$ : variável de educação, representada pelo número de pessoas com 15 ou mais anos de estudo. Fonte: IBGE.

A variável de educação $(E d)$ foi inserida posteriormente à formulação original, como variável de controle.

De modo especial, a variável In, representativa da inovação tecnológica, considera os gastos totais com ciência e tecnologia (C\&T). Contudo, diferentemente das variáveis citadas anteriormente, as quais já se encontram diretamente detalhadas nas fontes de dados citadas, os dados relativos à $\mathrm{C} \& \mathrm{~T}$ para os estados brasileiros encontram-se fragmentados em três tipos de informação: dispêndio dos governos estaduais em C\&T, investimento do governo federal em suas instituições de ensino superior, investimento do governo federal destinado a outros órgãos de pesquisa.

Assim, para calcular os investimentos totais em C\&T bastaria apenas somar essas três informações. Contudo, somente as duas primeiras encontram-se detalhadas por estado, sendo que para a última, dispõe-se do valor total despedido na federação.

Para realizar uma aproximação satisfatória desse montante para cada estado, foi utilizado o número de pesquisadores em cada estado brasileiro, em proporção ao total. Dessa forma, fez-se um rateio do investimento do governo federal destinado a outros 
órgãos de pesquisa em relação ao percentual estadual de pesquisadores, possibilitando a composição do investimento total em C\&T.

Por fim, é necessário ainda, explanar o motivo pelo qual se utilizam dispêndios em atividades de C\&T com o objetivo de promover inovação tecnológica, como uma proxy de inovação, ao invés de utilizar o output do processo inovativo (patentes).

De fato, utilizando como base estudos como o de $\mathrm{Hu}$ e Mathews (2005), que verificam a capacidade inovativa de países do leste asiático, a utilização de patentes como proxy para a inovação para países desenvolvidos é adequada. Em especial, os autores argumentam que o estoque de patentes possui um papel preponderante na inovação.

Especialmente para países em desenvolvimento, o estoque de patentes e o gasto com P\&D determinam respectivamente 91,4 e $63,8 \%$ da capacidade inovativa, mensurada via variação de patentes. Hu e Mathews (2005) e Peilei (2011) apontam o papel indispensável do P\&D público para os estágios iniciais do desenvolvimento de economias emergentes, sendo, portanto, os governos de tais países os maiores fomentadores de inovação. Tal argumento se sustenta para o Brasil, tendo em vista que as universidades públicas brasileiras são os maiores motores de inovação nacional.

É possível também verificar que muito da inovação realizada no Brasil provém de apropriação ou adaptação de inovações de outros países, contudo, isso não significa que o Brasil, ao adaptar tecnologia externa, não dispendeu recursos em atividades de C\&T para captar tais inovações. Isso ocorre pois, como apontado por Cohen e Levinthal (1989), o investimento próprio em atividades relativas à inovação também é fundamental para a absorção de tecnologias advindas de outras localidades. Ademais, muitas invenções nacionais acabam são patenteadas pelos mais diversos motivos. 
Assim, tendo em vista que:

$1-63,8 \%$ da capacidade inovativa é determinada por dispêndios em P\&D em países desenvolvidos (OCDE);

2 - Em países em desenvolvimento o principal estimulador de inovação são os gastos públicos em atividades de C\&T, dado referências como Hu e Mathews (2005) e Peilei (2011); bem como a preponderância das universidades na determinação de tecnologias apontada por Veugelers et al. (2012).

3 - Grande parte da inovação no Brasil não ser patenteada ou estar associada a adaptação de patentes externas;

O presente estudo faz uso dos dispêndios públicos em atividades de C\&T como proxy para a inovação no Brasil, especialmente tendo em vista a grande preponderância dos investimentos governamentais em C\&T para o potencial inovativo do Brasil.

A Tabela 2 apresenta as estatísticas descritivas das variáveis a serem utilizadas. 
Tabela 2 - Estatísticas descritivas dos dados coletados

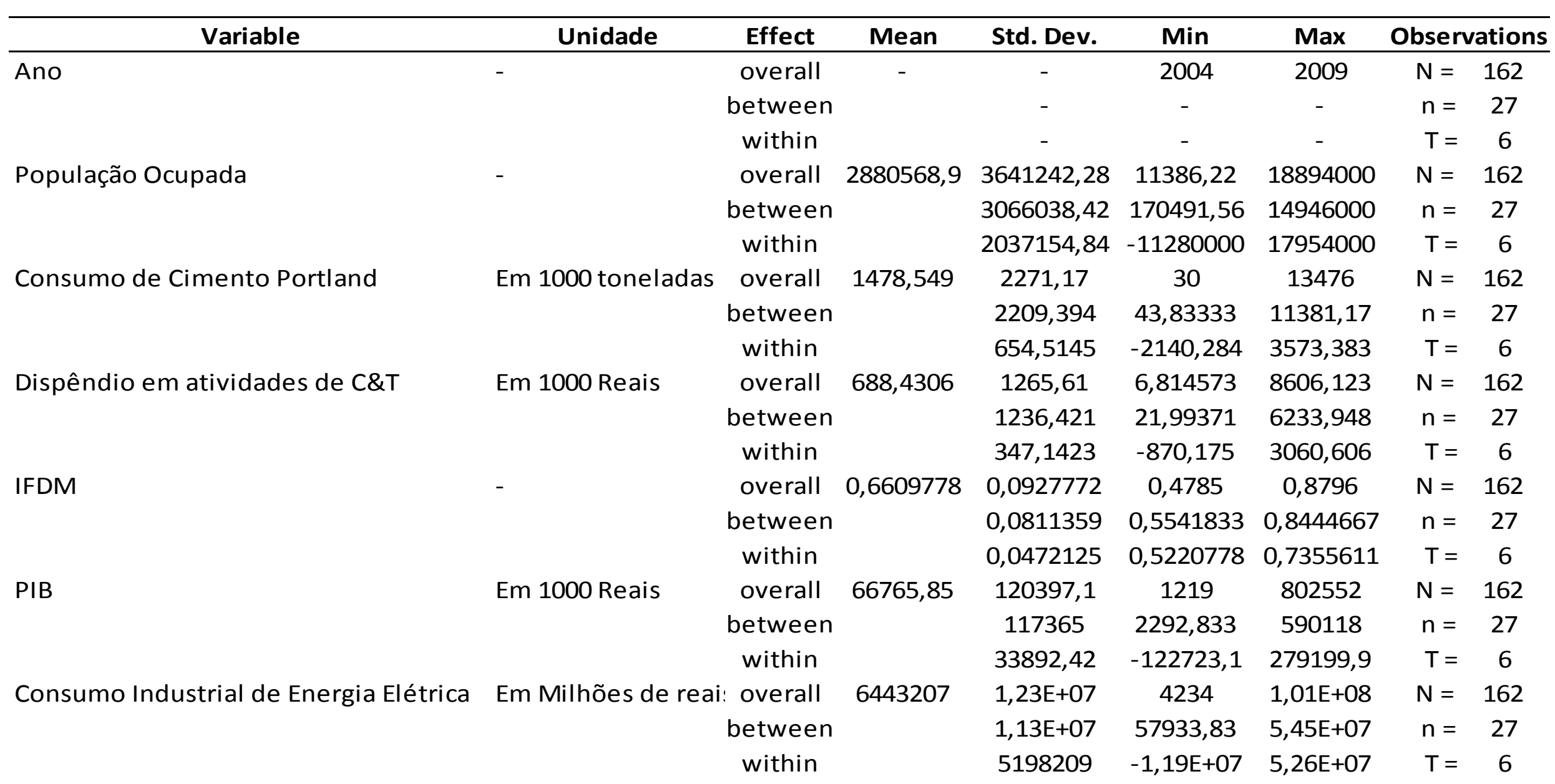


Tabela 2 (Continuação) - Estatísticas descritivas dos dados coletados

\begin{tabular}{|c|c|c|c|c|c|c|c|}
\hline Variable & Unidade & Effect & Mean & Std. Dev. & Min & Max & Observations \\
\hline Malha Ferroviária & Em quilometros & $\begin{array}{c}\text { overall } \\
\text { between } \\
\text { within }\end{array}$ & 966,3696 & $\begin{array}{l}1397,668 \\
1408,184 \\
179,1028\end{array}$ & $\begin{array}{l}1,00 E-05 \\
1,00 E-05 \\
240,9147\end{array}$ & $\begin{array}{l}6242,046 \\
5171,507 \\
2398,261\end{array}$ & $\begin{array}{cc}\mathrm{N}= & 162 \\
\mathrm{n}= & 27 \\
\mathrm{~T}= & 6\end{array}$ \\
\hline Malha Rodoviária & Em quilometros & $\begin{array}{c}\text { overall } \\
\text { between } \\
\text { within }\end{array}$ & 62822,34 & $\begin{array}{c}66110,69 \\
65982,5 \\
12334,57\end{array}$ & $\begin{array}{c}1348 \\
1659,5 \\
33473,17\end{array}$ & $\begin{array}{c}280725 \\
273576,5 \\
179295\end{array}$ & $\begin{array}{cc}\mathrm{N}= & 162 \\
\mathrm{n}= & 27 \\
\mathrm{~T}= & 6\end{array}$ \\
\hline Número de Portos & - & $\begin{array}{c}\text { overall } \\
\text { between } \\
\text { within }\end{array}$ & 2,703706 & $\begin{array}{c}2,860934 \\
2,90642 \\
0\end{array}$ & $\begin{array}{l}1,00 E-05 \\
1,00 E-05 \\
2,703706\end{array}$ & $\begin{array}{c}10 \\
10 \\
2,703706\end{array}$ & $\begin{array}{cc}\mathrm{N}= & 162 \\
\mathrm{n}= & 27 \\
\mathrm{~T} & =6\end{array}$ \\
\hline Movimento de Cargas em Portos & Em 1000 toneladas & $\begin{array}{c}\text { overall } \\
\text { between } \\
\text { within }\end{array}$ & 23,99753 & $\begin{array}{c}39,7947 \\
39,82368 \\
6,851632\end{array}$ & $\begin{array}{c}1,00 E-05 \\
1,00 E-05 \\
-5,769136\end{array}$ & $\begin{array}{c}155,2 \\
139,15 \\
57,93087\end{array}$ & $\begin{array}{cc}\mathrm{N}= & 162 \\
\mathrm{n}= & 27 \\
\mathrm{~T}= & 6\end{array}$ \\
\hline Número de Aeroportos Internacionais & - & $\begin{array}{c}\text { overall } \\
\text { between }\end{array}$ & 1,216051 & $\begin{array}{l}0,846761 \\
0,826657\end{array}$ & $\begin{array}{l}1,00 E-05 \\
1,00 E-05\end{array}$ & $\begin{array}{c}4 \\
3,166667\end{array}$ & $\begin{array}{cc}N= & 162 \\
n= & 27\end{array}$ \\
\hline Movimento de Cargas em Aeroportos & Em 1000 toneladas & $\begin{array}{c}\text { within } \\
\text { overall } \\
\text { between } \\
\text { within }\end{array}$ & 47456,55 & $\begin{array}{c}0,2342325 \\
125859,5 \\
127595,6 \\
8097,589\end{array}$ & $\begin{array}{c}0,0493842 \\
539 \\
756,8333 \\
7129,216\end{array}$ & $\begin{array}{c}2,049384 \\
697614 \\
665005,3 \\
80065,22\end{array}$ & $\begin{array}{cc}\mathrm{T}= & 6 \\
\mathrm{~N}= & 162 \\
\mathrm{n}= & 27 \\
\mathrm{~T}= & 6\end{array}$ \\
\hline Exportações & Em 1000 de reais & $\begin{array}{c}\text { overall } \\
\text { between }\end{array}$ & 5261629 & $\begin{array}{l}9361254 \\
9218179\end{array}$ & $\begin{array}{c}5780 \\
12840,67\end{array}$ & $\begin{array}{l}5,77 E+07 \\
4,45 E+07\end{array}$ & $\begin{array}{c}\mathrm{N}=162 \\
\mathrm{n}=27\end{array}$ \\
\hline Pessoas com 15 anos ou mais de estudo & Em 1000 & $\begin{array}{c}\text { within } \\
\text { overall } \\
\text { between } \\
\text { within }\end{array}$ & 1341,1111 & $\begin{array}{c}2301572 \\
1982,89222\end{array}$ & $\begin{array}{c}-8116431 \\
70\end{array}$ & $\begin{array}{l}1,84 \mathrm{E}+07 \\
1,14 \mathrm{E}+04\end{array}$ & $\begin{array}{cc}\mathrm{T}= & 6 \\
\mathrm{~N}= & 162 \\
\mathrm{n}= & 27 \\
\mathrm{~T}= & 6\end{array}$ \\
\hline
\end{tabular}


Aqui, são necessárias algumas considerações a respeito das demais variáveis utilizadas.

Primeiramente, cabe ressaltar que, para capital e trabalho, foram utilizadas variáveis diferentemente do proposto inicialmente. Dada a inexistência de dados sobre a formação bruta de capital fixo estadual (FBKF), foi utilizada a variável consumo industrial de energia elétrica como proxy.

Para a variável trabalho, havia sido proposta a população economicamente ativa (PEA); contudo, tal proxy também mostrou-se inadequada e com parâmetros opostos ao esperado. Desse modo, utilizou-se a variável população ocupada (PO), a qual retornou parâmetros com valores mais consistentes.

Quanto a variável de inovação, esta é representada pelas descentralizações estaduais e da união para atividades de C\&T com o objetivo de promover inovação, configurando-se, portanto, no input do processo de inovação.

Diferentemente das variáveis de infraestrutura de ferrovias e rodovias (mensuradas via extensão), as infraestruturas de portos e aeroportos são mensuradas em termos de variáveis proxy relativas ao movimento de cargas. Tal escolha reside no fato de que, ao utilizar simplesmente o número de portos e aeroportos em cada estado, desconsidera-se a escala e capacidade de tais infraestruturas.

Ademais, a simples utilização do número de infraestruturas para as variáveis de portos e aeroportos leva novamente à elevada colinearidade da matriz de inputs, especialmente no caso em que forem empregadas técnicas econométricas de ajuste como primeiras diferenças e demean.

Assim, a fim de remover a heterogeneidade individual do painel de dados (efeito fixo), utilizou-se a técnica de demean da amostra. 
Quanto à variável "População" presente no projeto original, esta foi retirada dos modelos a serem estimados por apresentar elevada colinearidade com a variável “Trabalho", representada pela população ocupada.

Por fim, visto que as variáveis a serem utilizadas são expressas em termos de logaritmos naturais, as observações que por ventura apresentem termos nulos, como por exemplo, movimento de cargas em portos no estado do Acre, tiveram seus valores substituídos por 0.00001 , pois a utilização de logaritmos possibilita a linearização e posterior interpretação dos coeficientes em termos de elasticidades.

\section{7 - Métodos de estimação}

O modelo proposto possui características de equações simultâneas com variáveis endógenas, dados em painel, bem como permite a existência de fatores espaciais, como a característica de erro espacial e defasagem espacial.

Contudo, dada a necessidade de controlar o modelo para efeitos específicos de dados em painel, bem como a questão de variáveis endógenas em um modelo de equações simultâneas, faz-se necessário o uso de técnicas ainda mais complexas de estimação.

Dessa forma, para estimação do modelo serão seguidos os seguintes passos.

1 - Tratamento da heterogeneidade individual do painel via rebaixamento pela média (demeaning) da amostra.

2 - Estimativa piloto da Equação 1 do modelo, a fim de verificar se a remoção da heterogeneidade individual via demean amostral é realmente a melhor, comparandoa com:

- Primeiras diferenças; 
- Adição de uma dummy para cada entidade do painel (LSDV);

- Between effects;

- Mínimos quadrados ordinários (POOLED).

3 - Verificação da extensão da defasagem da variável de inovação via critério de informação de Schwarz (BIC), em uma regressão prévia por efeitos fixos (LSDV). Mais especificamente, será utilizado um máximo de três defasagens para a variável de inovação. Tal valor decorre, primeiramente, do fato de painéis imporem naturalmente a extensão de defasagens, tendo em vista a série temporal disponível. Ademais, estudos prévios têm demonstrado que, para alguns setores da economia, a inovação tecnológica, em média, tarda dois anos para causar algum efeito no produto a nível micro ou macro (MORALLES e REBELATTO, 2012). Assim, será necessário testar o modelo com diferentes defasagens para a inovação, de modo que o melhor modelo escolhido seja aquele cuja defasagem acarreta o menor BIC.

O cálculo do BIC é dado por:

$$
B I C(p)=\ln \left(\frac{S Q R(p)}{T}\right)+(p+1) \frac{\ln T}{T}
$$

Onde,

p= Número de defasagens

$\mathrm{T}=$ Tamanho amostral

$\operatorname{SQR}(p)=$ Soma dos quadrados dos resíduos da regressão com "p" defasagens.

4 - Tratar a endogeneidade da variável $C_{i}$ (PIB estadual) via mínimos quadrados em dois estágios (MQ2E), de modo a utilizar valores estimados de $\hat{C}_{i}$. Nesse procedimento, são utilizadas as exportações anuais de cada unidade federativa como 
instrumento para explicar o crescimento econômico (PIB). Tal utilização pode ser justificada por estudos como Thornton (1997) que utilizam testes de cointegração e causalidade de Granger para demonstrar que o PIB está positivamente relacionado com exportações.

Assim, na Equação (4.2) do modelo, por exemplo, para a variável endógena $C_{i t}$, é necessário encontrar outra variável (instrumento) não correlacionada com $\varepsilon_{1}$, mas altamente correlacionada com $C_{i t}$ (WOOLDRIDGE, 2008).

Para tanto, é necessário estimar uma regressão da variável endógena em questão em função de outras variáveis exógenas que a explicam $(Z 1, Z 2, Z 3, \ldots$, Zn). Tal regressão é conhecida como forma reduzida e configura-se no primeiro estágio do método dos MQ2E. Assim, deve-se estimar, portanto, (4.12) representativa a forma reduzida de $C_{i t}$ (WOOLDRIDGE, 2008).

$$
C_{i t}=\pi_{0}+\pi_{1} Z_{1 i}+\pi_{2} Z_{2 i}+v_{2}
$$

Para que essa regressão seja válida, é necessário que os parâmetros $\pi_{k}$ sejam estatisticamente significantes (teste $t$ ), o que equivale a assumir $\pi_{k} \neq 0$. Não obstante, as variáveis exógenas devem ser não correlacionadas com a perturbação estocástica, e, portanto, $\operatorname{cov}\left(Z_{j}, \mu_{1}\right)=0($ WOOLDRIDGE, 2008). Aqui será utilizado o volume de exportações como variável exógena $Z_{i}$ para explicar o PIB, juntamente com a variável população e consumo de cimento Portland que reflete a dimensão predial da formação bruta de capital fixo.

O segundo estágio consiste em utilizar os valores estimados da variável dependente da forma reduzida $\hat{C}_{i t}$ no lugar de seus valores observados para estimar a equação (4.13). Portanto, 
$\ln D s e_{i t}=\rho W_{1} \ln D s e_{i t}+\beta_{1} \ln \hat{C}_{i t}+\beta_{2} \ln K_{i t}+\beta_{3} \ln L_{i t}+\beta_{4} \ln P o p_{i t}+$

$+\beta_{6} \ln \operatorname{In}_{i t-T}++\beta_{8} \ln T_{i t}+\beta_{5} W_{1} \ln C_{i t}+\beta_{7} W_{1} \ln \operatorname{In}_{i t-T}+\beta_{9} W_{1} \ln T_{i t}+$

$F e_{i}+\varepsilon_{2}$

Em que,

$\ln \hat{C}_{i t}=\pi_{0}+\pi_{1} \ln E x_{i t}+\pi_{2} \operatorname{Pop}_{i t}+\pi_{3} C p_{i t}+\mu_{i t}$

Onde,

$E x$ são exportações;

Pop é a quantidade de habitantes

$C p$ é o consumo aparente de cimento Portland.

Observa-se que os valores estimados obtidos no primeiro estágio servem de instrumento para $\hat{C}_{i t}$, o qual é assintóticamente não correlacionado com $\varepsilon_{1}$. Dessa forma, os estimadores serão consistentes, apesar de viesados. Eis, portanto, o preço para a obtenção de estimadores consistentes na presença de variáveis endógenas, motivo pelo qual o método dos MQ2E não é aconselhável na inexistência de variáveis endógenas (GUJARATI, 2006; WOOLDRIDGE, 2008).

Nessa etapa são utilizadas as funções de dados em painel do software STATA MP12 para computar os valores estimados $\hat{C}_{i t}$.

5 - Remoção da heteroscedasticidade via uso de logaritmos naturais, o qual também permite interpretar os coeficientes estimados em termos de elasticidades.

6 - Remoção da correlação serial da série temporal do painel via utilização de dummys temporais ou procedimento de Prais e Winsten (1954).

Aqui, realiza-se uma regressão prévia por MQO do painel das equações (4.1) e (4.2), e computam-se os resíduos estimados. Após isso, para cada equação, é realizada uma nova regressão nos moldes de (4.13). 


$$
\hat{\varepsilon}_{i t}=\alpha+\rho \hat{\varepsilon}_{i t-1}+u_{i t}
$$

Caso $\hat{\rho}$ seja estatisticamente diferente de zero via teste $t$ usual ao nível de significância de 5\%, será empregado o procedimento de Prais-Winsten (1954) para correção da autocorrelação.

7 - Construção das matrizes de ponderação espaciais para dados em painel. Nessa etapa utiliza-se o software STATA MP12, o qual possui uma rotina capaz de transformar uma matriz de ponderação cross-section em uma matriz para dados em painel (MABROUK e SAADI, 2012).

8 - Estimação dos modelos propostos com adição das variáveis que captam os efeitos de spillover via máxima verossimilhança. Modelos econométricos espaciais são usualmente estimados utilizando-se a lógica da máxima verossimilhança, como descritos em Anselin (1988), em um algoritmo iterativo semelhante ao procedimento de Cochrane-Orcutt para correlação no tempo (GUJARATI, 2006).

Nessa etapa, é interessante verificar que o método de estimação por máxima verossimilhança apesar de basear-se na função densidade de probabilidade de uma distribuição normal para calcular os scores eficientes dos parâmetros, não necessita que os dados sejam normalmente distribuídos.

Tal fato pode ser verificado pelo estudo de Kelegian e Prucha (1999), que demonstram que a estimação por máxima verossimilhança se mantém eficiente mesmo em situações em que as amostras em questão não possuem distribuição normal. Assim, não é necessária a realização de testes de normalidade como Kolmogorov-Smirnov ou Jarque-Bera para verificar a factibilidade da utilização da máxima verossimilhança na realização do presente estudo. 
9 - Verificação da existência de spillover pela significância estatística dos coeficientes das variáveis interadas com a matriz de pesos $W_{1}$; e de modo similar, a característica de erro espacial e defasagem espacial pela significância dos parâmetros $\rho$ e $\lambda$ nas equações (4.1) e (4.2).

Cabe informar que já existem programas desenvolvidos para os fins expostos, os quais deverão atuar como direcionadores. São eles os pacotes de econometria espacial para MATLAB® e STATA®, que são base para o script utilizado no presente trabalho.

De fato, tendo em vista as características do modelo proposto, o presente trabalho faz uso do software MATLAB 2009® em um toolbox organizado por Snoussi e El-Aroui (2010) para realizar a estimação dos parâmetros do modelo completo (com erro e defasagem espacial) por máxima verossimilhança, cujas variáveis que contabilizam o spillover pré-multiplicadas e com os dados já tratados tal qual fora descrito nos passos anteriores.

Aqui, salienta-se, ainda, que a estimação do modelo completo exige a utilização de duas matrizes de peso distintas, uma para a defasagem espacial, e outra para a estrutura do resíduo, a fim de evitar possíveis problemas de identificação. Nesses termos, será utilizada uma matriz de inverso da distância para a autocorrelação e contabilização do spillover, e uma matriz rainha de vizinhança binária para a estrutura do erro.

Por fim, o modelo original a ser estimado é dinâmico em termos espaciais e temporais, de modo que permite que a inovação passada de uma unidade espacial cause variação no crescimento e desenvolvimento futuro de uma unidade e suas vizinhas. Dessa forma, as matrizes de peso devem contemplar a perda de informações resultante da defasagem de variáveis. 
Desse modo, como são utilizadas duas matrizes de pesos na estimação do modelo completo e, tendo em vista a extensão de defasagem utilizada, será necessária a consideração de oito matrizes de ponderação espacial para dados em painel. 


\section{CAPÍTULO 5 - RESULTADOS E DISCUSSÕES}

A fim de verificar a existência de correlação serial AR(1) na série temporal do painel, empregou-se uma regressão prévia por MQO do painel das equações (4.1) e (4.2), e computou-se os resíduos estimados. Após isso, foram regredidos os resíduos estimados em função de seus valores defasados por meio de modelo de efeitos fixos. Tal procedimento visou, portanto, testar a existência de correlação serial $\operatorname{AR}(1)$ na série temporal do painel.

$$
\hat{\varepsilon}_{i t}=\alpha+\rho \hat{\varepsilon}_{i t-1}+u_{i t}
$$

Como $\hat{\rho}$ foi estatisticamente insignificante via teste $t$ usual, com $\mathrm{p}$-valor igual a 0,419; não foram necessárias medidas corretivas como o procedimento de PraisWinsten (1954).

Quanto à pré-estimativa da extensão da defasagem para a variável de inovação, foram realizadas quatro regressões prévias por efeitos fixos (LSDV), uma sem defasagem, e outras três, respectivamente com um, dois, e três anos de defasagem para a variável de inovação. Tal procedimento retornou o menor BIC para a regressão cuja variável de inovação possuía três anos de defasagem, denotando assim esta a melhor extensão da defasagem para o estudo.

Dessa forma, foi realizada a primeira estimativa piloto a fim de verificar a melhor forma de remoção da heterogeneidade individual do painel de dados, obtendo-se então a estimativa preliminar da Equação 1 do modelo original, exibida na Tabela 3.

Contudo, os resultados apresentados na Tabela 3 apresentam sérias inconsistências, como parâmetros com sinais contrários ao esperado, tal qual ocorre 
com o coeficiente angular da variável capital para as técnicas demean, pooled, e primeiras diferenças.

Ademais, a estimação por LSDV não foi possível. Tal fato deve-se a matriz de inputs não ser definida positiva com a adição das 27 variáveis dummy, necessária para a decomposição de Cholesky, realizada pelo programa no algoritmo de maximização.

Tais problemas provavelmente residem no fato da defasagem temporal de três anos na variável de inovação acarretar a perda de 3 observações por unidade espacial do painel. Assim, a amostra original de 162 observações $(\mathrm{N}=27$ e $\mathrm{T}=6)$, se reduz para 81 observações $(\mathrm{N}=27$ e $\mathrm{T}=3)$.

Tendo em vista tal fato, a proposição dos modelos A, B, e C os quais eliminam a questão da defasagem temporal na variável de inovação resultaria num modelo com uma estimativa mais consistente, como a conservação do tamanho amostral.

Isso é demonstrado pela nova estimação da Equação 1 do modelo original, apresentada na Tabela 4, a qual exibe agora sinais esperados e significâncias estatísticas adequadas para as variáveis de controle como capital e trabalho, especialmente para a técnica demean.

Dessa forma, os modelos $\mathrm{A}, \mathrm{B}$, e $\mathrm{C}$, que não levam em consideração a defasagem temporal na variável de inovação, foram estimados após a remoção da heterogeneidade individual pela técnica demean.

Salienta-se, portanto, que a formulação original com as defasagens temporais propostas mostra-se inviável tendo em vista extensão da série temporal disponível, de modo que a simplificação proposta nos modelos adicionais tende a retornar resultados mais factíveis. Os resultados apresentados para os modelos A, B, e C são apresentados nas Tabelas 5, 6 e 7. 
Tabela 3 - Resultados preliminares para a estimação da Equação 1 do modelo.

\section{ESTIMAÇÃO DO MODELO POR MÁXIMA VEROSSIMILHANÇA - COM DEFASAGEM EM C\&T}

\begin{tabular}{lccccccccccc}
\hline \multicolumn{1}{c}{ Variável } & \multicolumn{2}{c}{ POOLED } & \multicolumn{2}{c}{ LSDV } & \multicolumn{2}{c}{ BETWEEN EFFECTS } & \multicolumn{2}{c}{ DEMEAN } & \multicolumn{2}{c}{ PRIMEIRAS DIFERÊNÇAS } \\
\hline & Coeficiente & $\mathbf{p}$-valor & Coeficiente & $\mathbf{p}$-valor & Coeficiente & $\mathbf{p}$-valor & Coeficiente & p-valor & Coeficiente & p-valor \\
Intercepto & 0.521 & 0.685 & - & - & 0.605 & 0.011 & 0.376 & 0.487 & 0.423 & 0.034 \\
Capital & -0.006 & 0.801 & - & - & 0.010 & 0.686 & -0.031 & 0.201 & -0.010 & 0.099 \\
Trabalho & -0.037 & 0.352 & - & - & 0.053 & 0.195 & 0.034 & 0.128 & -0.016 & 0.296 \\
C\&T Lag 3 & 0.655 & 0.000 & - & - & 0.561 & 0.000 & 0.135 & 0.224 & 0.022 & 0.777 \\
Ferrovias & 0.001 & 0.948 & - & - & 0.019 & 0.002 & 0.020 & 0.406 & -0.010 & 0.923 \\
Rodovias & 0.079 & 0.037 & - & - & 0.088 & 0.022 & 0.739 & 0.096 & -0.055 & 0.082 \\
Portos & -0.045 & 0.000 & - & - & -0.067 & 0.000 & -0.013 & 0.001 & -0.012 & 0.035 \\
Aeroportos & 0.328 & 0.000 & - & - & 0.383 & 0.000 & -0.006 & 0.787 & 0.173 & 0.004 \\
W Capital & -0.469 & 0.000 & - & - & -0.345 & 0.002 & -0.440 & 0.005 & -0.087 & 0.001 \\
W Trabalho & -0.391 & 0.115 & - & - & 0.293 & 0.319 & 0.227 & 0.147 & -0.077 & 0.483 \\
W C\&T & 2.511 & 0.000 & - & - & 1.869 & 0.002 & 2.063 & 0.003 & -0.022 & 0.934 \\
W Ferrovias & -0.040 & 0.530 & - & - & 0.069 & 0.125 & 0.148 & 0.345 & -0.137 & 0.820 \\
W Rodovias & -0.122 & 0.554 & - & - & -0.111 & 0.596 & 3.901 & 0.181 & -0.402 & 0.004 \\
W Portos & -0.379 & 0.000 & - & - & -0.556 & 0.000 & -0.052 & 0.017 & -0.076 & 0.007 \\
W Aeroportos & 0.433 & 0.371 & - & - & 0.825 & 0.105 & -0.096 & 0.542 & 0.637 & 0.094 \\
Rho & -0.284 & 0.170 & - & - & -0.287 & 0.163 & -0.209 & 0.109 & -0.292 & 0.073 \\
Lambda & 0.066 & 0.095 & - & - & -0.043 & 0.356 & -0.005 & 0.909 & -0.021 & 0.562
\end{tabular}


Tabela 4 - Resultados preliminares para a estimação da Equação 1 do modelo sem defasagem na variável de inovação.

\section{ESTIMAÇÃO DO MODELO POR MÁXIMA VEROSSIMILHANÇA - SEM DEFASAGEM EM C\&T}

\begin{tabular}{lcccccccccc}
\hline \multicolumn{1}{c}{ Variável } & \multicolumn{2}{c}{ POOLED } & \multicolumn{2}{c}{ LSDV } & \multicolumn{2}{c}{ BETWEEN EFFECTS } & \multicolumn{2}{c}{ DEMEAN } & PRIMEIRAS DIFERÊNÇAS \\
\hline & Coeficiente & $\mathbf{p}$-valor & Coeficiente & $\mathbf{p}$-valor & Coeficiente & $\mathbf{p}$-valor & Coeficiente & p-valor & Coeficiente & $\mathbf{p}$-valor \\
Intercepto & 0.201 & 0.654 & 6.263 & 0.701 & -0.078 & 0.019 & 0.041 & 0.898 & 0.423 & 0.034 \\
Capital & 0.164 & 0.000 & 0.006 & 0.454 & 0.060 & 0.000 & 0.012 & 0.098 & -0.010 & 0.099 \\
Trabalho & 0.079 & 0.025 & 0.006 & 0.757 & 0.097 & 0.006 & 0.031 & 0.080 & -0.016 & 0.296 \\
C\&T & 0.050 & 0.034 & 0.273 & 0.000 & 0.394 & 0.000 & 0.227 & 0.000 & 0.022 & 0.777 \\
Ferrovias & 0.018 & 0.000 & 0.129 & 0.294 & 0.008 & 0.130 & -0.019 & 0.016 & -0.010 & 0.923 \\
Rodovias & 0.207 & 0.000 & -0.056 & 0.132 & 0.069 & 0.021 & 0.188 & 0.020 & -0.055 & 0.082 \\
Portos & 0.001 & 0.876 & -0.010 & 0.122 & -0.019 & 0.001 & -0.001 & 0.638 & -0.012 & 0.035 \\
Aeroportos & 0.438 & 0.000 & 0.134 & 0.046 & 0.487 & 0.000 & 0.020 & 0.017 & 0.173 & 0.004 \\
W*Capital & 0.036 & 0.011 & -0.083 & 0.001 & -0.061 & 0.015 & -0.035 & 0.000 & -0.087 & 0.001 \\
W*Trabalho & -0.064 & 0.002 & -0.120 & 0.371 & 0.244 & 0.216 & 0.104 & 0.385 & -0.077 & 0.483 \\
W*C\&T & 0.028 & 0.028 & 0.437 & 0.002 & 0.370 & 0.003 & 0.071 & 0.153 & -0.022 & 0.934 \\
W*Ferrovias & 0.002 & 0.325 & 0.481 & 0.523 & 0.002 & 0.954 & -0.124 & 0.007 & -0.137 & 0.820 \\
W*Rodovias & 0.005 & 0.857 & -0.461 & 0.002 & -0.130 & 0.349 & 0.751 & 0.070 & -0.402 & 0.004 \\
W*Portos & 0.003 & 0.554 & -0.020 & 0.476 & -0.226 & 0.000 & -0.008 & 0.300 & -0.076 & 0.007 \\
W*Aeroportos & 0.023 & 0.306 & 0.710 & 0.075 & 1.731 & 0.000 & 0.137 & 0.008 & 0.637 & 0.094 \\
rho & 1.600 & 0.016 & 5.310 & 0.000 & -0.284 & 0.018 & 0.082 & 0.133 & -0.292 & 0.073 \\
lambda & 0.156 & 0.000 & 5.353 & 0.000 & 0.068 & 0.011 & -0.002 & 0.954 & -0.021 & 0.562
\end{tabular}




VARIÁVEL DEPENDENTE
PIBhat
Consumo Industrial Eletricidade
População Ocupada
Inovação
Exten rodovias
Ferrovias
Movimento de cargas em portos
Movimento de cargas aeroportos
Educação
W PIBhat
W Consumo Industrial Eletricidade
W População Ocupada
W Inovação
W Exten rodovias
W Ferrovias
W Movimento de cargas em
portos
W Movimento de cargas
aeroportos
W Educação
Rho
Lambda

\section{EQUAÇÃO 1}

PIB

Coeficiente Asymptot t-stat p-valor Significante?

$\begin{array}{ccc}- & - & - \\ 0.012 & 1.641 & 0.098 \\ 0.031 & 1.758 & 0.080 \\ 0.227 & 4.541 & 0.000 \\ 0.188 & 2.333 & 0.020 \\ -0.019 & -2.435 & 0.016 \\ -0.001 & -0.471 & 0.638 \\ 0.020 & 2.415 & 0.017 \\ - & - & - \\ - & - & - \\ -0.035 & -3.732 & 0.000 \\ 0.104 & 0.879 & 0.385 \\ 0.071 & 1.462 & 0.153 \\ 0.751 & 1.834 & 0.070 \\ -0.124 & -2.723 & 0.007 \\ -0.008 & -1.049 & 0.300 \\ 0.137 & & \\ - & 2.681 & 0.008 \\ 0.082 & - & - \\ -0.002 & 1.433 & 0.133 \\ & -0.059 & 0.954\end{array}$

\section{EQUAÇÃO 2}

IFDM

Coefficient Asymptot t-stat p-valor Significante?

$\begin{array}{llll}-0.022 & -1.138 & 0.255 & \\ 0.006 & 1.861 & 0.063 & \text { Sim } \\ 0.005 & 0.902 & 0.367 & \\ -0.009 & -0.564 & 0.573 & \\ 0.188 & 5.551 & 0.000 & \text { Sim } \\ 0.006 & 2.159 & 0.031 & \text { Sim } \\ 0.001 & 1.289 & 0.198 & \\ -0.006 & -2.232 & 0.026 & \text { Sim } \\ 0.077 & 1.399 & 0.162 & \\ 0.042 & 0.421 & 0.674 & \\ -0.022 & -5.048 & 0.000 & \text { Sim } \\ 0.044 & 1.110 & 0.267 & \\ -0.250 & -4.390 & 0.000 & \text { Sim } \\ 1.103 & 5.363 & 0.000 & \text { Sim } \\ 0.039 & 2.441 & 0.015 & \text { Sim } \\ & & & \\ 0.006 & 1.835 & 0.066 & \text { Sim } \\ -0.043 & -2.413 & 0.016 & \text { Sim } \\ 0.814 & 3.107 & 0.002 & \text { Sim } \\ -0.242 & -2.160 & 0.031 & \text { Sim } \\ 0.086 & 3.437 & 0.001 & \text { Sim }\end{array}$




\section{EQUAÇÃO 1}

\section{PIB}

\section{VARIÁVEL DEPENDENTE}

\section{PIBhat_Lag1}

Consumo Industrial de eletricidade

População Ocupada

Inovação_Lag1

Extensão das Rodovias

Extensão de Ferrovias

Movimento de cargas em portos

Movimento de cargas em aeroportos

\section{Educação}

W PIBhat

W Consumo Industrial de eletricidade

W População Ocupada

W Inovação_Lag1

W Extensão das Rodovias

W Extensão de Ferrovias

W Movimento de cargas em portos

W Movimento de cargas em

aeroportos

W Educação

Rho

Lambda

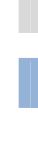

\section{Coeficiente}

0.171

0.011

0.021

0.249

0.213

$-0.019$

$-0.003$

0.024

-

$-0.055$

0.099

0.197

0.557

$-0.158$

$-0.016$

0.183

$-0.067$

0.025

Asymptot t-

\section{stat}

1.655

1.405

1.038

3.612

1.641

$-2.264$

$-1.152$

2.609

$-$

$-3.301$

0.710

2.337

0.750

$-3.219$

$-1.238$

3.251

$-0.678$

0.757 p-valor Significante?

\section{Coe}

Coefficient Asymptot t-stat

$-0.007$

0.004

0.013

$-0.021$

$-0.003$

0.067

0.000

0.003

0.085

$-0.013$

$-0.004$

0.106

$-0.163$

$-0.022$

0.390

0.001

0.022

0.558

$-0.289$

0.067

0.498

0.449

\section{EQUAÇÃO 2}

\section{IFDM}

$\begin{array}{ccc}-0.283 & 0.777 & \\ 1.477 & 0.140 & \\ 2.596 & 0.009 & \text { Sim } \\ -1.146 & 0.252 & \\ -1.133 & 0.257 & \\ 1.617 & 0.106 & \\ 0.619 & 0.536 & \\ 0.954 & 0.340 & \\ 1.554 & 0.120 & \\ -0.145 & 0.885 & \\ -1.033 & 0.301 & \\ 3.055 & 0.002 & \operatorname{Sim} \\ -2.211 & 0.027 & \operatorname{Sim} \\ -1.242 & 0.214 & \\ 1.519 & 0.129 & \\ 0.392 & 0.695 & \\ & & \\ 1.205 & 0.228 & \\ 2.303 & 0.021 & \operatorname{Sim} \\ -1.556 & 0.120 & \\ 2.126 & 0.033 & \operatorname{Sim}\end{array}$




\section{EQUAÇÃO 1}

\section{VARIÁVEL DEPENDENTE}

\section{PIBhat}

$\mathrm{K} * \ln$

L*In

Extensão das Rodovias

Extensão de Ferrovias

Movimento de cargas em portos

Movimento de cargas em aeroportos

\section{Educação}

W PIBhat

$W K^{*} \operatorname{In}$

$W L^{*} \ln$

W Extensão das Rodovias

W Extensão de Ferrovias

W Movimento de cargas em portos

W Movimento de cargas em

aeroportos

W Educação

Rho

Lambda
PIB

\section{Coeficiente Asymptot t-stat p-valor Significante?}

$\begin{array}{cccc}- & - & - & - \\ 0.050 & 2.048 & 0.041 & \text { Sim } \\ 0.035 & 0.798 & 0.425 & \\ -0.001 & -0.203 & 0.839 & \\ 0.161 & 2.605 & 0.009 & \text { Sim } \\ 0.000 & -0.180 & 0.858 & \\ 0.001 & 0.156 & 0.876 & \\ - & - & - & - \\ - & - & - & - \\ -0.024 & -0.890 & 0.373 & \\ 0.081 & 0.280 & 0.779 & \\ -0.002 & -0.055 & 0.956 & \\ 0.473 & 2.151 & 0.031 & \text { Sim } \\ -0.003 & -0.266 & 0.790 & \\ & & & \\ 0.002 & 0.042 & 0.967 & \\ - & - & - & - \\ 0.249 & 18.564 & 0.000 & \text { Sim } \\ 0.046 & 1.574 & 0.116 & \end{array}$

\section{EQUAÇÃO 2}

\section{IFDM}

\section{Coefficient Asymptot t-stat p-valor Significante?}

$\begin{array}{lccc}0.014 & 0.969 & 0.333 & \\ -0.003 & -0.453 & 0.650 & \\ 0.005 & 0.413 & 0.680 & \\ 0.000 & -0.188 & 0.851 & \\ 0.089 & 2.857 & 0.004 & \text { Sim } \\ 0.001 & 2.398 & 0.017 & \text { Sim } \\ 0.000 & 0.021 & 0.983 & \\ 0.050 & 1.155 & 0.248 & \\ 0.077 & 0.825 & 0.409 & \\ -0.007 & -1.177 & 0.239 & \\ -0.029 & -0.392 & 0.695 & \\ 0.005 & 0.350 & 0.727 & \\ 0.406 & 2.142 & 0.032 & \text { Sim } \\ 0.007 & 2.329 & 0.020 & \text { Sim } \\ -0.002 & -0.099 & 0.921 & \\ -0.111 & -0.887 & 0.375 & \\ 0.174 & 3.580 & 0.000 & \text { Sim } \\ -0.288 & -1.072 & 0.284 & \end{array}$


Observando-se as Tabelas 5, 6 e 7, referentes aos MODELOS A, B, e C; primeiramente é verificável que o MODELO C apresenta problemas funcionais como sinais avessos ao esperado e insignificância estatística de variáveis como $K^{*} \operatorname{In}$. Tal fato provavelmente decorre de alta multicolinearidade entre as variáveis iteradas com a variável de inovação, $K^{*} \operatorname{In}$ e $L^{*} \operatorname{In}$. De modo que tal modelo apresenta sérios problemas no que tange a interpretação e previsão.

Assim sendo, o MODELO C é descartado para os fins do presente trabalho, restando, portanto, os MODELOS A e B, cuja escolha do adequado é realizada novamente via BIC tal qual exibido em (5.2).

$$
B I C=1+\ln 2 \pi+\ln \left(\frac{S Q R}{T}\right)+\frac{k \ln T}{T}
$$

Tal formulação retornou os resultados exibidos na Tabela 8.

Tabela 8 - Critérios de informação para os MODELOS A e B.

\begin{tabular}{ccc} 
MODELO & EQUAÇÃO & BIC \\
\hline \multirow{3}{*}{ MODELO A } & Equação 1 & 3,34028 \\
& Equação 2 & 3,46330 \\
MODELO B & Equação 1 & 3,45402 \\
& Equação 2 & 3,54083 \\
\hline
\end{tabular}

Observa-se, portanto, pela Tabela 8, que para as Equações 1 e 2, os melhores critérios de informação de Schwarz se referem ao MODELO A, o qual demonstra-se portanto, o mais aderente à realidade pesquisada. 


\section{1 - Comentários a respeito dos resultados obtidos no MODELO A.}

Com a escolha do modelo mais adequado via BIC, é possível substituir os parâmetros estimados no modelo apresentado anteriormente, obtendo-se (5.3) e (5.4), lembrando que nem todas as variáveis são estatisticamente significantes.

$\ln C_{i t}=0.082 W_{1} \ln C_{i t}+0,012 \ln K_{i t}+0.031 \ln L_{i t}+0.227 \ln I_{i t}+0.188 \ln R_{i t}$ $-0.019 R r_{i t}-0.001 \ln P_{i t}+0.020 \ln A p_{i t}-0.035 W_{1} \ln K_{i t}+0.104 W_{1} \ln L_{i t}$ $+0.071 W_{1} \ln I n_{i t}+0.751 W_{1} \ln R_{i t}-0.124 W_{1} \ln R r_{i t}$

$-0.008 W_{1} \ln P_{i t}+0.137 W_{1} \ln A p_{i t}+\varepsilon_{1}$

Onde,

$\varepsilon_{1}=-0.002 W_{2} \varepsilon_{1}+u_{1}$

$\mathrm{E}$

$\ln D s e_{i t}=-0.242 W_{1} \ln D s e_{i t}-0.022 \ln C_{i t}+0.006 \ln K_{i t}+0.005 \ln L_{i t}$

$-0.009 \ln I n_{i t}+0.188 \ln R_{i t}+0.006 \ln R r_{i t}+0.001 \ln P_{i t}$

$-0.006 \ln A p_{i t}+0.077 \ln E d_{i t}+0.042 W_{1} \ln C_{i t}$

$-0.022 W_{1} \ln K_{i t}+0.044 W_{1} \ln L_{i t}-0.250 W_{1} \ln I n_{i t}$

$+1.103 W_{1} \ln R_{i t}+0.039 W_{1} \ln R r_{i t}+0.006 W_{1} \ln P_{i t}$

$-0.043 W_{1} \ln A p_{i t}+0.814 W_{1} \ln E d_{i t}+\varepsilon_{2}$

Onde,

$\varepsilon_{2}=0.086 W_{2} \varepsilon_{2}+u_{2}$

Observando-se os resultados obtidos para ambas as equações do modelo, é notável a baixa elasticidade das variáveis de controle capital e trabalho, resultado discrepante dos valores encontrados na literatura, especialmente no que tange a produção e crescimento econômico.

A título de exemplo, tais resultados equivalem à afirmação de que, para a Equação 1 do modelo, que explica o crescimento econômico, mensurado pelo PIB, um 
aumento de $1 \%$ no estoque de capital, eleva em 0,012\% o PIB nacional, e uma elevação de $1 \%$ na força de trabalho acarreta uma elevação de $0,031 \%$ no PIB.

Salienta-se que vários testes foram realizados a fim de validar a veracidade de tais resultados, como a realização de regressões auxiliares que incluíram variáveis e modificações nas formas funcionais, a fim de verificar a existência de viés de especificação ou autocorrelação serial induzida por má especificação funcional.

Os outros modelos considerados levam em conta algumas dessas possibilidades, como, por exemplo, a existência de efeitos de inércia para a explicação do crescimento econômico, denotada por variável explicativa defasada, como ocorre no MODELO B.

Ademais, alternativas foram exploradas, como a adição da variável educação na Equação 1, a consideração de diferentes matrizes de ponderação espacial, a utilização de diferentes formas de dados, o deflacionamento das séries temporais do PIB, e por fim, uma regressão não-espacial auxiliar do modelo proposto. Em todos os casos, as elasticidades das variáveis de capital e trabalho mantiveram-se no mesmo patamar.

Assim, uma explicação razoável para tal panorama pode encontrar fundamentação na Teoria das Restrições $\left(\mathrm{TOC}^{7}\right)$, que verifica as organizações com a analogia de uma corrente, cuja resistência e função dependem principalmente do elo mais fraco, que é a restrição.

Em linhas gerais, a TOC usa a lógica fundamental para identificar as principais relações responsáveis pela performance de uma organização. A TOC considera a empresa (ou para este estudo, uma unidade federativa) como uma cadeia de componentes inter-relacionados ou subsistemas (CHOU et al., 2011).

Nesse sentido, a TOC possui algumas premissas como:

\footnotetext{
${ }^{7}$ Do ingles, theory of constraints.
} 
- Cada sistema da empresa (ou unidade federativa) possui uma série de condições que devem ser satisfeitas para que se atinja o objetivo.

- A performance total é mais do que a simples soma da performance dos componentes.

- Apenas alguns fatores de restrição limitam a performance do sistema em um dado momento.

De fato, tendo em vista a natureza da produção cada vez mais dependente da tecnologia, bem como a grande participação do setor de serviços na economia brasileira, é possível inferir que exista uma restrição de natureza tecnológica para o crescimento econômico, de modo que somente a transposição de tal restrição é capaz de promover o crescimento econômico, ao invés do simples incremento de fatores de produção como capital e trabalho.

Recentemente, autores como Tseng (2009) tem argumentado que na economia do conhecimento, a inovação tem se mostrado mais importante que fatores de produção tradicionais como terra, capital físico, e trabalho, sendo, portanto, o fator primordial a afetar o crescimento e desenvolvimento.

Ademais, modelos econométricos consideram as variações entre as variáveis para mensurar o impacto e a significância entre elas, de modo que estes modelos desconsideram o estoque de inputs. Isso significa que variáveis como a de dispêndio com capital tenham seu impacto verdadeiro negligenciado, visto que se avalia apenas a variação desta, enquanto o estoque histórico de capital impacta a produção proporcionalmente mais do que a simples variação anual do capital físico.

Quanto às outras variáveis da Equação 1, primeiramente observa-se a elevada e significante elasticidade da variável de inovação (da ordem de 0,227), superior aos 
inputs tradicionais como capital e trabalho. Tal resultado denota a importância dos investimentos em inovação tecnológica com o objetivo de gerar crescimento econômico.

Já com respeito às infraestruturas de transportes próprias, observou-se um efeito positivo e significante das rodovias (0.188) e um efeito negativo e significante de ferrovias. Para infraestrutura portuária os resultados apontam insignificância para o crescimento econômico; contudo, a infraestrutura de aeroportos teve efeito positivo e significante, da ordem de 0,020 em média, para os estados brasileiros.

Agora, com relação aos efeitos de spillover, verificaram-se estatisticamente significantes as variáveis capital (-0.035), rodovias (0.751), ferrovias $(-0,124)$, e aeroportos $(0,137)$.

Tais resultados conduzem para as considerações seguintes:

Um aumento de $1 \%$ na extensão da malha rodoviária de um estado acarreta um incremento de $0,188 \%$ em seu PIB, e um impacto de $0.751 \%$ no PIB de seus vizinhos em média para o Brasil.

Tal fato se deve provavelmente ao fato das infraestruturas vizinhas se configurarem em uma restrição ao escoamento da produção de uma unidade espacial. Assim sendo, as infraestruturas rodoviárias vizinhas podem configurar condição sine qua non para o crescimento econômico estadual brasileiro.

Um aumento de $1 \%$ nos dispêndios com finalidade de inovação de um estado acarreta um incremento de $0,227 \%$ em seu PIB, tendo em vista valores médios para o Brasil, contudo, não causa impacto em seus vizinhos.

De modo semelhante, um aumento de $1 \%$ no capital físico de um estado acarreta um incremento de $0,012 \%$ em seu PIB, tendo em vista valores médios para o Brasil, 
contudo, causa uma diminuição no PIB de seus vizinhos da ordem de $-0.035 \%$. Resultado que se deve provavelmente a efeitos de concorrência.

Quanto à Equação 2, relacionada ao desenvolvimento sócio-econômico, denotado pelo índice IFDM, é possível verificar a significância estatística da maioria das variáveis utilizadas.

Contudo, diferentemente do que ocorre na Equação 1 do modelo, a variável de inovação não é significante, denotando que, para o Brasil, tais investimentos não tem ocasionado melhorias nas esferas sociais do desenvolvimento, visto que o índice IFDM contempla a aferição de educação, saúde, emprego e renda.

Contudo, no que tange às infraestruturas de transporte próprias foram computados efeitos positivos para as infraestruturas rodoviárias $(0,188)$ e ferroviárias $(0,006)$, sendo esta última de menor magnitude. Contudo, o movimento de cargas em aeroportos registrou um efeito significante e negativo para o desenvolvimento sócioeconômico $(-0,006)$.

Já para os efeitos de spillover, houve significância para todas as variáveis consideradas, com exceção da população ocupada. Foi apurado efeito negativo para a elasticidade da variável de capital $(-0,022)$, denotando, como ocorrera para a equação de crescimento econômico, efeito de concorrência. Isso equivale a dizer que o incremento marginal de $1 \%$ de capital em um estado reduz em média, $0,022 \%$ o bem estar social de seus vizinhos.

Da mesma forma, houve um efeito negativo para a variável de inovação, denotando que o incremento da inovação de um estado reduz o bem estar social de seus vizinhos na ordem de -0.250 . 
Ainda com relação à spillovers negativos, o mesmo ocorre para a infraestrutura de transporte de aeroportos, que obteve o parâmetro estimado de (-0.043).

Já para os spillovers positivos, é interessante salientar a elasticidade da variável de rodovias, onde um aumento de $1 \%$ na infraestrutura de transporte estadual ocasiona um efeito médio de $1,103 \%$ no bem estar social de seus vizinhos. Para ferrovias e portos esse efeito é da ordem de $(0,039)$ e $(0,006)$ respectivamente.

Novamente, tal qual a infraestrutura própria, os spillovers para os vizinhos associados ao transporte aeroportuário de um estado possui efeitos negativos.

Por fim, quanto à existência de efeitos espaciais como defasagem e erro espacial, ambas estão fortemente presentes na Equação 2. Em especial, é interessante notar o valor obtido para o termo de dependência espacial $-0.242 W_{1} \ln D s e_{i t}$ de tal equação, onde é possível verificar que o aumento de $1 \%$ no desenvolvimento sócio-econômico (IFDM) de um estado, ocasiona em média para o Brasil, uma diminuição de $-0,242 \%$ no IFDM de seus vizinhos.

Já para a Equação 1 do modelo, os efeitos espaciais não foram significantes ao nível usual de $10 \%$, contudo, para o termo de dependência espacial $0.082 W_{1} \ln C_{i t}$, o pvalor calculado foi de 0,133 ; sendo portanto, sua desconsideração arriscada, no sentido de causar um viés de especificação. Nesse sentido, a interpretação deste termo segue a lógica de que um incremento de $1 \%$ no crescimento de uma unidade estadual ocasiona um crescimento da ordem de $0,082 \%$ em seus vizinhos.

É notável, portanto, que o efeito de dependência espacial é positiva para o crescimento econômico, mas negativa para a esfera social. 


\section{2 - Comparação dos resultados de spillovers espaciais obtidos com outros estudos relevantes publicados recentemente.}

Aqui, é realizada uma comparação dos spillovers espaciais de estudos internacionais consultados em relação às elasticidades obtidas, em especial no que diz respeito às infraestruturas de transportes e o crescimento econômico. Para as outras relações analisadas pelo presente estudo, não foram encontrados, até o presente momento, estudos semelhantes que calculassem as elasticidades de efeitos espaciais, entre, por exemplo, desenvolvimento e inovação.

Estudos como o de Autant-Bernard e LeSage (2010) desenvolveram uma função de produção de conhecimento, mensurando o output inovativo como patentes em função dos inputs P\&D público e privado em um modelo econométrico espacial. Contudo, tendo em vista a divergência de variáveis dependentes, não é possível comparar as elasticidades obtidas; a comparação dos resultados obtidos se dá apenas no que tange à infraestruturas e crescimento econômico.

O presente estudo encontrou elasticidades significantes para infraestruturas de transportes próprias para o PIB da ordem de 0,188 para rodovias, -0,019 para ferrovias, e 0,020 para aeroportos; e quanto às insignificâncias, $-0,001$ para portos.

Com relação aos efeitos significantes de spillovers de infraestruturas de transportes vizinhas para o PIB de uma unidade espacial são da ordem de 0,751 para rodovias, $-0,124$ para ferrovias, e 0,137 para a infraestrutura de aeroportos; e quanto às insignificâncias, $-0,008$ para portos.

Uma síntese dos resultados encontrados é exibida na Tabela 9. 
Tabela 9 - Resultados encontrados em outros estudos relevantes.

\begin{tabular}{|c|c|c|}
\hline & & \\
Autor & País & Tipo de Infraestrutura \\
\hline$\underline{\text { (Hu e Liu, 2010) }}$ & China & Transportes em geral \\
\hline$\underline{\text { (Zhang, 2011) }}$ & China & Aeroportuário \\
\hline$\underline{(\text { Zhang, 2008) }}$ & China & Transportes em geral \\
\hline$\underline{\text { (Cohen e Monaco, 2009) }}$ & USA & Portos \\
\hline
\end{tabular}

\begin{tabular}{|c|c|c|c|}
\hline \multicolumn{4}{|c|}{ Elasticidades } \\
\hline \multirow{2}{*}{$\begin{array}{l}\text { Infraestruturas } \\
\text { próprias - Estudos }\end{array}$} & $\begin{array}{l}\text { Infraestruturas } \\
\text { Próprias - Obtidos }\end{array}$ & $\begin{array}{l}\text { Infraestruturas } \\
\text { vizinhas - Estudos }\end{array}$ & $\begin{array}{l}\text { Infraestruturas } \\
\text { vizinhas - Obtidos }\end{array}$ \\
\hline $0,220 \%$ & $0,189 \%^{* *}$ & $0,060 \%$ & $0,764 \%^{* *}$ \\
\hline $0,910 \%$ & $0,02 \%$ & - & - \\
\hline- & - & $0,028 \%$ & $0,764 \% * *$ \\
\hline $0,49 \% *$ & $-0,001 \% *$ & $0,220 \%$ & $-0,008 \% *$ \\
\hline$n n n n$
\end{tabular}

* Elasticidade estatisticamente insignificante

** Impacto somado das infraestruturas significantes obtidas. Ex.: 0,188\%-0,019\%+0,020\%=0,189\% 
Comparando os resultados por autor, em Hu e Liu (2010), para as estruturas próprias, foram obtidas elasticidades semelhantes, considerando-se o somatório das elasticidades de cada infraestrutura individual estatisticamente significante obtida no presente estudo. Contudo, para os efeitos de spillover de vizinhança, houve grande discrepância nos resultados, pois, enquanto Hu e Liu (2010) obtêm elasticidades de 0,06; os resultados obtidos apontaram para um valor de 0,764, em grande parte composto pelo elevado impacto de rodovias, da ordem de 0,751 .

Para o estudo do efeito das infraestruturas aeroportuárias próprias para o PIB realizado por Zhang (2011), há uma enorme disparidade entre os resultados obtidos pelo autor $(0,91)$ e aqueles encontrados no presente estudo $(0,02)$. Tais elevados resultados obtidos pelo autor em questão podem se dever em parte a viés de especificação tendo em vista a omissão de variáveis relevantes, fazendo que naquele estudo, a variável de infraestrutura aeroportuária absorvesse os efeitos de outras variáveis omitidas, fato recorrente em alguns artigos consultados.

Já para Zhang (2008), os resultados para spillovers infraestruturas de transportes de vizinhas são semelhantes aos resultados de Hu e Liu (2011), obtendo um valor de 0,028 de elasticidade para o impacto de infraestruturas vizinhas no PIB de uma dada unidade espacial. Tal valor novamente é, em termos absolutos, discrepante com aqueles encontrados no presente estudo.

Por fim, Cohen e Monaco (2009) que estudam a influência da infraestrutura portuária para o volume de comércio varejista na Califórnia encontram elasticidades insignificantes para infraestrutura própria, mas significantes para as vizinhas. $\mathrm{O}$ autor argumenta que tais resultados são devido ao fato dos comerciantes varejistas acondicionarem seus armazéns e centros de distribuição em estados com proximidade de portos, mas não contendo portos efetivamente, devido a custos menores nesses 
estados. Tais resultados se mostram semelhantes aos obtidos no presente estudo no que tange à insignificância para a infraestrutura portuária própria. Contudo, diferentemente de Cohen e Monaco (2009) que encontram elasticidade significante de 0,22; o presente estudo não obteve um resultado estatisticamente significante para a infraestrutura portuária vizinha. Portanto, uma unidade espacial vizinha a outra com infraestrutura portuária não obtém nenhum efeito de spillover em seu PIB. 


\section{CAPÍTULO 6 - CONCLUSÃO}

Este trabalho buscou explorar, validar, e quantificar a relação entre as principais variáveis relativas ao crescimento econômico (mensurado via PIB) e o desenvolvimento (mensurado via IFDM), no Brasil, em um contexto espacial.

A escolha das variáveis explicativas é calcada no fato destas figurarem entre os principais entraves para o crescimento econômico e desenvolvimento social das economias emergentes. Especialmente, a infraestrutura de transportes no que tange às facilidades econômicas e bem estar social que propicia; bem como a inovação, cada vez mais preponderante no cenário econômico atual, determinando cada vez mais a competitividade e geração de atividade econômica das nações.

A utilização de modelos espaciais é relativamente nova, sendo escassos estudos nacionais que levam em conta as interações geográficas no estudo de interações econômicas, demonstrando assim, a contribuição do trabalho para o conhecimento das relações econômicas e sociais entre os estados brasileiros, tendo em vista sua disposição territorial, de forma a levar em conta efeitos de dependência espacial e spillovers.

Ainda, este estudo é um dos poucos a utilizar dados em painel em um modelo espacial, área também relativamente nova na literatura e com escassez de referências. Unindo-se isso a questão do modelo com variáveis endógenas explicativas, spillovers, e a utilização de um modelo completo (com defasagem e erro espacial) é possível verificar a abordagem mais completa proposta pelo presente trabalho, bem como seu esforço para considerar tais características nas estimativas.

Ademais, a escolha do conjunto de variáveis explicativas, além de refletirem os fatores de maior preponderância para o desenvolvimento nacional, também exibem 
natureza de confiabilidade econométrica, tendo em vista evitar a omissão de importantes variáveis no modelo. Muitos estudos consultados utilizavam a lógica Cobb-Douglas, mas omitiam variáveis importantes, de forma a viesar os resultados obtidos, como relacionar o PIB apenas em função de infraestruturas de transportes, fazendo com que as infraestruturas absorvam o impacto de outras variáveis relevantes e, portanto, distorcendo o impacto real das infraestruturas em questão.

Outros estudos colocavam variáveis de controle, contudo não exibiam ou informavam a natureza de tais variáveis. Assim, o presente trabalho apresenta um panorama mais completo e confiável para a estimação do modelo proposto.

O modelo estimado retornou uma série de valores para as variáveis em questão, demonstrando sua existência ou não, bem como a ocorrência e intensidade de efeitos de spillover espaciais advindos de vizinhança em média para o Brasil.

Alguns resultados, porém, chamaram mais atenção, como por exemplo, a baixa elasticidade dos inputs de capital e trabalho próprios em ambas as equações do modelo, o que denotaria a necessidade de maiores investigações a respeito dos métodos de estimação ou do real impacto de tais variáveis para a realidade nacional, especialmente tendo em vista a elevada elasticidade encontrada para a variável de inovação da equação do PIB.

Assim, talvez seja necessário rever a importância dos inputs tradicionais como capital e trabalho para a determinação do PIB, em detrimento da cada vez mais preponderante influência de inputs relativos à inovação.

Ainda, para ambas as equações, foi encontrado um efeito de spillover negativo da variável de capital, denotando um efeito de concorrência. Isso equivale à afirmação 
de que em média para o Brasil, um incremento marginal de capital de um estado acarreta uma diminuição no PIB e no desenvolvimento estadual de seus vizinhos.

Outro resultado que merece atenção é a existência de spillovers de inovação negativos para o desenvolvimento, denotando que talvez a característica de geração de atividade econômica da inovação cause intensificação de investimentos públicos sociais (construção de escolas e hospitais, por exemplo) nessas unidades inovadoras em detrimento de suas vizinhas.

Quanto às infraestruturas de transportes, a malha rodoviária foi, como esperado, a infraestrutura com maior elasticidade para crescimento e desenvolvimento, tanto para infraestruturas próprias, quanto para os efeitos de spillover. Tais resultados refletem a decisão histórica e a importância dessa infraestrutura para a organização sócioeconômica brasileira, apesar de outras formas de transportes possuírem vantagens amplamente conhecidas. Assim, os resultados negativos para as infraestruturas de ferrovias, portanto, podem ter fundamentados na deterioração de tal infraestrutura, bem como sua subutilização em detrimento das rodovias. Portanto, a infraestrutura ferroviária não deve ser desconsiderada como alternativa para os transportes no Brasil.

Quanto aos efeitos espaciais, houve a ocorrência de erro espacial positivo e defasagem espacial negativa para a equação de desenvolvimento, esta última, denotando que o desenvolvimento social de uma unidade federativa acarreta em depreciação do desenvolvimento de suas vizinhas.

Já para a equação de crescimento econômico, ambos os efeitos de erro e defasagem espacial foram insignificantes. Contudo, a defasagem espacial retornou um p-valor de 0,133 ; o qual apesar de insignificante aos padrões tradicionais de $10 \%$, não deve ser negligenciado, denotando, portanto que o incremento do PIB de uma região impacta o crescimento de suas vizinhas. 
Tais resultados, aparentemente, exibem a existência de uma distinção entre a esfera econômica e de bem estar social, pelo fato de uma variável ou efeitos de vizinhança serem capazes de afetar tais esferas de forma diametralmente distintas.

Estudos futuros poderiam explorar mais os métodos numéricos envolvidos na maximização da função de verossimilhança, bem como utilizar outras formas funcionais, distintas das testadas no presente trabalho.

Ainda, é possível a consideração de outras matrizes de ponderação espacial ou o uso de variáveis proxy diferentes das utilizadas no presente trabalho para refletir as variáveis de capital e trabalho.

De qualquer maneira, são necessários mais estudos econométricos espaciais sobre crescimento econômico e desenvolvimento para apoiar os resultados obtidos, no que diz respeito a existência da relação real dos spillovers estatisticamente significantes, e as elasticidades estimadas. 


\section{REFERÊNCIAS}

AIYAR, S.; DALGAARD, C.-J. Accounting for productivity: Is it OK to assume that the world is Cobb-Douglas? Journal of Macroeconomics, v. 31, n. 2, p. 290-303, 2009. ISSN 0164-0704. Disponível em: http://www.sciencedirect.com/science/article/pii/S0164070408000645 >.

AMBE, N. The Development Theory of Transportation Infrastructure Examined in the Context of Central and West Africa. The Review of Black Political Economy, v. 36, n. 3, p. 227-243, 2009. Disponível em: < http://ideas.repec.org/a/spr/blkpoe/v36y2009i3p227-243.html >.

ANSELIN, L. Estimation methods for spatial autoregressive structures. 1980. (Ph.D.). Program in Urban and Regional Studies, Cornell University, Ithaca, N.Y.

. Spatial econometrics methods and models

Dordrecht: 1988 .

Spatial Econometrics. Bruton Center 1999.

ARROW, K. J. The Economic Implications of Learning by Doing. The Review of Economic Studies, v. 29, n. 3, p. 155-173, June 1, 1962 1962. Disponível em: < http://restud.oxfordjournals.org/content/29/3/155.short $>$.

AUTANT-BERNARD, C.; GUIRONNET, J.-P.; MASSARD, N. Agglomeration and social return to R\&D: Evidence from French plant productivity changes. International Journal of Production Economics, v. 132, n. 1, p. 34-42, 2011. Disponível em: < http://ideas.repec.org/a/eee/proeco/v132y2011i1p34-42.html >.

AUTANT-BERNARD, C.; LESAGE, J. P. QUANTIFYING KNOWLEDGE SPILLOVERS USING SPATIAL ECONOMETRIC MODELS. Journal of Regional Science, p. no-no, ISSN 1467-9787. Disponível em: < http://dx.doi.org/10.1111/j.1467-9787.2010.00705.x >.

\section{QUANTIFYING KNOWLEDGE SPILLOVERS USING SPATIAL} ECONOMETRIC MODELS. Journal of Regional Science, v. 51, n. 3, p. 471-496, 2011. ISSN 1467-9787. Disponível em: < http://dx.doi.org/10.1111/j.14679787.2010.00705.x $>$.

AZARIADIS, C.; DRAZEN, A. Threshold externalities in economic development. Quarterly Journal of Economics, v. 105, n. 2, p. 501-526, 1990. Disponível em: < http://www.scopus.com/inward/record.url?eid=2-s2.0-

0025587012\&partnerID=40\&md5=ac4a038e8906bd6e92b42cfe92367e6e $>$. 
AZARIADIS, C.; DRAZEN, A. Threshold Externalities in Economic Development. The Quarterly Journal of Economics, v. 105, n. 2, p. 501-526, 1990. ISSN 00335533. Disponível em: 〈http://www.jstor.org/stable/2937797 >.

BALTAGI, B. H.; GRIFFIN, J. M. Pooled estimators vs. their heterogeneous counterparts in the context of dynamic demand for gasoline. Journal of Econometrics, v. 77, n. 2, p. 303-327, 1997 . Disponível em: < http://ideas.repec.org/a/eee/econom/v77y1997i2p303-327.html >.

BAUM, J. A. C. Social benefits of road transport. 1998. University of Cologne, mimeo paper.

BAUM, J. A. C.; CAlABRESE, T.; SILVERMAN, B. S. Don't go it alone: alliance network composition and startups' performance in Canadian biotechnology. Strategic Management Journal, v. 21, n. 3, p. 267-294, 2000. ISSN 1097-0266. Disponível em: $<\quad$ http://dx.doi.org/10.1002/(SICI) 1097-0266(200003)21:3<267::AID-

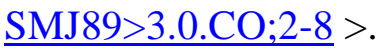

BECK, T.; LEVINE, R.; LOAYZA, N. Finance and the sources of growth. Journal of Financial Economics, v. 58, n. 1-2, p. 261-300, 2000. Disponível em: < http://ideas.repec.org/a/eee/jfinec/v58y2000i1-2p261-300.html >.

BEER, C.; RIEDL, A. Modelling spatial externalities in panel data: The Spatial Durbin model revisited*. Papers in Regional Science, p. no-no, 2011. ISSN 1435-5957. Disponível em: < http://dx.doi.org/10.1111/j.1435-5957.2011.00394.x >.

BENJAMIN, C. Influences and conflicts of federal policies in academic-industrial scientific collaboration. The Journal of Technology Transfer, v. 36, n. 5, p. 514-545, 2011. Disponível em: < http://ideas.repec.org/a/kap/jtecht/v36y2011i5p514-545.html >.

BERECHMAN, J. Urban and regional economic impacts of transportation investment: A critical assessment and proposed methodology. Transportation Research Part A: Policy and Practice, v. 28, n. 4, p. 351-362, 1994. Disponível em: < http://ideas.repec.org/a/eee/transa/v28y1994i4p351-362.html >.

BITZER, J.; GEISHECKER, I.; GÖRG, H. Productivity spillovers through vertical linkages: Evidence from 17 OECD countries. Economics Letters, v. 99, n. 2, p. 328331, 2008. ISSN 0165-1765. Disponível em: < http://www.sciencedirect.com/science/article/pii/S0165176507002844 >.

BLACK, S. E.; LYNCH, L. M. How to Compete: The Impact of Workplace Practices and Information Technology on Productivity. The Review of Economics and Statistics, v. 83, n. 3, p. 434-445, 2001. ISSN 00346535. Disponível em: < http://www.jstor.org/stable/3211544 >.

BODSON, P.; PEETERS, D. Estimation of the coefficients of a linear regression in the presence of spatial autocorrelation. An application to a Belgian labour-demand function. Environment and Planning A, v. 7, n. 4, p. 455-472, 1975. Disponível em: < http://www.envplan.com/abstract.cgi?id=a070455 >. 
BORJAS, G. J. Ethnicity, Neighborhoods, and Human-Capital Externalities. The American Economic Review, v. 85, n. 3, p. 365-390, 1995. ISSN 00028282. Disponível em: < http://www.jstor.org/stable/2118179 >.

BOTTAZZI, L.; PERI, G. Innovation and spillovers in regions: Evidence from European patent data. European Economic Review, v. 47, n. 4, p. 687-710, 2003. Disponível em: < http://ideas.repec.org/a/eee/eecrev/v47y2003i4p687-710.html >.

BRASINGTON, D. M.; HITE, D. Demand for environmental quality: a spatial hedonic analysis. Regional Science and Urban Economics, v. 35, n. 1, p. 57-82, 2005. Disponível em: < http://ideas.repec.org/a/eee/regeco/v35y2005i1p57-82.html >.

BURRIDGE, P. Testing for a common factor in a spatial autoregression model. Environment and Planning A, v. 13, n. 7, p. 795-800, 1981. Disponível em: < http://ideas.repec.org/a/pio/envira/v13y1981i7p795-800.html >.

CALLIGARIS, A. B.; TORKOMIAN, A. L. V. Benefícios do desenvolvimento de projetos de inovação tecnológica. Produção, v. 13, p. 21-32, 2003. ISSN 0103-6513. Disponível em: < http://www.scielo.br/scielo.php?script=sci_arttext\&pid=S0103$\underline{65132003000200003 \& n r m=i s o}>$.

CAMERON, A. C. T., PRAVIN K. . Microeconometrics Using Stata Texas: Stata Press, 2009.

CASE, A. Neighborhood influence and technological change. Regional Science and Urban Economics, v. 22, n. 3, p. 491-508, 1992. Disponível em: < http://ideas.repec.org/a/eee/regeco/v22y1992i3p491-508.html >.

CHIANG, A. C. Matemática para economistas. Rio de Janeiro: Editora Campus, 2006.

CHIARA DEL, B.; MASSIMO, F.; GIANCARLO, M. Regional Infrastructure and Convergence: Growth Implications in a Spatial Framework. Transition Studies Review, v. 17, n. 3, p. 475-493, 2010. Disponível em: < http://ideas.repec.org/a/spr/trstrv/v17y2010i3p475-493.html >.

CHOU, Y.-C.; LU, C.-H.; TANG, Y.-Y. Identifying inventory problems in the aerospace industry using the theory of constraints. International Journal of Production Research, v. 50, n. 16, p. 4686-4698, 2012/08/15 2011. ISSN 0020-7543. Disponível em: < http://dx.doi.org/10.1080/00207543.2011.631598 >. Acesso em: 2012/10/17.

CHRISTOPOULOS, D. K.; TSIONAS, E. G. Financial development and economic growth: evidence from panel unit root and cointegration tests. Journal of Development Economics, v. 73, n. 1, p. 55-74, 2004. Disponível em: < http://ideas.repec.org/a/eee/deveco/v73y2004i1p55-74.html >.

CLIFF, A. D. O., J. K. . Spatial autocorrelation. London: Pion. 1973. Disponível em: < http://phg.sagepub.com/content/19/2/245.short >. 
COCHRANE, D.; ORCUTT, G. H. Application of Least Squares Regression to Relationships Containing Auto- Correlated Error Terms. Journal of the American Statistical Association, v. 44, n. 245, p. 32-61, 1949. ISSN 01621459. Disponível em: $<$ http://www.jstor.org/stable/2280349 $>$.

COHEN, J.; MONACO, K. Inter-county spillovers in California's ports and roads infrastructure: the impact on retail trade. Letters in Spatial and Resource Sciences, v. 2, n. 2, p. 77-84, 2009. ISSN 1864-4031. Disponível em: < http://dx.doi.org/10.1007/s12076-009-0025-9 >.

COHEN, W. M.; LEVINTHAL, D. A. Innovation and Learning: The Two Faces of R\&D. Economic Journal, v. 99, n. 397, p. 569-96, 1989. Disponível em: < http://ideas.repec.org/a/ecj/econjl/v99y1989i397p569-96.html >.

CONLEY, T. G.; TOPA, G. Socio-Economic Distance and Spatial Patterns in Unemployment. Journal of Applied Econometrics, v. 17, n. 4, p. 303-327, 2002. ISSN 08837252. Disponível em: < http://www.jstor.org/stable/4129255 >.

CONNIFFE, D. Covariance Analysis and Seemingly Unrelated Regressions. The American Statistician, v. 36, n. 3, p. 169-171, 1982. ISSN 00031305. Disponível em: $<$ http://www.jstor.org/stable/2683170 $>$.

CRACOLICI, M.; CUFFARO, M.; NIJKAMP, P. The Measurement of Economic, Social and Environmental Performance of Countries: A Novel Approach. Social Indicators Research, v. 95, n. 2, p. 339-356, 2009. ISSN 0303-8300. Disponível em: < http://dx.doi.org/10.1007/s11205-009-9464-3 >.

The Measurement of Economic, Social and Environmental Performance of Countries: A Novel Approach. Social Indicators Research, v. 95, n. 2, p. 339-356, 2010 .

Disponível em: http://EconPapers.repec.org/RePEc:spr:soinre:v:95:y:2010:i:2:p:339-356 >.

CROOKES, P. I. China's new development model: Analysing Chinese prospects in technology innovation. China Information, v. 26, n. 2, p. 167-184, July 1, 20122012. Disponível em: < http://cin.sagepub.com/content/26/2/167.abstract $>$.

DACEY, M. A review of measures of contiguity for two and k-color maps

Evanston, Ill. : Dept. of Geography, Northwestern University, 1968.

DASGUPTA, P.; WEALE, M. On measuring the quality of life. World Development, v. 20, n. $1, \quad$ p. 119-131, 1992. Disponível em: < http://ideas.repec.org/a/eee/wdevel/v20y1992i1p119-131.html >.

DAVIDSON, R. M., JAMES G. . Econometric Theory and Methods. New York: Oxford University Press 2004.

DE FARIA, P.; LIMA, F.; SANTOS, R. Cooperation in innovation activities: The importance of partners. Research Policy, v. 39, n. 8, p. 1082-1092, 2010. ISSN 00487333. 
DIAMOND, P. A. National Debt in a Neoclassical Growth Model. American Economic Review, v. 55, n. 5, p. 1126-1150, 1965.

DOLL, J. P. On Exact Multicollinearity and the Estimation of the Cobb-Douglas Production Function. American Journal of Agricultural Economics, v. 56, n. 3, p. 556-563, 1974. ISSN 00029092. Disponível em: < http://www.jstor.org/stable/1238608 $>$.

DOWRICK, S.; TANI, M. International business visits and the technology frontier. Economics Letters, v. 110, n. 3, p. 209-212, 2011. ISSN 0165-1765. Disponível em: < http://www.sciencedirect.com/science/article/pii/S0165176510003964 >.

DREWES, T. Regional Wage Spillover in Canada. The Review of Economics and Statistics, v. 69, n. 2, p. 224-231, 1987. ISSN 00346535. Disponível em: < http://www.jstor.org/stable/1927229 >.

DURBIN, J. Estimation of Parameters in Time-Series Regression Models. Journal of the Royal Statistical Society. Series B (Methodological), v. 22, n. 1, p. 139-153, 1960. ISSN 00359246. Disponível em: < http://www.jstor.org/stable/2983884 >.

DURLAUF, S. N. Spillovers, stratification, and inequality. European Economic Review, v. 38, n. 3-4, p. 836-845, 1994. ISSN 0014-2921. Disponível em: < http://www.sciencedirect.com/science/article/pii/0014292194901201 >.

ELHORST, J. P. Specification and Estimation of Spatial Panel Data Models. International Regional Science Review, v. 26, n. 3, p. 244-268, July 1, 20032003. Disponível em: < http://irx.sagepub.com/content/26/3/244.abstract $>$.

EMBRAPA. Política de P\&D. Brasília, DF, p.39p. 1999

ERTUR, C.; KOCH, W. Growth, technological interdependence and spatial externalities: theory and evidence. Journal of Applied Econometrics, v. 22, n. 6, p. 1033-1062, 2007. ISSN 1099-1255. Disponível em: < http://dx.doi.org/10.1002/jae.963 $>$.

FAGERBERG, J. A technology gap approach to why growth rates differ. Research Policy, v. 16, n. 2-4, p. 87-99, 1987. Disponível em: < http://ideas.repec.org/a/eee/respol/v16y1987i2-4p87-99.html >.

FIRJAN. Índice FIRJAN de Desenvolvimento Municipal (IFDM). http://www.firjan.org.br/IFDM/, $2012 . \quad$ Disponível em: < http://www.firjan.org.br/IFDM/ >. Acesso em: 01/09/2012.

FURMAN, J. L.; PORTER, M. E.; STERN, S. The determinants of national innovative capacity. Research Policy, v. 31, n. 6, p. 899-933, 2002. Disponível em: < http://ideas.repec.org/a/eee/respol/v31 y2002i6p899-933.html >.

GARTNER, I. R.; ZWICKER, R.; RÖDDER, W. Investimentos em tecnologia da informação e impactos na produtividade empresarial: uma análise empírica à luz do 
paradoxo da produtividade. Revista de Administração Contemporânea, v. 13, p. 391409, 2009. ISSN 1415-6555. Disponível em: < http://www.scielo.br/scielo.php?script=sci_arttext\&pid=S1415$\underline{65552009000300004 \& \text { nrm }=\text { iso }}>$.

GATRELL, A. C. Autocorrelation in spaces. Environment and Planning A, v. 11, n. 5, p. 507-516, 1979. Disponível em: < http://www.envplan.com/abstract.cgi?id=a110507 >.

GITTELMAN, M. National institutions, public-private knowledge flows, and innovation performance: A comparative study of the biotechnology industry in the US and France. Research Policy, v. 35, n. 7, p. 1052-1068, 2006. Disponível em: < http://ideas.repec.org/a/eee/respol/v35y2006i7p1052-1068.html >.

GLAESER, E. L.; SACERDOTE, B.; SCHEINKMAN, J. A. Crime and Social Interactions. The Quarterly Journal of Economics, v. 111, n. 2, p. 507-48, 1996. Disponível em: < http://ideas.repec.org/a/tpr/qjecon/v111y1996i2p507-48.html >.

GOODWIN, P. P., S. Assessing the Benefits of Transport. OECD Publishing, 2001. Disponível em: </content/book/9789282112847-en http://dx.doi.org/10.1787/9789282112847-en >.

GOTO, A.; SUZUKI, K. R\&D Capital, Rate of Return on R\&D Investment and Spillover of R\&D in Japanese Manufacturing Industries. The Review of Economics and Statistics, v. 71, n. 4, p. 555-64, 1989. Disponível em: < http://ideas.repec.org/a/tpr/restat/v71y1989i4p555-64.html >.

GREENE, W. H. Econometric Analysis. New York: Prentice Hall, 2002.

GREENWOOD, J.; SMITH, B. D. Financial markets in development, and the development of financial markets. Journal of Economic Dynamics and Control, v. 21, n. 1, p. 145-181, $1997 . \quad$ Disponível em: < http://ideas.repec.org/a/eee/dyncon/v21y1997i1p145-181.html >.

GRIFFITH, D. A.; PERES-NETO, P. R. Spatial Modeling in Ecology: The Flexibility of Eigenfunction Spatial Analyses. Ecology, v. 87, n. 10, p. 2603-2613, 2006. ISSN 00129658. Disponível em: < http://www.jstor.org/stable/20069270 >.

GRILICHES, Z. Production Functions in Manufacturing: Some Additional Results. Southern Economic Journal, v. 35, n. 2, p. 151-156, 1968. ISSN 00384038. Disponível em: < http://www.jstor.org/stable/1056324 >.

Sibling Models and Data in Economics: Beginnings of a Survey. The Journal of Political Economy, v. 87, n. 5, p. S37-S64, 1979. ISSN 00223808. Disponível em: < http://www.jstor.org/stable/1829908 >.

The Search for R\&D Spillovers. The Scandinavian Journal of Economics, v. 94, n. ArticleType: primary_article / Issue Title: Supplement. Proceedings of a Symposium on Productivity Concepts and Measurement Problems: Welfare, Quality and Productivity in the Service Industries / Full publication date: 1992 / Copyright (C) 
1992 The Scandinavian Journal of Economics, p. S29-S47, 1992. ISSN 03470520. Disponível em: < http://www.jstor.org/stable/3440244 >.

GUJARATI, D. N. ECONOMETRIA BASICA. CAMPUS, 2006. ISBN 9788535216646. Disponível em:

http://books.google.com.br/books?id=YxwW4gMGv5AC >.

H. C XU., J. L., Y. YANG. Relationship between highway transportation and economic development in China. Journal of Chang'an University (Social Sciences Edition), v. 9, n. 2, p. 8-13, 2007.

HALL, J. L.; HOWELL-MORONEY, M. E. Poverty, Innovation Capacity, and State Economic Development in the Knowledge Economy: Evidence from the U.S. Growth and Change, v. 43, n. 2, p. 228-251, 2012. ISSN 1468-2257. Disponível em: < http://dx.doi.org/10.1111/j.1468-2257.2012.00584.x >.

HILL, C. G., W.; JUDGE, G. . Econometria. São Paulo: Saraiva, 2003.

HOWELLS, J. Innovation and regional economic development: A matter of perspective? Research Policy, v. 34, n. 8, p. 1220-1234, 2005. Disponível em: < http://www.scopus.com/inward/record.url?eid=2-s2.0-

24344437220\&partnerID=40\&md5=7920d7b605a0a39ea868eb68cb98b9a2 $>$.

HSIAO, C. Analysis of Panel Data. Cambridge: Cambridge University Press, 1990.

HU, A.; LIU, S. Transportation, economic growth and spillover effects: The conclusion based on the spatial econometric model. Frontiers of Economics in China, v. 5, n. 2, p. 169-186, 2010. Disponível em: < http://www.scopus.com/inward/record.url?eid=2$\underline{\text { s2 } .0-77952823841 \& p a r t n e r I D=40 \& m d 5=a d 0 e 267708 d 67 a 11421 \mathrm{c} 0 \mathrm{dc} 08 \mathrm{fbf} 0016}>$.

JAFFE, A. B. Technological Opportunity and Spillovers of R\&D: Evidence from Firms' Patents, Profits, and Market Value. American Economic Review, v. 76, n. 5, p. 9841001, 1986. Disponível em: < http://ideas.repec.org/a/aea/aecrev/v76y1986i5p984$\underline{1001 . h t m l}>$.

JENSEN, J.; MENEZES-FILHO, N.; SBRAGIA, R. Os determinantes dos gastos em P\&D no Brasil: uma análise com dados em painel. Estudos Econômicos (São Paulo), v. 34, p. 661-691, 2004. ISSN 0101-4161. Disponível em: < http://www.scielo.br/scielo.php?script=sci_arttext\&pid=S0101$\underline{41612004000400002 \& n r m=i s o}$ >.

KAISER, U. Measuring knowledge spillovers in manufacturing and services: an empirical assessment of alternative approaches. Research Policy, v. 31, n. 1, p. 125144, 2002. Disponível em: < http://ideas.repec.org/a/eee/respol/v31y2002i1p125144.html >.

KANG, K.-N.; PARK, H. Influence of government R\&amp;D support and inter-firm collaborations on innovation in Korean biotechnology SMEs. Technovation, n. 0, ISSN 0166-4972. Disponível em:

http://www.sciencedirect.com/science/article/pii/S0166497211001234 >. 
Influence of government R\&D support and inter-firm collaborations on innovation in Korean biotechnology SMEs. Technovation, 2011. ISSN 01664972. Disponível em: < http://dx.doi.org/10.1016/j.technovation.2011.08.004 >.

KELEJIAN, H. H.; ROBINSON, D. P. INFRASTRUCTURE PRODUCTIVITY ESTIMATION AND ITS UNDERLYING ECONOMETRIC SPECIFICATIONS: A SENSITIVITY ANALYSIS. Papers in Regional Science, v. 76, n. 1, p. 115-131, 1997. ISSN 1435-5957. Disponível em: < http://dx.doi.org/10.1111/j.14355597.1997.tb00684.x >.

KHASNABIS, S. et al. Mechanisms for transportation infrastructure investment in developing countries. Journal of Urban Planning and Development, v. 136, n. 1, p. 94-103, 2010. Disponível em: < http://www.scopus.com/inward/record.url?eid=2-s2.077950646664\&partnerID=40\&md5=b15467f2061dd69e62774b0959732851 >.

LAUMAS, P. S. Schumpeter's Theory of Economic Development and Underdeveloped Countries. The Quarterly Journal of Economics, v. 76, n. 4, p. 653-659, 1962. ISSN 00335533. Disponível em: < http://www.jstor.org/stable/1879552 >.

LESAGE, J.; DOMINGUEZ, M. The importance of modeling spatial spillovers in public choice analysis. Public Choice, v. 150, n. 3, p. 525-545, 2012. ISSN 00485829. Disponível em: 〈 http://dx.doi.org/10.1007/s11127-010-9714-6 >.

LESAGE, J. P.; PACE, R. K. Introduction to spatial econometrics. CRC Press, 2009. ISBN 9781420064247. Disponível em: < http://books.google.com.br/books?id=EKiKXcgL-D4C >.

LEVIN, R. C. Appropriability, R\&D Spending, and Technological Performance. The American Economic Review, v. 78, n. 2, p. 424-428, 1988. ISSN 00028282. Disponível em: < http://www.jstor.org/stable/1818162 >.

LEVINE, R. Financial Development and Economic Growth: Views and Agenda. Journal of Economic Literature, v. 35, n. 2, p. 688-726, 1997. Disponível em: < http://www.scopus.com/inward/record.url?eid=2-s2.0-

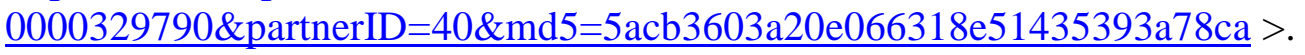

LEWISON, G. The scientific output of the EC's less favoured regions. Scientometrics, v. 21, n. 3, p. 383-402, 1991/07/01 1991. ISSN 0138-9130. Disponível em: < http://dx.doi.org/10.1007/BF02093977 >.

LIU, H.-L.; LIN, H.-Y.; PENG, S.-K. The spillover effects of R\&D on manufacturing industry in Taiwan's metropolitan areas. The Annals of Regional Science, v. 45, n. 3, p. 519-546, 2010. ISSN 0570-1864. Disponível em: < http://dx.doi.org/10.1007/s00168-009-0309-4 >.

LUCAS, R., JR. On the mechanics of economic development. Journal of Monetary Economics, v. 22, n. 1, p. 3-42, 1988. Disponível em: < http://ideas.repec.org/a/eee/moneco/v22y1988i1p3-42.html >. 
LYNNE, G. Z.; MICHAEL, R. D.; JEFF, S. A. Commercializing knowledge: university science, knowledge capture and firm performance in biotechnology. Proceedings, $n$. Sep, p. 149-170, 2003. Disponível em: < http://ideas.repec.org/a/fip/feddpr/y2003isepp149-170.html >.

MABROUK, S.; SAADI, S. Parametric Value-at-Risk analysis: Evidence from stock indices. Quarterly Review of Economics and Finance, 2012. Disponível em: < http://www.scopus.com/inward/record.url?eid=2-s2.0$\underline{84861436632 \& \text { partnerID }=40 \& \mathrm{md} 5=\mathrm{f} 6584 \mathrm{f} 20 \mathrm{c} 09 \mathrm{c} 8 \mathrm{dc} 02 \mathrm{fcf} 35847 \mathrm{fe} 7 \mathrm{c} 936}$ >.

MANKIW, N. G.; ROMER, D.; WEIL, D. N. A Contribution to the Empirics of Economic Growth. The Quarterly Journal of Economics, v. 107, n. 2, p. 407-37, 1992. Disponível em: < http://ideas.repec.org/a/tpr/qjecon/v107y1992i2p407-37.html $>$.

MEFFORD, R. N. INTRODUCING MANAGEMENT INTO THE PRODUCTION FUNCTION. Review of Economics and Statistics, v. 68, n. 1, p. 96-104, 1986. ISSN 0034-6535. Disponível em: < <Go to ISI>://WOS:A1986A579400012 >.

MEYER, D. S.; WHITTIER, N. Social Movement Spillover. Social Problems, v. 41, n. 2, p. 277-298, 1994. ISSN 00377791. Disponível em: < http://www.jstor.org/stable/3096934 >.

MONTORO-SÁNCHEZ, A. O.-D.-U.-C., MARTA; MORA-VALENTÍN, EVA M. . Effects of knowledge spillovers on innovation and collaboration in science and technology parks. Journal of Knowledge Management, v. 15, n. 6, p. 948 - 970, 2011.

MORAlleS, H. F.; REBELATTO, D. A. N. Modelling Cobb-Douglas Production Function with Non-Traditional Time Lagged Inputs. The Empirical Economics Letters, v. 11, n. 4, 2012. ISSN 1681- 8997

MORAN, P. A. P. The Interpretation of Statistical Maps. Journal of the Royal Statistical Society. Series B (Methodological), v. 10, n. 2, p. 243-251, 1948. ISSN 00359246. Disponível em: 〈 http://www.jstor.org/stable/2983777 >.

MUNDLAK, Y. Empirical Production Function Free of Management Bias. Journal of Farm Economics, v. 43, n. 1, p. 44-56, 1961. ISSN 10711031. Disponível em: < http://www.jstor.org/stable/1235460 >.

NASSIF, A. The structure and competitiveness of the Brazilian capital goods industry. CEPAL Review v. 96, 2008.

NAUDÉ, W.; GRIES, T. Explaining regional export performance in a developing country: The role of geography and relative factor endowments. Regional Studies, $v$. 43, n. 7, p. 967-979, 2009. Disponível em: < http://www.scopus.com/inward/record.url?eid=2-s2.0-

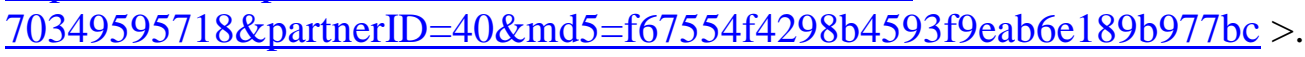


$\mathrm{NJOH}$, A. J. Impact of transportation infrastructure on development in east africa and the indian ocean region. Journal of Urban Planning and Development, v. 138, n. 1, p. 1-9, 2012. Disponível em: < http://www.scopus.com/inward/record.url?eid=2-s2.0-

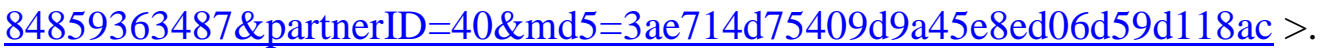

O'MAHONY, M.; VECCHI, M. R\&D, knowledge spillovers and company productivity performance. Research Policy, v. 38, n. 1, p. 35-44, 2009. Disponível em: < http://ideas.repec.org/a/eee/respol/v38y2009i1p35-44.html >.

OCDE. OSLO Manual - Guidelines for Collecting and Interpreting Technological Innovation Data. Organisation for Economic Co-Operation and Development OECD: Statistical Office of the European Communities - Eurostat. Paris. 2005

OCDE, M. F.-. Manual de Frascati 2002 Proposta de Práticas Exemplares para Inquéritos sobre Investigação e Desenvolvimento Experimental: Proposta de Práticas Exemplares para Inquéritos sobre Investigação e Desenvolvimento Experimental. F-Iniciativas, Spain, 2002. ISBN 9789264065611. Disponível em: < http://www.mct.gov.br/index.php/content/view/4639.html >.

PEILEI, F. Innovation capacity and economic development: China and India. Economic Change and Restructuring, v. 44, n. 1, p. 49-73, 2011. Disponível em: < http://ideas.repec.org/a/kap/ecopln/v44y2011i1p49-73.html >.

PORTUGAL, M. S. Notas Introdutórias sobre o Princípio de Máxima Verossimilhança: Estimação e Teste de Hipóteses. Porto Alegre: DECON / UFRGS, 1995.

PRADHAN, R. P.; BAGCHI, T. P. Effect of transportation infrastructure on economic growth in India: The VECM approach. Research in Transportation Economics, 2012. Disponível em: < http://www.scopus.com/inward/record.url?eid=2-s2.0-

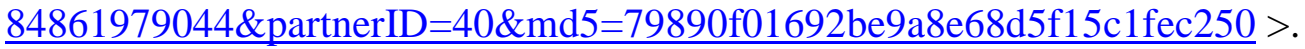

PRAIS, S. J.; WINSTEN, C. B. Trend estimators and serial correlation. Chicago, IL Discussion paper no. 383 Cowles Commission, 1954.

QUAH, D. Empirics for Economic Growth and Convergence. C.E.P.R. Discussion PapersMar. 1995

ROINE, J.; VLACHOS, J.; WALDENSTRÃđIM, D. The long-run determinants of inequality: What can we learn from top income data? Journal of Public Economics, v. 93, n. 7-8, p. 974-988, 2009. Disponível em: < http://www.scopus.com/inward/record.url?eid=2-s2.067649429793\&partnerID=40\&md5=09e537e21f4d0d3413dab21c94f5b5e4 >.

ROMER, P. M. Increasing Returns and Long-run Growth. Journal of Political Economy, v. 94, n. 5, p. 1002-37, 1986. Disponível em: < http://ideas.repec.org/a/ucp/jpolec/v94y1986i5p1002-37.html >.

RUTTEN, R.; BOEKEMA, F. Regional social capital: Embeddedness, innovation networks and regional economic development. Technological Forecasting and Social 
Change, v. $74, \quad$ n. 9 , p. 1834-1846, 2007. Disponível em: < http://www.scopus.com/inward/record.url?eid=2-s2.0-

$\underline{36148938776 \& \text { partnerID }=40 \& m d 5=c 2 f 4 b 9 \mathrm{e} 212 \mathrm{a} 523 \mathrm{a} 4 \mathrm{a} 0 \mathrm{ac} 3 \mathrm{dc} 87602 \mathrm{c} 74 \mathrm{~d}}>$.

SAVIOTTI, P. P.; PYKA, A. Economic development, qualitative change and employment creation. Structural Change and Economic Dynamics, v. 15, n. 3, p. 265-287, 2004. Disponível em: < http://ideas.repec.org/a/eee/streco/v15y2004i3p265287.html >.

SCHUMPETER, J. The Theory of Economic Development. Cambridge, Massachusetts: 1934.

SEGARRA-BLASCO, A.; ARAUZO-CAROD, J.-M. Sources of innovation and industry-university interaction: Evidence from Spanish firms. Research Policy, v. 37, n. 8 , p. 1283-1295, 2008. ISSN 0048-7333. Disponível em: < http://www.sciencedirect.com/science/article/pii/S0048733308001145 >.

SEN, A. THE LIVING STANDARD. Oxford Economic Papers, v. 36, n. supp, p. 7490, November 1, $19841984 . \quad$ Disponível em: < http://oep.oxfordjournals.org/content/36/supp/74.short >.

SNOUSSI, W. A.; EL-AROUI, M. A. Comparing value-at-risk semi-parametric estimators from serial dependent nancial data. Economics Bulletin, v. 30, n. 1, 2010. Disponível em: < http://www.scopus.com/inward/record.url?eid=2-s2.0$\underline{77953591171 \& \text { partnerID }=40 \& m d 5=e f 3837 f 36 a 4 b 7 c 1 f 6 b a b d f 7 e 93622 a 91}>$.

SOLOW, R. M. A Contribution to the Theory of Economic Growth. The Quarterly Journal of Economics, v. 70, n. 1, p. 65-94, February 1, 1956 1956. Disponível em: < http://qje.oxfordjournals.org/content/70/1/65.abstract $>$.

STOCK, J. H.; WATSON, M. Introduction to Econometrics. Pearson Education, Limited, 2011. ISBN 9781408264331. Disponível em: < http://books.google.com.br/books?id=vyGncQAACAAJ >.

STUART, T. E.; OZDEMIR, S. Z.; DING, W. W. Vertical alliance networks: The case of university-biotechnology-pharmaceutical alliance chains. Research Policy, v. 36, n. 4, p. 477-498, 2007. Disponível em: < http://ideas.repec.org/a/eee/respol/v36y2007i4p477-498.html >.

THORNTON, J. Exports and economic growth: Evidence from 19th Century Europe1. Economics Letters, v. 55, n. 2, p. 235-240, 1997. Disponível em: < http://ideas.repec.org/a/eee/ecolet/v55y1997i2p235-240.html >.

TOBLER, W. R. A Computer Movie Simulating Urban Growth in the Detroit Region. Economic Geography, v. 46, n. ArticleType: research-article / Issue Title: Supplement: Proceedings. International Geographical Union. Commission on Quantitative Methods / Full publication date: Jun., 1970 / Copyright (C) 1970 Clark University, p. 234-240, 1970. ISSN 00130095. Disponível em: < http://www.jstor.org/stable/143141 >. 
TSAI, D. H. A.; LIN, M. Industrial and Spatial Spillovers and Productivity Growth: Evidence from Taiwan High-Technology Plant Level Data. Journal of Productivity Analysis, v. 23, n. 1, p. 109-129, 2005. ISSN 0895-562X. Disponível em: < http://dx.doi.org/10.1007/s11123-004-8550-4 >.

TSENG, C.-Y. Technological Innovation in the BRIC Economies. ResearchTechnology Management, v. 52, n. 2, p. 29-35, 2009. Disponível em: < http://www.ingentaconnect.com/content/iri/rtm/2009/00000052/00000002/art00006 >.

UlVEling, E. F.; FLETCHER, L. B. A Cobb-Douglas Production Function with Variable Returns to Scale. American Journal of Agricultural Economics, v. 52, n. 2, p. 322-326, 1970. ISSN 00029092. Disponível em: < http://www.jstor.org/stable/1237508 >.

UZAWA, H. Optimum Technical Change in An Aggregative Model of Economic Growth. International Economic Review, v. 6, n. 1, p. 18-31, 1965. ISSN 00206598. Disponível em: < http://www.jstor.org/stable/2525621 >.

VERSPAGEN, B. Measuring intersectoral technology spillovers: estimates from the European and US patent office databases. Maastricht University. 1997

VERSPAGEN, B.; LOO, I. D. Technology Spillovers between Sectors and over Time. Maastricht University. 1999

VEUGELERS, R. et al. The participation of universities in technology development: do creation and use coincide? An empirical investigation on the level of national innovation systems. Economics of Innovation and New Technology, v. 21, n. 5-6, p. 445-472, 2012/09/01 2012. ISSN 1043-8599. Disponível em: < http://dx.doi.org/10.1080/10438599.2012.656527 >. Acesso em: 2012/10/24.

VEUGELERS, R.; CASSIMAN, B. R\&amp;D cooperation between firms and universities. Some empirical evidence from Belgian manufacturing. International Journal of Industrial Organization, v. 23, n. 5-6, p. 355-379, 2005. ISSN 01677187. Disponível

em: http://www.sciencedirect.com/science/article/pii/S0167718705000251 >.

VITON, P. A. Notes on Spatial Econometric Models. City and regional Planning 870.03, 2010.

WERKER, C.; ATHREYE, S. Marshall's disciples: Knowledge and innovation driving regional economic development and growth. Journal of Evolutionary Economics, v. 14, n. 5, p. 505-523, 2004. Disponível em: < http://www.scopus.com/inward/record.url?eid=2-s2.0$\underline{11244315291 \& \text { partnerID }=40 \& \mathrm{md} 5=53 \mathrm{eb} 7 \mathrm{~b} 0527 \mathrm{a} 47 \mathrm{bcc} 522 \mathrm{e} 033 \mathrm{a} 1 \mathrm{aedabb} 0}>$.

WOOD, S. Inference. Bath: Bath University 2009.

WOOLDRIDGE, J. M. Introductory Econometrics: A Modern Approach. SouthWestern College Publishers 2008. 
ZELLNER, A. An Efficient Method of Estimating Seemingly Unrelated Regressions and Tests for Aggregation Bias. Journal of the American Statistical Association, v. 57, n. 298, p. 348-368, 1962. ISSN 01621459. Disponível em: < http://www.jstor.org/stable/2281644 >.

ZELLNER, A.; KMENTA, J.; DRÈZE, J. Specification and Estimation of CobbDouglas Production Function Models. Econometrica, v. 34, n. 4, p. 784-795, 1966. ISSN 00129682. Disponível em: < http://www.jstor.org/stable/1910099 >.

ZHANG, W. B. Interregional economic growth with transportation and residential distribution. Annals of Regional Science, v. 46, n. 1, p. 219-245, 2011. Disponível em: $\quad<\quad$ http://www.scopus.com/inward/record.url?eid=2-s2.0$\underline{78650797618 \& \text { partnerID }=40 \& m d 5=d 762 a 7549 \mathrm{ded} 577846 \mathrm{e} 141 \mathrm{eefc} 0 \mathrm{ab} 73 \mathrm{~b}}>$.

ZHANG, X. Transport infrastructure, spatial spillover and economic growth: Evidence from China. Frontiers of Economics in China, v. 3, n. 4, p. 585-597, 2008. ISSN 1673-3444. Disponível em: 〈 http://dx.doi.org/10.1007/s11459-008-0029-1 >. 


\section{APÊNDICE - CONCEITOS \\ MATEMÁTICOS UTILIZADOS EM \\ ECONOMETRIA ESPACIAL}

Neste capitulo serão apresentados alguns ferramentais relacionados à matemática e estatística muito utilizados para a estimação dos modelos de econometria espacial. Assim, será realizada uma breve revisão dos conceitos de derivada parcial, jacobiano, otimização condicionada e não condicionada, máxima verossimilhança, e métodos numéricos.

\section{A.1. DERIVADAS PARCIAIS E DETERMINANTE JACOBIANO}

Dada uma função $Z=X^{2}+Y^{2}$ a derivada parcial $\partial Z / \partial X$ é a taxa de variação da variável $\mathrm{Z}$ com respeito às variações infinitesimais na variável $\mathrm{X}$, enquanto $\mathrm{Y}$ é mantida constante. Dessa forma, as derivadas parciais com relação a X ( $\mathrm{Y}$ é considerada constante) e Y (X é considerada constante) serão (2) e (3).

$$
\begin{aligned}
& Z=X^{2}+Y^{2} \\
& \frac{\partial Z}{\partial X}=2 X \\
& \frac{\partial Z}{\partial Y}=2 Y
\end{aligned}
$$

Assim, como demonstrado em (3), para pequenas variações de Y, $2 \mathrm{Y}$ representa o impacto de $\mathrm{Y}$ em $\mathrm{Z}$ considerando-se $\mathrm{X}$ constante. A representação gráfica de tal conceito é fornecida na Figura 11, para os pontos $(-1,1,2)$. 


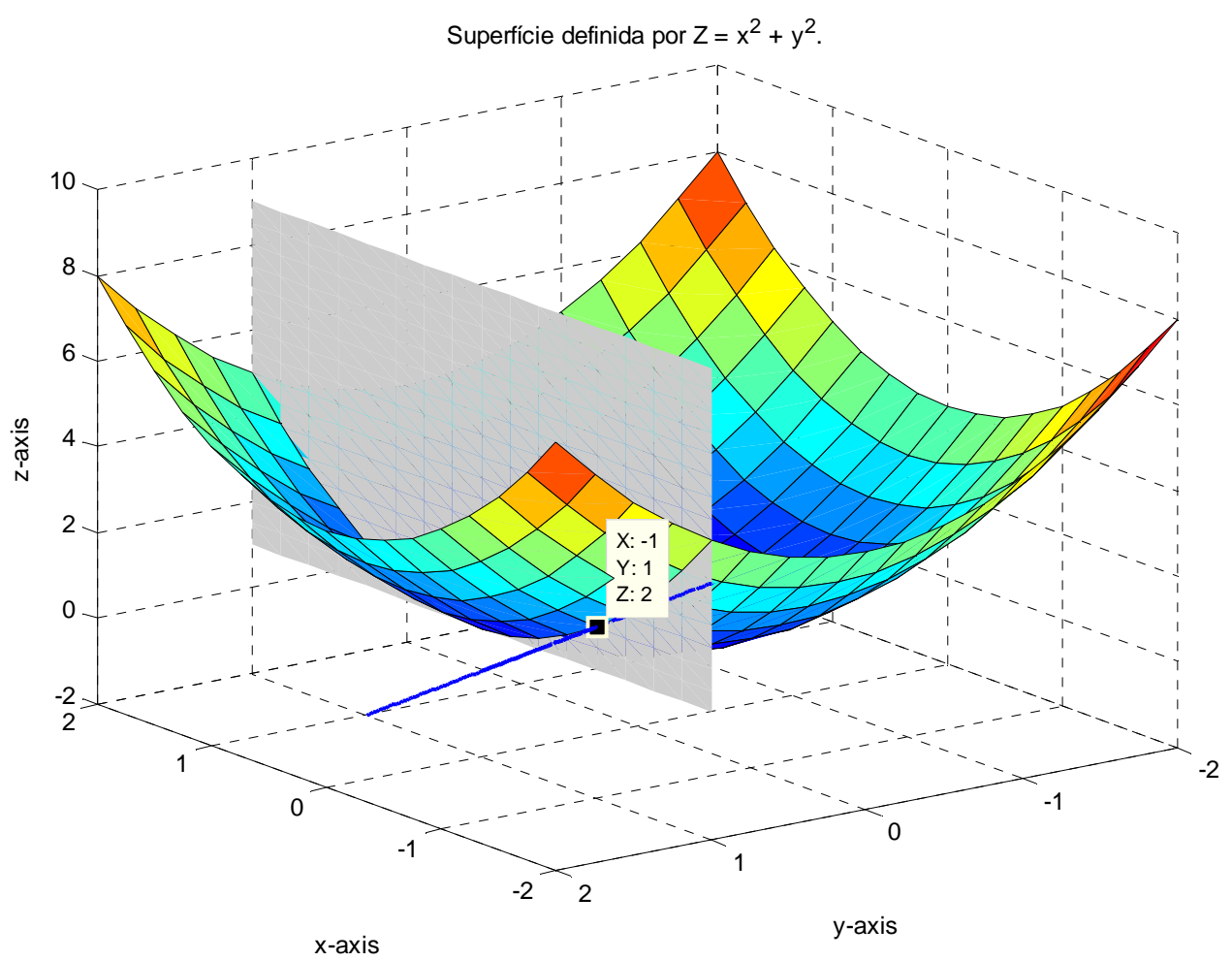

Figura 11 - Representação gráfica da derivada parcial ${ }^{8}$.

Já o conceito de determinante Jacobiano é muito utilizado para testar se existe dependência funcional, linear ou não, em um conjunto de $n$ funções em $n$ variáveis (Chiang, 2006).

Dessa forma, dadas (4) e (5),

$$
y_{1}=2 x_{1}+3 x_{2}
$$

\footnotetext{
${ }^{8}[\mathrm{x}, \mathrm{y}]=\operatorname{meshgrid}(-2: .25: 2)$;

$>\operatorname{mesh}(\mathrm{x}, \mathrm{y}, \mathrm{z})$; figure $(\mathrm{gcf})$

$>\mathrm{z}=\mathrm{x} \cdot{ }^{\wedge} 2+\mathrm{y} \cdot{ }^{\wedge} 2$

$>\mathrm{h} 1=\operatorname{surf}(\mathrm{x}, \mathrm{y}, \mathrm{z})$

$>$ > $\mathrm{x}, \mathrm{z}]=$ meshgrid $(-2: .25: 2,1: 0.5: 9)$;

$>\mathrm{y}=$ ones $(\operatorname{size}(\mathrm{x}))$;

$>>$ hold on

$>$ h2 $=\operatorname{surf}(\mathrm{x}, \mathrm{y}, \mathrm{z})$;

$>\mathrm{t}=$ linspace $(0,-2)$;

$>\mathrm{x}=\mathrm{t}$;

$>>\mathrm{y}=$ ones $(\operatorname{size}(\mathrm{t}))$

$>\mathrm{z}=-2 * \mathrm{t}$
} 


$$
y_{2}=4 x_{1}^{2}+12 x_{1} x_{2}+9 x_{2}^{2}
$$

Arranjando as quatro derivadas parciais das equações (4) e (5) na forma de uma matriz quadrada, chamada de matriz jacobiana $(\mathrm{J})$, seu determinante será o Jacobiano $(|J|)$. Assim a matriz jacobina será (6),

$$
J=\left|\begin{array}{ll}
\frac{\partial y_{1}}{\partial x_{1}} & \frac{\partial y_{1}}{\partial x_{2}} \\
\frac{\partial y_{2}}{\partial x_{1}} & \frac{\partial y_{2}}{\partial x_{2}}
\end{array}\right|=\left|\begin{array}{cc}
2 & 3 \\
\left(8 x_{1}+12 x_{2}\right) & \left(12 x_{1}+18 x_{2}\right)
\end{array}\right|
$$

Enquanto o determinante Jacobiano é representado em (7).

$$
|J|=3\left(8 x_{1}+12 x_{2}\right)+2\left(12 x_{1}+18 x_{2}\right)=0
$$

Nesse caso, quando $|J|$ é idêntico à zero para todos os valores de $x_{1} \ldots x_{n}$ as $n$ funções $y_{1} \ldots y_{n}$ são funcionalmente (linearmente ou não) dependentes. Assim, no exemplo de (4) e (5), para todos os valores de $x_{1}$ e $x_{2}$, as funções são dependentes; de fato, $y_{2}$ é $\left(y_{1}\right)^{2}$, o que demonstra dependência não linear (Chiang, 2006).

\section{A.2. OTIMIZAÇÃ̃}

As técnicas usuais de otimização tratam basicamente de encontrar, máximos, mínimos e pontos de inflexão dadas variáveis de escolha. Contudo, as formas de se encontrarem os valores ótimos desejados dependem do número de variáveis de escolha (independentes), bem como se a otimização envolve ou não alguma condição (restrição). 


\section{A.2.1 - Otimização não-condicionada}

Quando considerada uma função de apenas uma variável dependente, o valor ótimo é calculado através do ponto em que a derivada primeira é igual a zero, bem como este ponto é definido como máximo ou mínimo de acordo com a derivada segunda ( $f$ ”) de uma função $f(x)$. Assim,

Se $f^{\prime \prime}(x)<0$ a função possui um máximo local.

Se $f^{\prime \prime}(x)>0$ a função possui um mínimo local.

Assim, dada uma função lucro (receita total - custo total) de (8), para se encontrar ponto em que a quantidade produzida correspondente ao lucro máximo, basta aplicar a condição de primeira e segunda ordem (CPO e CSO respectivamente).

$$
\pi=5 Q-\left(Q^{2}+3\right)
$$

CPO (Condição de primeira ordem):

$$
\frac{d \pi}{d Q}=5-2 Q=0, \text { assim, } \mathrm{Q}^{*}=2,5
$$

CSO (Condição de segunda ordem):

$$
\frac{d^{2} \pi}{d Q^{2}}=-2<0
$$

Dessa forma, $\pi(2,5)$ é um máximo local definido nos reais positivos para a função lucro.

Contudo, para funções com duas ou mais variáveis explicativas (independentes), a forma de otimização utilizada para a função lucro de (8) não é adequada, sendo necessária a utilização da função da matriz hessiana, a qual é simplesmente uma matriz contendo as derivadas parciais segundas da função a ser otimizada. 
Dessa forma, dada uma função $Z=f\left(x_{1}, x_{2}, x_{3}\right)$ com derivadas parciais primeiras $f_{1}, f_{2}, f_{3}$ para que $\mathrm{Z}$ seja máximo, $d Z$ deve estar instantaneamente estacionário $(d Z=0)$, onde,

$$
d Z=f_{1} d x_{1}, f_{2} d x_{2}, f_{3} d x_{3}
$$

Em que,

$d x_{i}$ é variação infinitesimal, mas não necessariamente zero.

Assim, para que $d Z$ seja zero, o somatório $\sum_{i=1}^{3} f_{i}$ deve ser igual a zero, isto é, todas as derivadas parciais de primeira ordem devem ser iguais a zero. Contudo, o problema para a otimização é expressar as derivadas parciais segundas e determinar sua definidade positiva ou negativa, que indicará, respectivamente, mínimo ou máximo da função (Chiang, 2006).

A título de exemplo, considerando a função $Z=x_{1}^{2}-3 x_{1} x_{2}+3 x_{2}^{2}+4 x_{2} x_{3}+6 x_{3}^{2}$, para que tal função seja otimizada:

CPO:

$$
\begin{aligned}
& \frac{\partial Z}{\partial x_{1}}=2 x_{1}+3 x_{2}=0 \\
& \frac{\partial Z}{\partial x_{2}}=-3 x_{1}+6 x_{2}+4 x_{3}=0 \\
& \frac{\partial Z}{\partial x_{3}}=4 x_{2}+12 x_{3}=0
\end{aligned}
$$


CSO:

$f_{x 1 x 1}=\frac{\partial}{\partial x_{1}} \frac{\partial Z}{\partial x_{1}}=\frac{\partial^{2} Z}{\partial x_{1}^{2}}=2$

$f_{x 1 x 2}=\frac{\partial}{\partial x_{1}} \frac{\partial Z}{\partial x_{2}}=\frac{\partial^{2} Z}{\partial x_{2}^{2}}=-3$

$f_{x 1 x 3}=\frac{\partial}{\partial x_{1}} \frac{\partial Z}{\partial x_{3}}=\frac{\partial^{2} Z}{\partial x_{3}^{2}}=0$

$f_{x 3 x 3}=\frac{\partial}{\partial x_{3}} \frac{\partial Z}{\partial x_{3}}=\frac{\partial^{2} Z}{\partial x_{3}^{2}}=12$

Assim, a matriz Hessiana será:

$$
H=\left[\begin{array}{lll}
f_{x 1 x 1} & f_{x 1 x 2} & f_{x 1 x 3} \\
f_{x 2 x 1} & f_{x 2 x 2} & f_{x 2 x 3} \\
f_{x 3 x 1} & f_{x 3 x 2} & f_{x 3 x 3}
\end{array}\right]=\left[\begin{array}{ccc}
2 & -3 & 0 \\
-3 & 6 & 4 \\
0 & 4 & 12
\end{array}\right]
$$

Encontrada a matriz Hessiana em (19), a definidade positiva ou negativa, correspondente à existência de um mínimo ou máximo dependerá dos determinantes de submatrizes da matriz Hessiana chamados de menores principais. São estes (20), (21), (22)

$$
\begin{aligned}
& \left|H_{1}\right|=\left|f_{x 1 x 1}\right|=|2| \\
& \left|H_{2}\right|=\left|\begin{array}{ll}
f_{x 1 x 1} & f_{x 1 x 2} \\
f_{x 2 x 1} & f_{x 2 x 2}
\end{array}\right|=\left|\begin{array}{cc}
2 & -3 \\
-3 & 6
\end{array}\right|
\end{aligned}
$$




$$
\left|H_{2}\right|=H=\left|\begin{array}{ccc}
2 & -3 & 0 \\
-3 & 6 & 4 \\
0 & 4 & 12
\end{array}\right|
$$

Portanto, $\left|H_{1}\right|=2>0 ;\left|H_{2}\right|=3>0 ;\left|H_{3}\right|=4>0$. Com isso, seguindo a regra dos menores principais:

$\left\{\begin{array}{l}\left|H_{1}\right|>0 ;\left|H_{2}\right|>0 ;\left|H_{3}\right|>0 \\ \left|H_{1}\right|<0 ;\left|H_{2}\right|>0 ;\left|H_{3}\right|<0\end{array}\right\} d^{2} Z$ é $\left\{\begin{array}{l}\text { definida positiva }(Z \text { mínimo }) \\ \text { definida negativa }(Z \text { máximo })\end{array}\right\} s e \sum_{i=1}^{3} f_{i}=0$

Assim, $d^{2} Z$ é definida positiva, e, portanto, a função $Z$ apresenta um ponto de mínimo.

\section{A.2.2 - Otimização condicionada}

A otimização condicionada trata-se simplesmente de otimizar uma função sujeita a uma restrição. Aqui, utiliza-se o mesmo procedimento utilizado em A.2.1, por meio da matriz hessiana, contudo há uma modificação que une a função a ser otimizada e sua restrição, em uma só expressão, tal alteração é conhecida como multiplicador de Lagrange. Segue o exemplo do procedimento para a maximização da função de (23) dada a restrição de (24).

$\max x_{1} x_{2}+2 x_{1}$

Sujeito à restrição $4 x_{1}+2 x_{2}=60$

Com a aplicação do multiplicador de Lagrange encontra-se (25).

$$
l\left(\lambda, x_{1}, x_{2}\right)=x_{1} x_{2}+2 x_{1}+\lambda\left[60-\left(4 x_{1}+2 x_{2}\right)\right]
$$


Para a otimização executa-se novamente a CPO e a CSO.

$\mathrm{CPO}$

$l_{\lambda}=\partial l / \partial \lambda=60-4 x_{1}-2 x_{2}=0$

$l_{x 1}=\partial l / \partial x_{1}=x_{2}+2-4 \lambda=0$

$l_{x 1}=\partial l / \partial x_{2}=x_{1}-2 \lambda=0$

Onde os valores ótimos são $x_{1}^{*}=8$ e $x_{2}^{*}=14$. Basta agora saber se estes configuram um máximo ou um mínimo. Para tanto, aplica-se a CSO.

CSO

$$
H=\left[\begin{array}{lll}
l_{\lambda \lambda} & l_{\lambda 1} & l_{\lambda 2} \\
l_{2 \lambda} & l_{11} & l_{12} \\
l_{3 \lambda} & l_{21} & l_{22}
\end{array}\right]=\left[\begin{array}{ccc}
0 & -4 & -2 \\
-4 & 0 & 1 \\
-2 & 1 & 0
\end{array}\right]
$$

Aqui, é possível saber se os valores ótimos configuram um mínimo ou um máximo pelo determinante da matriz de (29). Tal matriz é conhecida como "matriz hessiana orlada", pois os valores da linha 1 e da coluna 1 formam uma orla ao redor da submatriz restante, sendo não simétrica entre a diagonal principal, diferentemente da matriz hessiana utilizada na otimização não condicionada.

Para matrizes de dimensão até $3 \times 3$, tem-se que se o determinante de $H$ for maior que zero, observa-se um máximo, caso for menor do que zero, observa-se um mínimo. Já para matrizes de dimensão superior existe outra regra. Para o exemplo da função (26), $|H|=16>0$, portanto, observa-se um máximo.

Geometricamente, a otimização condicionada é equivalente ao que ocorre na Figura 12, que também exibe sua diferença para a otimização não-condicionada. 


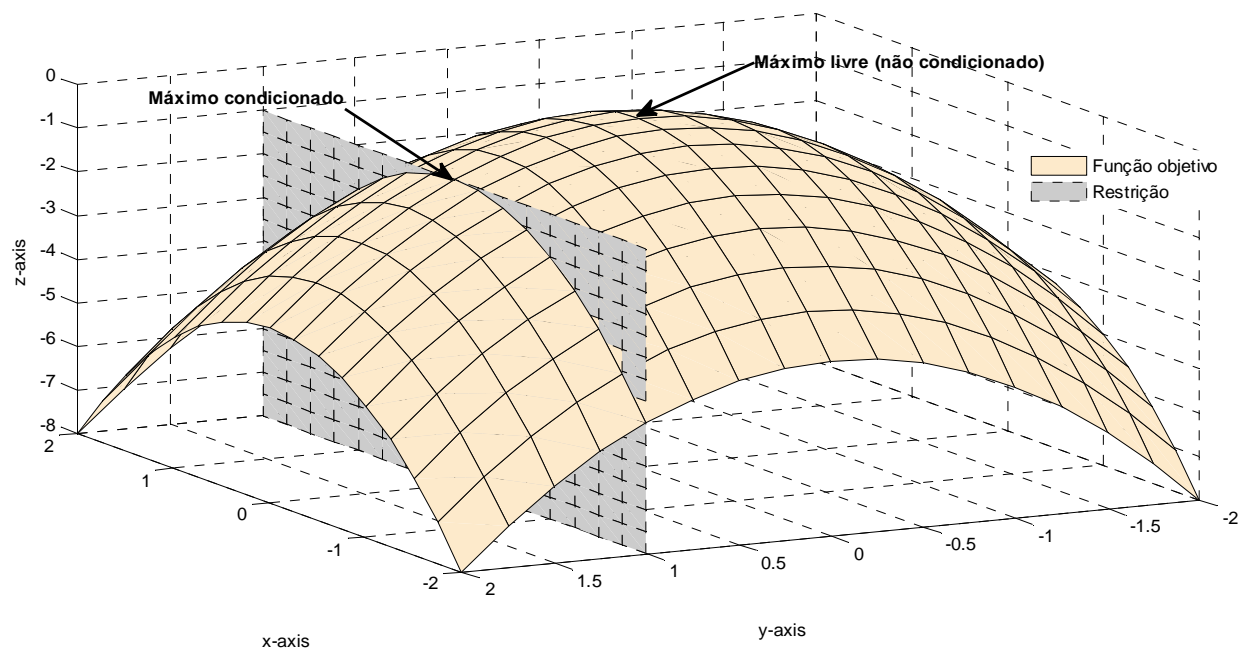

Figura 12 - Demonstração gráfica da otimização condicionada e não-condicionada. ${ }^{9}$

É observável na Figura 12 que o máximo condicionado é sempre inferior ao máximo livre (não-condicionado).

\footnotetext{
${ }^{9}[\mathrm{x}, \mathrm{y}]=$ meshgrid $(-2: .25: 2)$;

$\mathrm{z}=-\mathrm{x} .^{\wedge} 2-\mathrm{y} .{ }^{\wedge} 2$

$\mathrm{h} 1=\operatorname{surf}(\mathrm{x}, \mathrm{y}, \mathrm{z})$;

$[\mathrm{x}, \mathrm{z}]=$ meshgrid $(-2: .25: 2,-8: 0.5:-1)$;

$\mathrm{y}=$ ones $(\operatorname{size}(\mathrm{x}))$;

hold on

$\mathrm{h} 2=\operatorname{surf}(\mathrm{x}, \mathrm{y}, \mathrm{z})$;
} 